\title{
Movement in the Classroom: Contingent Factors Underlying Teacher Change
}

\author{
Annie E. Machamer \\ Student, aemachamer@mix.wvu.edu
}

Follow this and additional works at: https://researchrepository.wvu.edu/etd

Part of the Health and Physical Education Commons

\section{Recommended Citation}

Machamer, Annie E., "Movement in the Classroom: Contingent Factors Underlying Teacher Change" (2019). Graduate Theses, Dissertations, and Problem Reports. 4047.

https://researchrepository.wvu.edu/etd/4047

This Dissertation is protected by copyright and/or related rights. It has been brought to you by the The Research Repository @ WVU with permission from the rights-holder(s). You are free to use this Dissertation in any way that is permitted by the copyright and related rights legislation that applies to your use. For other uses you must obtain permission from the rights-holder(s) directly, unless additional rights are indicated by a Creative Commons license in the record and/ or on the work itself. This Dissertation has been accepted for inclusion in WVU Graduate Theses, Dissertations, and Problem Reports collection by an authorized administrator of The Research Repository @ WVU.

For more information, please contact researchrepository@mail.wvu.edu. 
Movement in the Classroom: Contingent Factors Underlying Teacher Change

Annie Machamer, M.S.

Dissertation defense submitted to the College of Physical Activity and Sport Sciences

at West Virginia University

in partial fulfillment of the requirements for the degree of

Doctorate of Education in

Physical Education

Andrea R. Taliaferro, Ph.D., Chair

Sean M. Bulger, Ed.D.

Eloise M. Elliott, Ph.D.

Yoav Kaddar, Ph.D.

Stephanie M. Lorenze, Ed.D.

Department of Coaching and Teaching Studies

Morgantown, West Virginia

2019

Keywords: Classroom physical activity, Professional development, Continued practice

Copyright 2019 Annie Machamer 


\title{
ABSTRACT \\ Movement in the Classroom: Contingent Factors Underlying Teacher Change
}

\begin{abstract}
Annie Machamer
Background: Teachers' use of classroom physical activity (PA) has been found to significantly impact students PA participation, time on task, and academic performance. However, teachers have continued to identify barriers affecting delivery related to professional development opportunities, learning environment, and experiences in practice. An understanding of the connection between these experiences and their impact on teacher change is needed.
\end{abstract}

Purpose: The purpose of this study was to investigate teachers' perceptions of specific factors that have influenced their continued implementation of classroom PA. This study provides insight into the teacher perceptions, and aims to identify connections among orientation to learning and learning change that have supported this practice.

Design \& Methodology: This research employed two rounds of data collection and used Opfer et al.'s (2011) model of teacher change as a guiding theoretical framework. First, a questionnaire was administered to teachers $(n=26)$ who had experience integrating movement into the academic classroom. Next, semi-structured interviews were conducted with participants $(n=6)$ who have experienced success in continued delivery for three or more years, had implemented three or more days a week, and used both PA breaks and content-rich/standards-based PA. Round One data analysis included frequency and measure of central tendency. Round Two data analysis included transcription, an inductive coding approach, jotting and memoing, and member checking.

Results: Survey results indicated that professional development, student reactions, and beliefs and attitudes of classroom PA had the greatest influence on teachers' continued use of classroom PA. Five main areas of influence were identified: (a) social and environmental influences, (b) professional development, (c) integration practices, (d) student reactions, and (e) teacher beliefs and attitudes.

Conclusion: Results of this study provide insights into the connections of influential factors on teachers' implementation of classroom PA and sustained use. This study provides a framework for further investigation in order to support teachers' continued use of classroom PA. 


\section{Dedication}

This is dedicated to all the educators out there who continue to work hard, despite the lack of resources or funding, to provide better opportunities for students. Thank you for your inspiration. Keep on pursuing for the betterment of your students; you are changing their lives today and forever.

This is also dedicated to my always understanding family and other half. Thank you for your continued support and patience in this process. I would not be where I am today without you all. 


\section{Acknowledgments}

I would first like to thank all the teachers in this study who took the time to share their experiences with me and supported my research. Without you, this study would not have been possible. I would also like to thank the West Virginia University Office of the Provost and the College of Physical Activity and Sport Sciences for their combined efforts of support to fund this research study. I am continually grateful for the financial support as a young professional. I would also like to thank Mrs. Wheeler and Mrs. Weston-Anderson in the CPASS business office for their diligent efforts to ensure that all funding was processed.

I would like to thank the dream team of academic leaders that have supported me in this process. Each and every one of my committee members has contributed to the professional that I am today. I would like to thank Dr. Andrea Taliaferro for her continued support as the chair of my committee. Her diligent efforts to push me in my research have helped me to become more mindful in my writing and study endeavors. I would also like to thank Dr. Eloise Elliott for her sparking my interest of movement in the classroom, and her continued support in the completion of my research. I am forever grateful for all the Active Academics adventures we have been on together, and I owe you so much for your support in my data collection and analysis. I would also like to thank Dr. Sean Bulger for his continued wisdom that has helped me to navigate the world of higher education and life. He is a large reason why I have been able to accomplish my goal of sharing dance education throughout the state of West Virginia, and I am forever inspired by his awesome dance moves. I would also like to thank Dr. Yoav Kaddar and Dr. Stephanie Lorenze who have been willing to share their experiences in dance education to inform my research. I am forever grateful for you both coming over to the "PE World" to help provide opportunities of dance for all learners.

In addition to my wonderful committee, I would like to thank the professors at Appalachian State University who sparked my interest in going beyond my undergraduate studies. Dr. Derek Mohr and Dr. Scott Townsend have continued to support my professional journey far beyond graduation, and I am forever grateful for their guidance. I would also like to thank the West Virginia Department of Education and Mr. Josh Grant for the ample amount of opportunities you have provided me to share movement in the classroom with educators around the state.

Next, I would like to thank my family and my other half for their unconditional love and support throughout this process. They have continued to understand the time and dedication needed to complete my degree, and I am forever grateful to have such supportive people in my life that have enabled me to pursue my passion.

Lastly, but surely not least, I would like to thank the doctoral students of West Virginia University who have helped me maintain my sanity through it all. To those that came before me, thank you for your words of wisdom and guidance throughout the process of tackling my first research endeavor. To those that came in with me, thank you for the thoughtful chats, physical activity breaks around the track and laughs to release the tension of trying to wrap my head around graduate school. I miss seeing you all every day, but I look forward to what is to come for us all. 


\section{Table of Contents}

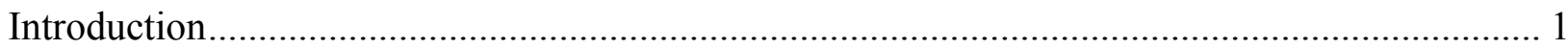

Statement of the Purpose …………………………………........................................... 7

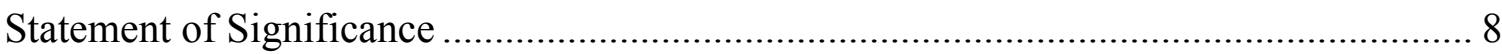

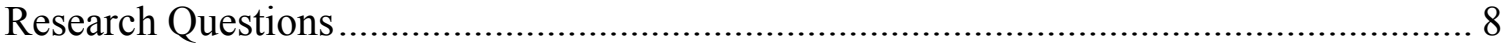

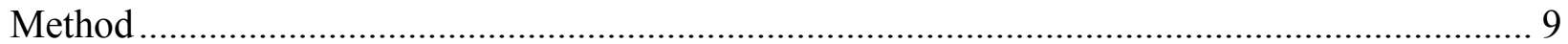

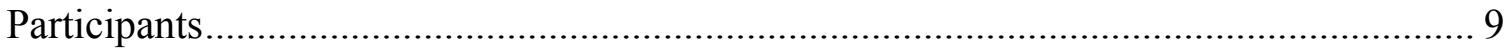

Data Collection Procedures.............................................................................................. 11

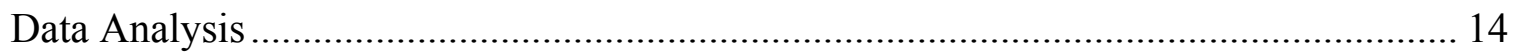

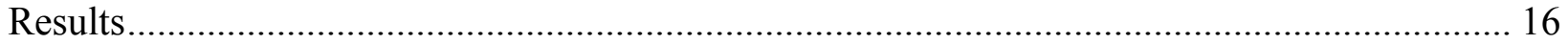

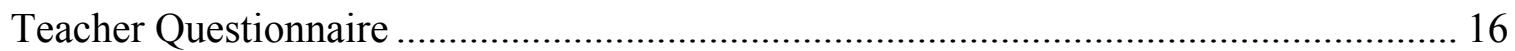

Semi-Structured Interviews ................................................................................... 17

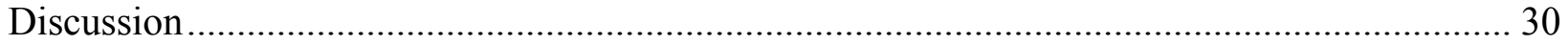

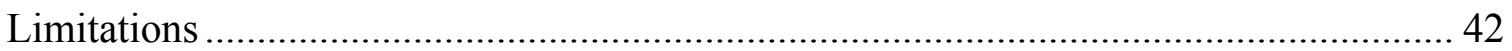

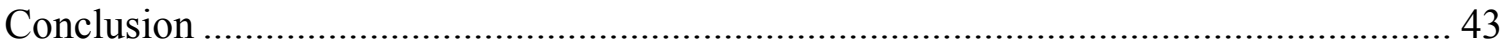

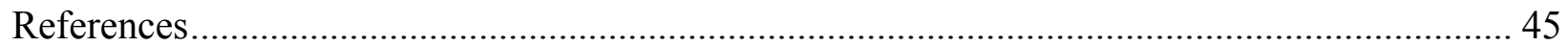

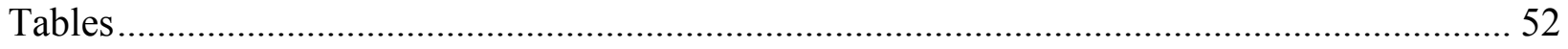

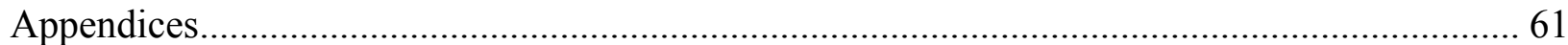

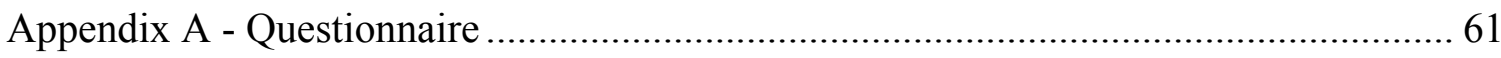

Appendix B - Semi-Structured Interview Guide ………………..................................... 64

Appendix C - Inductively Developed Codebook ……………….................................... 69

Appendix D - Extended Literature Review ………………........................................... 71

Appendix E - Extended List of References ................................................................ 114 
Appendix F - IRB Exemption Notice ................................................................ 126

Appendix G - Recruitment Email Script................................................................ 128

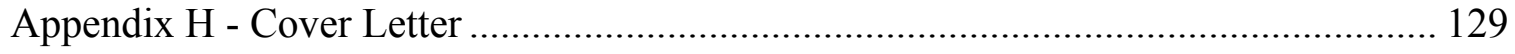

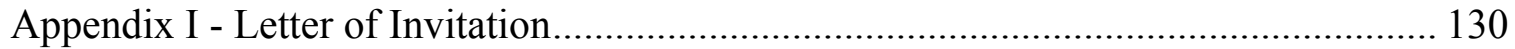

Appendix J - Confirmation of Semi-Structured Interview ..................................... 131

Appendix K - Reminder of Scheduled Semi-Structured Interview ............................ 132

Appendix L - Codebook Version 1 ...................................................................... 133 


\section{List of Tables}

Table 1 - Round One Participant Demographics .......................................................... 52

Table 2 - Round Two Participant Demographics …......................................................... 53

Table 3 - Impacts of Orientation to Learning and Learning Change ...................................... 54

Table 4 - Inductively Developed Thematic Categories and Sample Quotes ........................... 55

Table 5 - Recommendations for Professional Development Design ...................................... 60 


\section{List of Figures}

Figure 1 - Connections of Teacher Change to Sustain Use of Classroom Physical Activity ....... 39

Figure 2 - Teacher Orientation to Learning and the Influence on Teacher Learning Change.... 108 


\section{Introduction}

The World Health Organization (2018) has identified physical inactivity as the fourth leading risk factor for death in the world. This is of particular concern in the United States, as many individuals are below the recommended 60 minutes of moderate-to-vigorous PA (MVPA) daily, on at least three days per week (Center for Disease Control \& Prevention [CDC], 2015; NASPE, 2008; National Center for Health Statistics, 2011; U.S. Department of Health and Human Services [USDHHS], 2008, 2010). According to the National Health and Nutrition Examination Survey, a low percentage of students met the daily physical activity (PA) guidelines, with only $42 \%$ of children aged 6 to 11 years and $8 \%$ of youth aged 12 to 15 years participating in at least 60 minutes of MVPA per day (National Center for Health Statistics, 2011; Troiano et al., 2008). This highlights the need for an intervention to support increased levels of students' daily PA participation. The USDHHS (2012) has identified the educational setting as an opportune environment to address daily PA participation in school-aged youth, considering that a high percentage of children are enrolled in schools (95\%), a majority of the child's day is spent in schools (6-7 hours), and schools enable a supportive and controlled environment in which equal opportunity for PA can be provided to all students.

Forty-three states in the U.S. adopted plans to increase PA in the school setting between the years of 2002-2010 (Eyler et al., 2014). Specifically, in the state of West Virginia, Policy 2510 was initiated by the West Virginia Board of Education (WVBE) in the 2014-2015 school year, in which elementary and middle schools were required to provide at least 30 minutes of daily PA through recess and other opportunities, beyond course requirements in health and physical education (PE) (WVDE, 2014). While plans and policies have been supportive of 
increased PA for students, educators also need support in the process of developing these opportunities.

\section{Comprehensive School Physical Activity Programs}

The Society of Health and Physical Educators (SHAPE) America (2013) has encouraged a whole school approach (e.g., school personnel and community collaboration) to help schools meet state PA plans and provide daily PA opportunities for students. SHAPE America (2013) has referred to their model as a comprehensive school physical activity program (CSPAP), which consists of multiple components including PE, PA during school, PA before and after school, family and community engagement, and staff involvement (SHAPE, 2013).

While each component of the CSPAP model impacts students' daily PA participation, implementation of all components at once is difficult to achieve. Researchers have suggested that an appropriate start to CSPAP development is for school personnel to focus on singular components that best fit the needs of their surrounding environment (Beaulieu, Butterfield, Mason, \& Loovis, 2012; Kulinna, Brusseau, Cothran, \& Tudor-Locke, 2012). Teachers have reported that PE and before and after school PA have been the most difficult components of CSPAP to implement, and development is often limited due to access to resources in the surrounding environment (Beaulieu et al., 2012; Moore et al., 2018). In contrast, teachers have found that the implementation of PA during school was not impacted by these limitations and was, therefore, one of the easier components to deliver (Beaulieu et al., 2012; Jones et al., 2014). Investigations into teachers' CSPAP use have also found that classroom PA is the most often implemented and has held the greatest impact on students (Brusseau, Hannon, \& Burns, 2016; Centeio et al., 2014b; Kulinna et al., 2012). Considering the impact of classroom PA on students 
and the lack of influence from the surrounding environment, movement in the classroom is the most logical choice of focus for all school settings.

\section{Movement in the Classroom}

Classroom PA has been implemented in the academic environment in the form of both PA breaks and content-rich/standards-based PA. PA breaks are short active periods in the classroom setting that provide students the opportunity to participate in physical activity and take a break from academic content learning. Content-rich/standards-based PA are active lessons in the academic classroom that teach core concepts through the use of movement (SHAPE, 2013). Classroom PA has been associated with positive increases in students' PA participation (Centeio et al. 2014b; Kulinna et al., 2012), time on task (Carlson et al., 2015; Grieco, Jowers, \& Bartholomew, 2009; Mahar et al., 2006) and academic performance (Erwin, Fedewa, \& Ahn, 2017; Hollar et al. 2010; Mullender-Wijnsma et al., 2015; Reed et al., 2010). Despite these positive outcomes, teachers are not always successful in the delivery of classroom PA. Magnusson, Sigurgeirsson, Sveinsson, and Johannsson, (2011) found that a lack of continued support in teacher delivery of classroom PA led to decreased implementation, which led to decreased PA participation of students. Carlson et al. (2015) also identified that teacher delivery of classroom PA decreased with a lack of student effort in participation. Issues in the delivery of classroom PA suggest the need to better understand teachers' experiences and perceived needs related to continued use of classroom PA.

\section{Teacher Perceptions of Practice}

Across multiple studies, teachers have expressed similar thoughts on barriers and facilitators related to the daily practice of using PA in the academic classroom. Teachers have identified the importance of professional development in providing initial opportunities to 
develop knowledge of classroom PA and additional resources for guidance in implementation, as well as the need for continued professional development support to address questions in practice (Cothran, Kulinna, \& Garn, 2010; Goh, Hannon, Webster, Podlong, \& Pillow, 2014b; Goh, Hannon, Webster, \& Podlong, 2017; McMullen, Kulinna, \& Cothran, 2014; Raymond, 2013; Strampel et al., 2014). Other facilitators have included a supportive school environment (Cothran et al., 2010; Goh et al., 2017; Raymond, 2013; Strampel et al., 2014), scheduling and planning for implementation, and student enjoyment and positive participation (Goh et al., 2017).

In contrast, many common barriers that negatively impacted classroom PA implementation have been identified. Teachers have identified barriers related to limited academic time within the school day and the small space in the classroom setting (Cothran et al., 2010; Goh et al., 2017; Goh et al., 2014b; McMullen et al., 2014; Raymond, 2013; Strampel et al., 2014). Further, the push from administration to focus on academics has been identified as a limitation to classroom PA implementation (Cothran et al., 2010; Strampel et al., 2014). Teachers' pre-developed beliefs of classroom PA either hindered or aided continued use, where positive beliefs on the use of PA in the classroom supported continued use, and vice versa (Cothran et al., 2010; Strampel et al., 2014). Researchers have identified that teachers' experiences in the delivery of classroom PA are impacted by multiple components; yet the connection between these, and their collective impact on teachers' sustained implementation, have not been investigated.

\section{Classroom Physical Activity Professional Development}

Classroom PA professional development has been identified by teachers as a facilitator to implementation. Thus far, professional development experiences for classroom PA have included opportunities to develop knowledge and background of why PA is important, hands-on 
experience in learning practice, and resources to support implementation (Erwin, Beighle, Morgan, \& Noland, 2011; Goh et al., 2014a; Grieco et al., 2009; Mahar et al., 2006; Reed et al., 2010; Stewart, Dennison, Kohl, \& Doyle, 2004). In addition to the inclusion of significant content, effective delivery methods, and the duration in which professional development occurs, are important considerations to support teacher change (Birman, Desimone, Porter \& Garet, 2000). Classroom PA professional development thus far has varied in delivery methods and duration, and a common ground for support is needed. Researchers have found that educators have been most successful in change when professional development opportunities have included face-to-face learning experiences in the actual classroom environment, have encouraged teacher reflection upon these experiences, and feedback was delivered to the educator from an expert to develop future lesson implementation (Delk, Springer, Kelder \& Grayless, 2014; Egan

et al., 2018; Patton, Parker \& Pratt, 2013). In addition to components of professional development learning, teachers' continued use of classroom PA has also been influenced by multiple components within application experiences. A better understanding of the connection among teachers' experiences in learning and practice is needed, as well as how these factors collectively impact the sustained delivery of classroom PA.

\section{Theoretical Framework}

Many theoretical frameworks have been designed to investigate the process of teacher change. Multiple researchers have identified linear models of understanding (Desimone, 2009; Guskey, 2002). However, Opfer, Pedder, and Lavicza (2011) suggested that this linear relationship in the process of teacher change often misses connections that occur among these components. Opfer et al. (2011) proposed a model of teacher change influenced by two phases: (a) teacher orientation to learning, and (b) experiences in learning change. There are multiple 
components within each phase that are often reciprocal of each other, which collectively influence teachers' overall experience and impact continued use.

Individuals' orientation to learning is influenced by three components: (a) beliefs about learning, (b) the experiential context, and (c) learning experiences. It is found that beliefs of learning about the experiential context in which the change will occur have already been developed by individuals prior to learning practices (Burn, Hagger, Mutton, \& Everton, 2003; Opfer et al., 2011). Teachers' pre-conceived beliefs of change in their individual setting, combined with professional development learning experiences, develop their perceptions in the choice to make the change.

Following a teacher's experiences in an orientation to learning, the process of learning change begins. A teacher's learning change is influenced by three components: (a) changes in practice, (b) changes in students, and (c) changes in beliefs. Opfer et al. (2011) suggested that changes made in practice by the teacher, therefore, impact a change in students. Teachers' experiences in the change of practice and the changes observed in students influence a change in belief. Opfer et al. (2011) suggested that this cycle is constantly occurring and continually influences teacher belief to continue the change in practice.

Researchers have found that some components of a teacher's orientation to learning and learning change are more influential than others. For example, teachers identified that a supportive school context for implementation and realistic learning practices most impacted their developed belief to deliver the change in practice. Professional development has been found to have infleunced teachers' changes in practice and changes in students, yet had little to no influence on changes in teachers' beliefs (Dole et al., 2016; Opfer \& Pedder, 2011; Opfer et al., 2011). However, it has been found that when a teacher observes positive student reactions to 
change, this can positively impact their belief to continue practice (Goh et al., 2017; Guskey, 2002; Opfer et al., 2011). This suggests that teachers'attitudes and beliefs regarding continued use are most influenced by what is experienced in practice. While current research into Opfer et al.'s (2011) model of teacher change have provided understanding into connections of teachers' experiences, these studies have been conducted in areas unrelated to classroom PA and a majority of the research has been quantitatively focused. Opfer et al. (2011) identified the need for further investigation from a qualitative perspective to develop a deeper understanding of perceptions of influence on change.

\section{Conclusion}

A CSPAP approach has been used to provide opportunities for students to increase daily PA participation. PA during school is the most commonly implemented component within CSPAP, often delivered in the form of classroom PA. Classroom PA has been found to significantly impact students’ PA participation, time on task, and academic performance; however, teachers have continued to identify barriers related to classroom PA delivery including experiences that occur in both learning and practice. Multiple areas of influence have been found to impact teachers' use of classroom PA, yet an understanding of the connection between these experiences and their impact on teacher continued change in practice is lacking. Opfer et al.'s (2011) model will be used to guide this study in order to understand the connection among multiple experiences of components within teachers' orientation to learning and the process of learning change.

\section{Statement of the Purpose}

The purpose of this study was to investigate teachers' perceptions of specific factors that have influenced their continued implementation of movement in the classroom. This study 
provides insight into the perceptions of teachers who have continued the use of classroom PA and aims to identify connections among orientation to learning and learning change that have supported this practice.

\section{Statement of Significance}

Investigations thus far have addressed individual components of influence on teacher use of classroom PA. A lack of research has identified the connection of experiences in classroom PA implementation and the impact on continued use from the teachers' perspective. The investigation of teachers' perceived connections will help to understand significant contributing factors of support and experience in practice that have encouraged teachers' continued use of movement in the academic classroom.

\section{Research Questions}

This study addresses the following research questions:

RQ1. What are experienced teachers' beliefs about their orientation to learning in regard to the use of physical activity in the classroom setting? (Orientation to Learning) RQ2. What are influencing factors that contribute to teachers' continued practice of integrating movement in the classroom? (Learning Change)

RQ3. What is the influence between experienced teachers' orientation to learning and learning change related to physical activity implementation in the classroom setting? (Orientation to Learning and Learning Change)

RQ4. What are common practices that experienced teachers use related to the continued implementation of classroom physical activity? (Common Practice for Success) 


\section{Method}

This research employed two rounds of data collection. Round One consisted of quantitative data collection in the form of a questionnaire (see Appendix A) to support and guide qualitative measures, as well as develop an understanding of teachers' practice and initial perceptions of influence. Round Two of this study consisted of semi-structured interviews (see Appendix B). The addition of qualitative collection enabled a deeper understanding into how factors of teachers' orientation to learning and learning change have influenced their continued use of PA in the academic classroom (Merriam \& Tisdell, 2015; Taylor et al., 2015). Multiple data sources were collected in this study to provide insight into teachers' sustained delivery of classroom PA. These data sources were used to develop a chain of evidence, and converged in data analysis to enhance the credibility and internal validity of findings among teacher experiences (Merriam \& Tisdell, 2015; Patton, 2002; Yin, 2015). IRB approval was obtained prior to data collection.

\section{Participants}

Recruitment. Potential participants were recruited from a pool of in-service PK-12 teachers who participated in a previous professional development workshop provided by the West Virginia Department of Education (WVDE) and the WV Fit and Active Schools Team. The professional development trainers who delivered this daylong workshop, which included both lecture and hands-on activity sessions, were public educators in the state of WV. The professional development began with lecture sessions for two hours which highlighted key reasons behind the need for increased PA opportunities for students, defined the difference between PA breaks and content-rich/standards-based PA, and made educators aware of state policy requiring the increase of thirty additional minutes of PA needed for students outside of 
daily PE. Teachers then experienced four hours of hands-on activity sessions focused on both types of classroom PA (PA breaks and content-rich/standards-based PA), spending around fifty percent of the hands-on session time on each type of PA.

All teachers who attended the professional development workshop were given the opportunity to provide their email on a post-workshop evaluation if they were interested in learning more about opportunities to participate in research focused on the development of classroom PA interventions. Responses were shared by the principal investigator (PI) of the WVDE professional development referred study, and permission was further gained to contact participants regarding interest in this current study. A total of fifty potential participants were identified from the previously referred study who identified as a PK-8 classroom teacher, with experience in the implementation of classroom PA of at least one year at the time the professional development was delivered. All potential participants were contacted for participation in the current study.

Round one participants. In considering the number of potential participants invited to participate in Round One of data collection, an attrition rate of 30\% to 50\% was expected for responses to the questionnaire (Gay, Mills, \& Airasian, 2009). A total of twenty-six ( $N=26)$ responses were collected in Round One and included teachers who reported (a) teaching in a WV public school PK-8 general classroom, and (b) two or more years of classroom PA integration. A majority of the participants identified that they taught at the PK-2 grade level $(n=16)$, with fewer participants teaching at the 3-5 grade level $(n=5)$ and 6-8 grade level $(n=2)$. Two participants were teaching at multiple grade levels, which included grades K-6 and K-3. Round One participants ranged from 0-4 years $(n=5), 5-9$ years $(n=8), 10-14$ years $(n=9)$, and 15-19 years 
$(n=4)$ of teaching experience. Participants represented sixteen of the fifty-five counties in the state of West Virginia. Please refer to Table 1 for Round One participant demographics.

Round two participants. Participants from Round One were then selectively invited to Round Two based on questionnaire responses if they (a) reported three or more years of classroom PA integration, (b) implemented classroom PA 3 or more times a week, and (c) used PA breaks and content-rich/standards-based PA. A total of ten participants met Round Two inclusion criteria and were invited to complete a semi-structured interview. Six participants accepted the invitation to participate in Round Two of data collection, and one participant indicated no interest. The PI attempted to contact the three remaining potential participants via email over a month-long period regarding interest in study participation, with no response. Six participants $(n=6)$ completed Round Two of data collection. These participants ranged in grade level taught (pre-kindergarten to sixth grade), teaching experience (0 to 14 years), and years of classroom PA use (3 to more than 5 years). Please refer to Table 2 for Round Two participant demographics.

\section{Data Collection Procedures}

Round one. Potential participants received a cover letter via email, which included study details and benefits of participation. Those who elected to participate were then directed to the Round One questionnaire delivered via an online survey system. The questionnaire was open to participants for a one-month period. Potential participants received weekly follow-up emails requesting participation in this research study.

Round one instrumentation. The questionnaire (see Appendix A) was developed by the PI and two co-investigators and was informed by previously delivered questionnaires related to classroom PA and Opfer et al.'s (2011) model of teacher change. The questionnaire began with 
directions, followed by definitions of classroom PA. The questionnaire included a total of seventeen questions and was organized into three sections: (a) participant information (4 questions), (b) classroom physical activity implementation (7 questions), and (c) impacts on classroom PA use (6 questions). Section one and two included both structured and unstructured questions. Section three included structured questions in the form of a Likert scale (1-strongly disagree, 5-strongly agree). Section three consisted of questions aimed at participants' perceptions of Opfer et al.'s (2011) orientation to learning and learning change that has impacted continued use including (a) prior beliefs and/or attitudes, (b) school environment, (c) professional development, (d) student change, (e) change in practice, and (f) change in beliefs. Pilot. The completed questionnaire was reviewed by the chair and co-chair of the PI's committee to determine the clarity of the questions and format. The questionnaire was then sent to three classroom teachers who were similar to the desired participant population. Based on feedback, changes were made to the wording of response intervals in sections two and three. The revised questionnaire was again peer-reviewed by the chair and co-chair of the PI's committee. The feedback from multiple experienced professionals in the field of study developed the internal validity of this measurement by ensuring clarity of questions and answer selection content (Merriam \& Tisdell, 2015).

Round two. Round Two participants received a letter of invitation via email with a link to a Doodle Poll to select a preferred date and time to participate in a semi-structured interview. Participants who completed the Doodle poll received a confirmation via email and were asked to provide contact information. Due to the variety of locations of prospective participants within the state of WV, all semi-structured interviews were conducted via phone and audio recorded. Immediately following the conclusion of each interview, the PI performed individual post- 
reviews of the semi-structured interviews conducted to reflect on delivery, increase the quality of data collection, and ensure authenticity (Merriam \& Tisdell, 2015; Patton, 2002). Round Two of data collection continued until an understanding of participants' experiences was exhausted, identified in consensus among participants. The acceptable minimum of 6 participants was met (Merriam \& Tisdell, 2015). Participants that completed the semi-structured interview received an incentive in the form of an e-gift card valued at twenty-five dollars. One additional participant was randomly drawn and received a fifty-dollar e-gift card to support classroom PA resource needs.

Round two instrumentation. The semi-structured interview guide included a total of fourteen questions, and was organized by content related questions aligning to Opfer et al.'s (2011) model of teacher change and common practices for success in classroom PA integration. Questions were divided into three sections: (a) orientation to learning (4 questions), (b) learning change (6 questions), and (c) suggestions for successful practice (4 questions). Each question included two optional probe questions for further elaboration. Section one addressed participants' orientation to learning related to the implementation of classroom PA and included questions regarding (a) preconceived notions of classroom PA, (b) the influence of the school environment, and (c) professional development learning experienced. Section two addressed participant experiences in learning change related to the implementation of classroom PA and included questions regarding (a) changes made in practice, (b) changes observed in students, and (c) developed beliefs. Section three addressed participants' perceptions of common practices that have helped in their delivery of classroom PA, and any additional suggestions for other educators in the implementation of classroom PA. 
Pilot. The completed semi-structured interview guide was reviewed by the chair and cochair of the PI's committee to determine the clarity of questions, format, and alignment to Opfer et al.'s (2011) model of teacher change. The guide was then sent to the same three classroom teachers who reviewed the Round One questionnaire. Classroom teachers received Opfer et al.'s (2011) model to review prior to the conduction of individual pilot sessions. Memos were used by the PI during pilot sessions to note significant feedback for consideration. Based on feedback, changes were made to section one and two questions to condense the focus on each component within orientation to learning and learning change. The revised semi-structured interview guide was again peer-reviewed by the chair and co-chair of the PI's committee. The feedback from multiple experienced professionals in the field of study developed the content validity of this assessment by ensuring understanding of collection, readability interview question format, and clarity of verbiage used (Merriam \& Tisdell, 2015).

\section{Data Analysis}

Prior to data analysis, the PI attempted to bracket personal interests and beliefs to limit bias. Additional professionals in the line of research assisted throughout study procedures and data analysis to ensure that any bias was limited. The PI's engagement in the process of analysis, acknowledgment of biases, previous knowledge and experiences, and the use of experienced research professionals to peer review practices helped to develop the internal validity of data analysis (Merriam \& Tisdell, 2015; Patton, 2002). Internal validity of data analysis was also assured by the use of an accounting log to monitor all planned correspondence between the PI and participants to decrease the often overwhelming collection of data in multiple rounds (Miles et al., 2014). 
Round one. Round One questionnaire responses were exported from the online survey system, Qualtrics, into an excel spreadsheet. Frequency counts were calculated for all sections of the questionnaire. Measures of central tendency (mean and standard deviation) were calculated for questions in section three.

Round two. Each semi-structured interview audio file was downloaded, transcribed verbatim, and saved into a Microsoft Word document. Transcriptions were then uploaded into the qualitative data analysis software NVivo for coding. An inductive approach to coding was used to analyze transcriptions and reveal emerging themes. The coding process began with the open coding of two interviews separately coded by the PI and a second coder to develop the codebook (Merriam \& Tisdell, 2015; Miles et al., 2014). The PI and second coder individually organized identified themes into categories. Categories with ample content for support were considered as master codes, while categories with minimal yet significant content were determined as sub-codes (Merriam \& Tisdell, 2015). The PI and second coder then compared code lists to organize and reorganize codes into major themes and sub-themes (Merriam \& Tisdell, 2015; Miles et al., 2014). The same two interviews were coded again by the PI and second coder individually, using a focused coding approach with the identified themes and subthemes of the developed codebook (Appendix C).

The PI and second coder met a minimum of an $82 \%$ inter-rater agreement between coders (range $=80-100 \%$ ), which met the determined acceptable range (Miles et al., 2014). The remaining interviews were coded by the PI, in addition to the use of memos and jotting in an attempt to synthesize higher levels of analytic meaning (Miles et al., 2014). Trustworthiness and validity of interpretations were assured through the use of member checking (Merriam \& Tisdell, 2015; Yin, 2015). After the completion of semi-structured interview analysis, Round Two 
participants were delivered via email a summary of main themes and sub-themes, and were asked to confirm the representation of data collected with a response email. Final results of themes and sub-themes were organized into a summary spreadsheet, with example quotes to allow the researcher to easily review findings and participants' perceptions (Merriam \& Tisdell, 2015).

\section{Results}

\section{Teacher Questionnaire}

Twenty-six $(n=26)$ teachers completed a questionnaire that was delivered in Round One of the data collection procedures. Data revealed the results below related to classroom PA use, orientation to learning, and learning change.

Classroom physical activity use. Participants reported experience in the use of classroom PA, with 58\% reporting more than 5 years $(n=15)$. Lower levels of participantreported experience in the use of classroom PA included $8 \%$ at 5 years $(n=2), 4 \%$ at 4 years $(n=1), 15 \%$ at 3 years $(n=4)$, and $15 \%$ at 2 years $(n=4)$. None of the participants reported experience in the use of classroom PA at 1 or 0 years. Participants identified the average weekly use of movement in the classroom, with $50 \%$ of participants reporting 5 days per week $(n=13)$, and $42 \%$ of participants reporting 3-4 days per week $(n=11)$. One participant identified average weekly use of classroom PA at 1-2 days per week, and one identified 0 days per week. Participants reported their average daily use of classroom PA, with $68 \%$ of participants reporting 2-3 times per day $(n=17), 15 \%$ reporting $0-1$ times per day $(n=4), 12 \%$ at more than 5 times per day $(n=3)$, and $8 \%$ at $4-5$ times per day $(n=2)$.

All participants identified their use of classroom PA breaks. A majority of participants reported the use of classroom PA breaks at three or more days per week, with $46 \%$ of 
participants reporting 3-4 days per week $(n=12)$, and $46 \%$ of participants reporting 5 days per week $(n=12)$. Four percent of participants reported using classroom PA breaks 1-2 days per week $(n=1)$, and $4 \%$ reported 0 days per week $(n=1)$. The use of content-rich/standards-based PA in the classroom was reported by $65 \%$ of the participants $(n=17)$. Of the participants who implemented content-rich/standards-based PA, nine identified average weekly implementation of 1-2 days per week. Fewer participants reported the use of content-rich/standards-based classroom PA 3-4 days per week $(n=5)$ and 5 days per week $(n=3)$.

Participants reported the extent to which students actively participated during classroom PA implementation. A majority of participants identified that all students $(n=13,50 \%)$, or more than half of the students $(n=12,46 \%)$ actively participated. Only one participant reported lower student engagement, reporting that half of the students actively participated during classroom PA implementation.

Orientation to learning and learning change. Teachers attributed professional development experienced $(M=4.69, S D=0.54)$ and student reactions observed $(M=4.62, S D=0.49)$ as having the greatest influence on the implementation of classroom PA. In addition, teachers also identified that prior beliefs of using classroom PA $(M=4.35, S D=0.68)$, experience in practice $(M=4.31, S D=0.61)$, developed beliefs $(M=4.04, S D=0.90)$, and the school environment $(M=3.77, S D=0.93)$ influenced their implementation of movement in the classroom. Please refer to Table 3 for detailed data.

\section{Semi-Structured Interviews}

Selected participants $(n=6)$ participated in semi-structured interviews to better inform this study. Findings from the semi-structured interviews determined five core themes: (a) social and environmental influences, (b) professional development, (c) integration practices, (d) student 
reactions, and (e) teacher beliefs and attitudes. Please refer to Table 4 for an expanded table of representative quotes for all sub-themes.

Social and environmental influences. The impact of social and environmental influences on the teacher implementation of classroom PA was evident across all cases. Three sub-themes emerged and included (a) student need, (b) school context, and (c) support from others.

Student need. Teachers often perceived the need for student movement in the academic setting. Prior to professional development, teachers recognized that students needed some kind of movement to be successful in the classroom. For example, Teacher D stated..."I knew that these little ones needed movement to be able to survive throughout the school day" (Teacher D). This theme also applied to teachers' experiences after delivery of classroom PA. Participants discussed that after professional development and in the experience of classroom PA implementation, their understanding of student need for movement was reassured. For example, Teacher B stated..."I started out feeling like something was needed, and now it seems imperative that it happens in every classroom for students to be able to be successful" (Teacher B).

School context. The impact of the school context on the delivery of classroom PA was also found to influence teacher continued use. Participants discussed prior concerns related to the small classroom space, which led to the initial hesitation of using classroom PA. However, many of the participants noted that positive prior perceptions of their supportive school environment, including availability and access to bigger movement spaces, supported their belief in the ability to implement classroom PA. Participants further suggested the importance of advocating for the use of larger spaces outside of the classroom environment to support the implementation of active lessons. Teacher E stated..."We have a small classroom so what we do in the classroom is 
limited, but we advocated for access to the gymnasium ... access to the playground and outside time...so I knew I would have the space available" (Teacher E).

Teachers' prior perceptions of access to resources (i.e., lesson materials and equipment) were also found to be both a limitation and advantage. Participants discussed that the current supportive school environment in which they taught allowed for access to resources needed yet previous school environments were limited. However, participants identified their ability as effective educators to "make it work" with what resources were available. The ability to adapt was often rooted in teacher drive to continue classroom PA implementation related to the understanding of student need for movement and personal positive belief.

Support from others. It was evident across all cases that support from others (i.e., administration, peers) aided in teachers' continued use of classroom PA. Participants identified positive perceptions of administrative support. For example, Teacher B stated... "We have a really supportive administrator for any initiatives we want to try in our classrooms. So, I was not hesitant about that" (Teacher B). Teachers also identified prior positive perceptions of peer support in the delivery of classroom PA. Participants noted that attending professional development with other colleagues from the school environment encouraged a teamwork mentality toward implementation. Participants further noted that in practice, support from peers who attended similar professional development aided the development of classroom PA lesson, as well as encouraged continued motivation for implementation of classroom PA. Teacher E noted the importance of peer support by stating...

"it is helpful to have those supporting teachers...I know that when I am running low on ideas or I am not sure how to adapt something to meet a student's needs...I have someone I can go to...... have other people to collaborate with..." (Teacher E) 
Teachers suggested that in order to be successful in the continued implementation of classroom PA, peer collaboration was of utmost importance. Participants noted that the ability to collaborate with peers on the delivery of classroom PA often increased levels of comfort in implementation and expanded lesson ideas for integration. Teacher A specifically mentioned that...

"teachers feel better, and they feel more comfortable, and sometimes you just help each other out in an area where I'm not comfortable, and the other person is comfortable. So, collaborating I think it is really helpful, especially for teachers that aren't comfortable using physical activity. It will help them to kind of see how to do it. How to implement into that classroom and give them ideas". (Teacher A)

Professional development. Professional development experiences on teacher implementation of classroom PA was found to support success in sustaining continued delivery. Two sub-themes emerged and included (a) hands-on activities and resources, and (b) contentrich/standards-based PA.

Hands-on activities and resources. It was evident across all cases that hands-on activities and resources included in professional development learning experiences supported teacher implementation of classroom PA. Providing access to classroom PA resources during professional development was beneficial in support of lesson development for movement in the academic environment. For example, Teacher E noted that...

"The resources took all the guesswork out of it. Like when you go to the professional development, and you're like man, this is great, this is awesome. And then you get back to the classroom, and you're like Oh my God, I don't even know where to begin. Having those developed resources really helped set a foundation to build off of and keep you motivated until it [classroom PA] becomes part of your routine..." (Teacher E)

In addition, participants often discussed that hands-on experience in these active lesson resources supported their understanding of how classroom PA worked and increased comfort in implementation. Teacher A suggested that seeing examples of classroom PA could positively 
impact teachers' implementation: "I think that modeling really helped teachers be like, hey you know what that is not so bad, fear of chaos out there is not really necessary. I think that it can help more teachers to want to do it" (Teacher A). Teachers identified the connection of early hands-on experiences in learning to success and motivation to continue classroom PA implementation. For example, Teacher E stated...

"I think the one that has definitely influenced my delivery the most has been the hands-on training experience. You can read, and you can implement, but it still almost feels like you're going through the motions. But when an adult makes you stand there for 30 minutes doing exercises going over the importance of classroom physical activity, and why, and showing you the lessons, and showing you how to implement and adapt it to different needs and students with exceptionalities, it makes it feel like it's actually possible. It's a really daunting task to just take on by yourself". (Teacher E)

Content-rich/standards-based $\boldsymbol{P}$ A. Hands-on experience during professional development in content-rich/standards-based PA helped to lay the foundation of teacher understanding for integrating movement in academic subjects. For example, Teacher D stated... "Once we had the professional development, we had better ideas and more ways to integrate PA into the actual lesson [content] so that for me was beneficial just to see different math games we could play or reading/language games" (Teacher D). Teachers further identified that personal experience participating in content-rich/standards-based PA during professional development helped them to realize that movement through learning was achievable. For example, Teacher B stated... " just the idea that you can review stuff with students while they're being active...they [students] can be doing squat jumps or jumping jacks just to get your brain going and still be learning” (Teacher B). Participants often found that early learning experiences during professional development also increased belief in the ability to integrate movement in academic learning. Teacher F stated...

"Being at the training and having hands-on experiences... I felt comfortable doing it that way when I went into my classroom. That's probably the most significant impact on my 
ability to integrate movement in the classroom, especially in an academic sense". (Teacher F)

Integration practices. Significant practices used when incorporating PA in the academic classroom were identified by teachers in order to best support sustained delivery. Four subthemes emerged and included (a) planning; (b) rules, routines, and expectations; (c) progression for integration; and (d) use of classroom PA as an incentive.

Planning. The importance of planning for implementation was evident as teachers often attributed their success in continued classroom PA delivery to lesson preparation. Participants identified the need to have a plan of action for implementation and to be prepared with all materials for active lessons ahead of time. Teachers often suggested that the practice of preparation and planning supported increased levels of daily classroom PA delivery. For example, Teacher A stated...

"Preparing it ahead of time and having the materials available at any time I need has been able to help me keep going with it... if I didn't have it then I would just say I'll do it tomorrow and it probably never would happen. Being prepared, knowing what you want to do, having a list of your games that you want, or your activities". (Teacher A)

Participants further suggested having multiple classroom PA lessons ready that could be applied to any lesson. For example, Teacher B noted that preparation of materials ahead of time has supported the use of content-rich/standards-based PA: "Having a toolkit of like maybe 10 or 15 physical activities that can be incorporated into any content lesson pretty quickly has been really beneficial for me" (Teacher B). Another teacher found preparation of materials helped to keep students on task and focused on lesson content.

"Planning ahead has helped me a lot...Sometimes you're in the middle of a lesson, and you might see the kids off task or not paying attention because they are a little bored... Then there might be a quick activity that I can throw in there". (Teacher D) 
Rules, routines, and expectations. Teachers suggested the importance behind setting rules, routines, and expectations to support a smooth delivery of classroom PA. Participants identified that the establishment of rules, routines, and expectations early on in implementation was necessary for success in delivery, and for positive student reactions to be possible. Participants found that the adaptation of regular classroom rules and routines to the delivery of classroom PA enabled increased student understanding due to transferability of expectations already learned. Teachers also stressed the importance of not only identifying these rules, but also practicing them with students. Participants found that expectations for student participation in classroom PA were best learned through the delivery of PA breaks. Once rules and routines were established with PA breaks, teachers then suggested moving into practice with content related PA. For example, Teacher C stated... "I mean most of our routines are just learned from day one. I did a lot of practice with physical activity breaks with my students before getting into moving with academics” (Teacher C).

In addition to the importance of establishing rules and routines for classroom PA, teachers also found that the management of expectations was just as important to success in continued classroom PA implementation. Teachers often suggested that the lack of student understanding of these guidelines would lead to a negative experience in practice, and would therefore discourage continued delivery of classroom PA. For example, Teacher A stated...

"Letting the kids know the expectations. I think that is a big part of it, especially because if I didn't have an expectation and the kids knew, then they would just go crazy and be running around and kind of chaotic like everybody is nervous about". (Teacher A)

Teachers found that being consistent in upholding these expectations led to positive experiences in the delivery of classroom PA. For example, Teacher F stated..." just follow through with what you expect of your students, and things will go much smoother" (Teacher F). Participants 
suggested that the establishment and management of rules, routines, and expectations led to more positive student reactions to classroom PA, and therefore, supported teacher continued engagement in delivery.

Progression for integration. The importance of mindful-progression for integration was evident in teachers' experiences in practice to support continued use. Participants first suggested that starting small with one activity daily helped to maintain continued use over time. For example, Teacher E noted...

"You need to start small. Rome was not built in a day. You need to be smart about it in that you don't want to implement a practice that is going to take a chunk of your time, that if you deviate from that time frame it will set your whole schedule off. You need to start with something simple that you can maintain day after day after day". (Teacher E)

Once participants were comfortable in day-to-day use of classroom PA, they began to add more opportunities for movement in the classroom throughout the day. Teachers suggested that this progression limited the overwhelming nature of changes made to regular practice and supported the sustained delivery of classroom PA. Participants also suggested that classroom PA lessons be repeated to allow students to become comfortable with the idea of movement in the classroom, which then supported positive student reactions to the change made in the academic environment. For example, Teacher D stated...

"Sometimes I'll do the same activities...like at the beginning of the year I do a lot of the same activities...but then I try to change it up here and there as the students get more comfortable...There are activities that I would maybe do once a week that they are used to...just to help them get used to using movement in learning”. (Teacher D)

Teachers further noted how they chose to integrate both classroom PA breaks and content-rich/standards-based PA. Participants often identified the use of PA breaks as a transition between content lessons or when traveling from one area of the school to another to maintain student behavior. For example, Teacher E stated... 
"We utilize physical activity breaks, especially like bathrooms and in line routine... all of our lineup routines have painter's tape lines to follow where we're hopping, zigzag, slithering or crawling on the floor to get there. In the bathrooms, we do a lot of bouncing when we are in line ... or jumping or clapping our hands". (Teacher E)

Participants discussed the use of content-rich/standards-based PA when time was limited during the school day, and less active breaks were possible. For example, Teacher F stated...

"I feel like I only have like 40 minutes to teach them the content that I need to cover...If I could incorporate activity and they're still learning, but they're still getting to move, I felt like I killed two birds with one stone". (Teacher F)

Use of classroom PA as an incentive. Teachers found that the use of classroom PA as an incentive to students fostered positive reactions in the academic setting. Participants often discussed the use of classroom PA as a reward to encourage student focus in the classroom.

"So, it [classroom PA] became a reward. It started out with I'm going to try classroom physical activity because it seems fun and it's a good thing... and then it became a reward system in my classroom like let's focus for this long and then we'll do an activity". (Teacher B)

Participants suggested the use of classroom PA multiple times throughout the school day to maintain students' focus. For example, Teacher A stated..."I probably do an activity every 15 minutes, we are doing something up of our chair just because I don't really want them to sit and get the lazy brain and tiredness" (Teacher A). Teachers further identified that allowing student choice of classroom PA to be implemented not only supported focus, but also increased students' motivation in participation.

Student reactions. The influence of student reactions to classroom PA on teacher decision to continue use was evident across all cases. Three sub-themes of student reactions emerged and included (a) student enjoyment, (b) student engagement, and (c) student learning.

Student enjoyment. Teacher observation of student enjoyment in classroom PA was found to support positive beliefs and/or attitudes to continue delivery. While positive reactions of 
students were most prominent across cases, teachers also identified the limitation of negative student reactions. While few, participants discussed that these negative student reactions were disappointing. For example, Teacher F noted...

"And of course, you still have the kids that do not like to move and just stand there the entire time...that was a negative impact on my use, it was hard to get some of them to move". (Teacher F)

However, participants claimed that the overwhelming amount of other students' enjoyment often overshadowed negative student reactions. Participants identified that the combination of positive student reactions and their positive personal belief of the need for classroom PA diminished the influence of any negative student reactions on continued use.

Student engagement. Participants further suggested that students' enjoyment in classroom PA lessons often led to increased motivation for participation. For example, Teacher C stated... "They're [students] definitely excited to do anything where they're moving. So, I think motivation has definitely increased in my students with classroom physical activity” (Teacher C). Teachers discussed the observation of increased engagement levels of students both during and following active lessons in the classroom. Many participants identified changes in students' time on task when comparing active lesson to non-active lessons. For example, Teacher E stated... “ it [classroom PA] helped to focus them...because in the moments when we're not able to move, you can definitely see the kids struggle in paying attention..." (Teacher E). Teachers also found that discipline issues were often absent when students participated in classroom PA.

Participants provided reasons for increased student discipline related to increased engagement in the active lesson opportunities. For example, Teacher D stated... "I tell you what, your classroom behavior is phenomenal with physical activity in the classroom. There are some ornery kids in my class...getting them moving and keeping them moving... it really cuts down on 
nasty behaviors and things" (Teacher D). Teachers suggested that increased student engagement as a result of classroom PA participation had a positive impact on teacher experiences in implementation. For example, Teacher B stated..."When the students are more engaged, it is overall a more enjoyable experience in the classroom" (Teacher B).

Student learning. The observation of students' increased learning was found to positively impact teachers' continued engagement in classroom PA implementation. Participants most often connected the use of content-rich/standards-based classroom PA to increased student learning. Increased student academic performance in reading was observed by teachers as a result of active lessons integrated within language arts. For example, Teacher A stated...

"Once I started to do the physical activity and incorporating it into my reading lessons, I've noticed that those students who were at a lower academic level are actually becoming better, or they are getting more answers correct on their test. They're excited to take the test because they feel confident in themselves and that they know the material". (Teacher A)

Participants also discussed the positive impact of math-related classroom PA on student levels of math achievement. One of the participants teaching at the youngest age level (PK) noted that students had developed past the expected math learning achievement levels for the next grade.

"We have our students counting to higher numbers after we have started implementing movement in the classroom. Our goal by the end of preschool is to have them counting to 20 because that is what they need to know at the start of kindergarten... and currently, we have kids counting into the 50 s and 60s". (Teacher E)

Participants suggested that increased student learning related to the use of classroom PA supported the desire to continue daily use of movement in the academic environment. For example, Teacher D stated...

"seeing that after your lesson or your movement break...you see that they [students] are learning the material. You are able to see the results that they are getting it... When they learn, I'm like oh yeah, I am going to keep doing this because it really is benefiting my students". (Teacher D) 
Teacher beliefs and attitudes. Teachers' beliefs and/or attitudes of classroom PA impacted the choice to continue implementation. Three sub-themes emerged related to teacher beliefs and/or attitudes of classroom PA and included (a) positive belief/attitude of classroom PA, (b) understanding the chaos of an active classroom, and (c) continued engagement.

Positive belief/attitude of classroom $\boldsymbol{P}$ A. The need for a positive belief and/or attitude of using movement in the classroom in order to support continued implementation was evident across all cases. Participants discussed that prior positive personal interest in movement was present, which supported their desire to learn more about classroom PA. For example, Teacher F stated...

"Sometimes, I think this might be a personality thing. I think I'm a mover, so I feel like I have to move to make it through the day... whereas I think some teachers are happy with being still in their classroom”. (Teacher F)

Participants further identified that prior positive beliefs and/or attitudes of classroom PA greatly influenced their continued use. For example, Teacher E noted... " going into it with a positive attitude definitely helped me to maintain my momentum with continuing to use it" (Teacher E). Teachers suggested that a positive outlook on classroom PA was necessary to support a positive experience in practice and positive student reactions. Teacher A specifically stated... "I believe that you have to want to be able to implement it [classroom PA] and have to be excited about it...so that the kids are excited about it" (Teacher A). Teachers further identified that the connection between prior perceptions of classroom PA and success in practice led to a continued positive belief and/or attitude in the use of movement in the academic environment.

Understanding the chaos of an active classroom. The need to understand an active classroom environment was evident to support teacher continued use of classroom PA. Participants discussed the presence of prior negative beliefs and/or attitudes of classroom PA in 
regards to the concern of being able to handle the perceived chaos of an active classroom. For example, Teacher A stated... “ before I used it, I was a little nervous I think because I listened to people and they thought it was going to be chaos" (Teacher A). Participants further identified the concern of calming students down after classroom PA participation and the ability to focus on academic learning. Teacher B stated... "I was hesitant...getting them to be able to sit down and show me the steps on paper, that they could do it after being up and active was kind of a concern” (Teacher B).

After experience in classroom PA implementation, teachers identified suggestions for successful practice to manage the perceived chaos of an active environment. Teachers suggested that rules and expectations needed to be established and consistently enforced. For example, Teacher D stated..."It's OK they don't have to be perfect in their little seat, and it's ok to be wiggly... as long as it is controlled chaos, it is good chaos"(Teacher D). Participants identified that positive experiences in being able to manage the active classroom environment often diminished the fear of chaos, and positively influenced the desire to continue use.

Continued engagement. Teachers' beliefs and/or attitudes to continue engagement in the implementation of classroom PA was often connected to positive experiences in practice. Teachers identified that positive experiences in implementation and positive student reactions supported continued engagement in the delivery of classroom PA. For example, Teacher B stated... "I feel like I enjoy teaching more because the students seem to enjoy those active lessons more. Them being motivated then motivates me to do more of it. So, it's kind of the cycle of good stuff happening” (Teacher B). Teachers further suggested that the more they practiced and experienced positive instances of classroom PA implementation, the more comfortable they 
became with the use of movement. One participant specifically described that developed belief and/or attitude of the use of classroom PA led to the continued use of more difficult activities.

"I definitely try a lot more. There are a lot of activities that I would see or find, and think I can't do that with my kids, they are going to be crazy...I'm a lot more ambitious and I give my kids a lot more credit... and we try a lot more that's because I'm more comfortable with it". (Teacher E)

While participants identified that initial implementation was often difficult, they suggested the importance of persistence, often rooted in the knowledge and experiences of the positive impact on students in the academic environment. For example, Teacher E stated...

"You have to stick with it. There are so many days where you're going to be so overwhelmed, and you're just like I am not about to do this today...You've got to stick with it and keep on pushing, because the end reward is awesome". (Teacher E)

Participants further suggested that they learned from these initial trials and errors in classroom PA, which led to revisions to improve practice in classroom PA implementation. This revised practice led to smoother classroom PA delivery experiences, which fostered a positive belief and/or attitude to continue use.

\section{Discussion}

Classroom PA has been associated with positive increases in students' PA participation (Centeio et al. 2014b; Kulinna et al., 2012), time on task (Carlson et al., 2015; Grieco et al., 2009; Mahar et al., 2006) and academic performance (Erwin et al., 2017; Hollar et al. 2010; Mullender-Wijnsma et al., 2015; Reed et al., 2010). Research on classroom PA thus far has identified multiple facilitators and barriers to teachers' implementation of movement in the academic environment. Facilitators have included professional development, additional resources, implementation practices, a supportive school environment, and positive student reactions. Teacher-identified barriers have included time and space in the classroom, the focus on academics, and integration into the daily curriculum (Cothran et al., 2010; Goh et al., 2017; 
Goh et al., 2014b; McMullen et al., 2014; Raymond, 2013; Strampel et al., 2014). Teachers have also identified that beliefs and/or attitudes of classroom PA could be a barrier or facilitator to implementation, dependent on teacher positive or negative perceptions of classroom PA (Cothran et al., 2010; Strampel et al., 2014).

While multiple influences have been found to impact teachers' use of classroom PA, researchers have yet to investigate teacher perceived connections between these experiences and their resulting impact on change in practice. The current study investigated teachers' perceptions of these barriers and facilitators to classroom PA implementation, and the perceived connection among these experiences that have impacted continued change. This investigation, using Opfer et al.'s (2011) model of teacher change, focused on the connections among an individual's experiences in learning (orientation to learning) and practice (learning change). Opfer et al.'s (2011) model of teacher change considers the reciprocal and continued process of change. The use of this model enabled the PI to connect factors of influence in teacher learning and practice, and identify their impact on the success of classroom PA delivery. Main themes found in the current study aligned with previous classroom PA research and included (a) social and environmental influences, (b) professional development, (c) integration practices, (d) student reactions, and (e) teacher beliefs and attitudes of classroom PA.

Success in teacher implementation of classroom PA has often been perceived as connected to social and environmental influences of the surrounding school setting. In alignment with previous findings, teachers in the current study described the importance of administrative support in order to facilitate the implementation of classroom PA (Goh et al., 2017; McMullen et al., 2014; Raymond, 2013). While support from the administration was of value to teachers in the current study, it was suggested that peer collaboration was more influential on continued 
classroom PA implementation. Researchers have often identified peer collaboration as a facilitator of teacher practice of classroom PA (Goh et al., 2017; McMullen et al., 2014; Raymond, 2013). For example, Goh et al. (2017) found that collaboration among peers in implementation led to teachers' success in their continued use of classroom PA. While teachers in the current study suggested the positive influence of peer collaboration in practice, peer support during learning was also identified as influential on teacher continued use of classroom PA. Teachers identified that peer support that occurred during learning increased positive experiences in professional development and led to increased engagement in collaboration throughout implementation. Therefore, the teamwork mentality in teacher implementation of classroom PA needs to be established during professional development in order to best support positive experiences and encourage continued use.

Teachers described that professional development experiences impacted their continued use of classroom PA. Patton et al. (2013) and Dole et al. (2016) found that teachers were most successful in a change of practice when supported with realistic learning experiences during professional development, delivered by experts in context. In alignment with previous studies, teachers identified success in implementation as a result of professional development experiences that occurred in a realistic classroom environment and included support from experts in classroom PA implementation. Erwin et al. (2011), Goh et al. (2014a), and Grieco et al. (2009) each found that the inclusion of resources and hands-on experience in classroom PA during professional development facilitated implementation by teachers. Teachers in this study further identified that hands-on experiences utilizing these classroom PA resources were some of the most significant influences on their continued use. Teachers also suggested the importance of hands-on activities in content-rich/standards-based PA in understanding how to integrate 
movement into academics. Previous studies have continually identified the teacher barrier of lack of time for implementation due to the focus on academics (Cothran et al., 2010; McMullen et al., 2014; Raymond, 2013; Strampel et al., 2014). The inclusion of meaningful practice in content related PA could diminish the barrier of interfering with academic instruction and encourage teachers' continued use of classroom PA.

The importance of successful integration practices to support continued use was necessary to encourage positive experiences in teachers' classroom PA implementation. Goh et al. (2017) found that teachers were successful in the continued delivery of classroom PA when movement opportunities were scheduled into weekly routines and practice was continued over time in order to increase confidence and implementation. Similar teacher-identified suggestions for success were found in this study, including pre-planning of activities and thoughtful progression over time to support comfort in implementation. Yet, teachers in the current study also revealed the need for management techniques and established protocols for a moving classroom. McMullen et al. (2014) found that teachers identified management of active classrooms as a perceived barrier in implementation, with lack of support in effective methods. Development of rules and routines enabled teachers in this study to overcome this barrier, yet it was often found that experience in application of classroom PA expectations, and often learning from failure, is what led to success. Teachers identified that their persistence, often backed by their positive beliefs of classroom PA, aided in the ability to overcome management barriers experienced in implementation. However, other teachers who hold negative beliefs behind movement in the classroom may not be as persistent with continued implementation if barriers in integration are experienced. This suggests that in order to prepare teachers for success and continued engagement in classroom PA delivery, 
effective rules, routines, and expectations should be included as a focus of professional development learning experiences.

Positive student reactions were found to be one of the greatest influences on teachers' sustained delivery of classroom PA. Goh et al. $(2014 b, 2017)$ identified that teacher observations of students' enjoyment and positive participation in classroom PA were a facilitator to implementation. Carlson et al. (2015) and Magnusson et al. (2011) also found that teachers were often successful in the implementation of classroom PA if positive student reactions were present. Positive student reactions are most often present when teachers use PA breaks as rewards (McMullen et al., 2014) and provide student choice in activity (Bershwinger \& Brusseau, 2013). The results of the current study align with previous findings, as teachers identified the influence of student involvement in encouraging positive student reactions. Additionally, the barrier of negative student reactions identified in previous research (Cothran et al., 2010; Goh et al., 2014b, 2017; Raymond, 2013; Strampel et al., 2014) was also experienced by teachers in the current study. Carlson et al. (2015) found that negative student reactions to classroom PA participation often discouraged teachers continued use. Yet, teachers in the current study expressed that these perceived negative student reactions did not inhibit their delivery. Teachers suggested that positive beliefs of classroom PA and a majority of positive student reactions worked together to overcome this barrier. These results indicate that a positive connection between teachers' personal interest in classroom PA and student reactions needs to be present in order to support continued use.

Positive beliefs and/or attitudes of classroom PA had one of the greatest impacts on teachers' continued use of classroom PA. Researchers thus far have identified that a teacher's belief of classroom PA can either hinder or aid implementation dependent upon the individual's positive 
or negative view (Cothran et al., 2010; Raymond, 2013; Strampel et al., 2014). In this study, positive beliefs and/or attitudes of classroom PA were identified by teachers to be a facilitator in implementation. Yet, teachers in this study further suggested the influence of positive prior beliefs of classroom PA on continued motivation for implementation. Opfer et al. (2011) determined that teachers have already formed their own beliefs of the change to be made prior to learning experiences, which then impact experiences in change. Teachers in this study identified that attendance at professional development was based upon their personal interest in classroom PA. Positive prior beliefs of classroom PA is needed to support teachers' positive learning experiences and continued practice, despite any limitations that may occur.

\section{Connections of Change and Continued Use}

The five main themes identified in the current study were found to have influenced one another in the overall impact on teachers' classroom PA implementation and continued use. Similar to Opfer et al.'s (2011) model of teacher change, these themes occurred within teachers' experiences in orientation to learning and learning change. Teachers often suggested that these themes worked together and across both learning and practice to influence their continued use of classroom PA.

Teachers first identified perceived connections among themes related to their orientation to learning to include social and environmental influences, teacher beliefs and attitudes of classroom PA, and professional development. Opfer et al. (2011) suggested that influences within the experiential environment in which the change is to be made impacts an individual's experience in learning. Opfer and Pedder (2011) found that teachers believed a committed school environment had the highest level of influence on their belief to make a change. Similarly, teachers in this study indicated that social and environmental influences in the school 
environment influenced a positive belief in their ability to implement classroom PA. Teachers identified that support from colleagues (administration and peers) during both learning and practice encouraged continued classroom PA delivery over time. Students' need for movement was also identified by teachers to influence their positive belief of the need to implement PA in the academic environment. Opfer et al. (2011) further determined that teachers have developed a prior belief of the change to be made, often related to the experiential environment and personal attitudes. Teachers in the current study noted that the connection between social and environmental influences and their personal interest in PA resulted in a positive influence on their prior belief and/or attitude of classroom PA. Teachers identified that these perceived connections of influence led to the desire to attend the professional development learning opportunity.

What is experienced during these learning opportunities has also impacted teachers' continued delivery of classroom PA. Opfer et al. (2011) and Dole et al. (2016) found that providing the opportunity to practice in a realistic environment during professional development had high levels of influence on teachers' positive belief to make a change and success in practice. Similarly, the results of this study indicated that realistic hands-on experiences during professional development most supported teachers' belief in the ability to integrate classroom PA. Teachers suggested that the early development of confidence in classroom PA implementation led to increased delivery in practice. Considering the influence of early learning experiences on teacher positive belief and sustained implementation, it can be suggested that preservice teachers would benefit from early exposure to movement in the academic environment. Teacher preparation programs should consider the inclusion of courses focused on movement in the classroom. Providing pre-service teachers with early learning opportunities in classroom PA 
could lead to increased levels of confidence in implementation, and support sustained delivery throughout their teaching career.

A positive experience in orientation to learning is necessary to support teachers in the change to be made; yet components of learning change are also influential on teachers' continued use. Teachers' experiences in integration practices, student reactions, and teacher beliefs and attitudes of classroom PA have influenced sustained implementation of the change made. Opfer et al. (2011) has identified that the process of learning change often begins with a teachers' change in practice. Teachers in this study identified the importance of planning and preparation of materials for classroom PA to encourage daily use; as well as the establishment of rules, routines, and expectations for classroom PA to support a smoother delivery. Opfer et al.'s (2011) model of teacher change has further identified that changes made in practice have directly influenced resulting student reactions. The design of this study allowed for a better understanding of teacher integration practices and their influence on student reactions, and identified that carefully planned methods for implementation are needed to support positive student reactions. Teachers identified that through the use of these integration practices, students were comfortable in the moving environment and were aware of expectations, and positive reactions flourished.

Teachers' experiences in practice and student reactions have been found to influence an individual's belief and/or attitude to continue delivery of movement in the classroom. Opfer et al.'s (2011) model of teacher change suggested that students' reactions as a result of the change made in practice are what form an individual's belief to continue this change. Teachers in the current study suggested that positive experiences in implementation and positive student 
reactions occurred, thereby influencing a developed positive belief and/or attitude to continue the use of classroom PA.

Opfer et al.'s (2011) model of teacher change is different from many other models in that it suggests that teachers' experiences in orientation to learning and learning change are reciprocal of one another, and often continually occurring. The results of this study have identified connections between influences in learning and practice of classroom PA. Many themes occurred across stages of this model. First, teachers' belief and/or attitude of classroom PA occurred across both stages, related to the need of a positive perspective to support teacher continued implementation. Supporting teacher prior positive belief and/or attitude of classroom PA is important in order to support sustained use. Next, social and environmental influences and student reactions were connected across stages related to student need for movement and success in the academic environment. Teachers' positive belief of the need for student movement helped to overcome negative student reactions, and supported continued use to encourage further positive student reactions. While positive teacher beliefs of classroom PA may be the root of teacher change, positive student reactions hold a great amount of influence on this belief; therefore, positive student reactions also influence teacher-sustained implementation of classroom PA. Another connection that occurred across both stages included the themes of social and environmental influences and integration practices. The connections between these themes were related to the importance of peer support and collaboration during learning and practice on teacher success in classroom PA implementation. Opfer et al. (2011) found that teachers valued peer support groups at much lower levels of impact on change. Yet, teachers in this study suggested that peer support during learning and collaboration in practice encouraged use in the presence of barriers. In addition to teachers' positive beliefs and positive student reactions, 
support among peers early on and throughout the use of classroom PA is necessary to encourage sustained engagement in implementation. The themes of professional development and integration practices were also identified by teachers as connected across the stages of teacher change. Teachers suggested that hands-on learning experiences using the resources provided during professional development supported successful integration practices, and in turn influenced their desire to continue engagement in implementation. In comparing these findings to Opfer et al.'s (2011) reciprocal model of teacher change, this study has identified connections of influence among teachers' experiences that have led to the continued delivery of classroom PA. These connections shed insight into the factors of influence that underlie teacher continued change. Please refer to Figure 1 for a visual representation of connections among themes in relation to Opfer et al.’s (2011) model of teacher change.

Figure 1. Connections of Teacher Change to Sustain Use of Classroom Physical Activity.

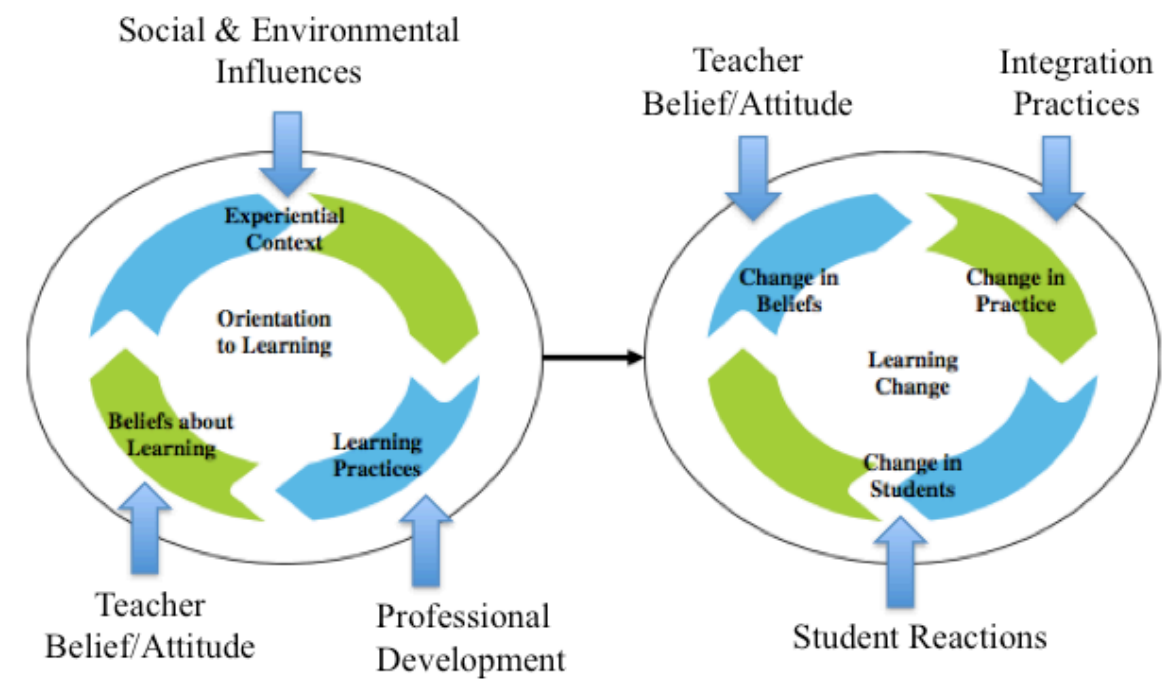

\section{Recommendations for Professional Development Design}

In order to have the greatest impact on teacher belief and/or attitude to continue classroom PA use, teachers must be prepared with the knowledge and skill needed to support successful practice (Armour \& Yelling, 2007). Multiple recommendations for professional 
development have resulted from this study and include (a) consideration of teacher perceptions in professional development design, (b) provided resources, (c) hands-on experience in practice, (d) meaningful progression for integration, and (e) effective management practices. Please refer to Table 5 for a summary of recommendations for professional development design.

The impact of teachers' beliefs and/or attitudes of classroom PA suggests that individuals conducing professional development need to understand teachers' perceptions prior to the delivery of learning experiences. Using movement in the academic environment is not only a change in teacher practice, but a change in the culture of the classroom environment. In order to support this change in culture, professional development should focus on encouraging teacher positive belief and/or attitude of classroom PA. This begins with the understanding of the learners' needs to support positive experiences in practice. Researchers thus far have not identified the influence of a learner's perceived needs on a framework for professional development design. The understanding of the learner's needs and the incorporation of previously identified methods of successful professional development delivery (e.g., face-to-face delivery, hands-on experience) could encourage sustained classroom PA use among attendees and a positive culture related to movement-based learning.

Cothran et al. (2010) and McMullen et al. (2014) have found that teachers found it easier to implement movement in the academic environment when provided with resources for support. Teachers in this study also valued the resources provided during professional development, finding that they aided in the development of lesson ideas and implementation. Bershwinger and Brusseau (2013) also found that when teachers were included in resource development, they developed a sense of confidence in implementation. These findings suggest the need to provide 
classroom PA lesson resources, as well as to encourage teachers to participate in the development of said resources, to best support continued implementation.

Future professional development opportunities should also focus on hands-on learning experiences. Classroom PA professional development opportunities that have included hands-on experiences for teachers have resulted in increased student daily PA levels and academic performance (Erwin et al., 2011; Goh et al., 2014a; Grieco et al., 2009; Mahar et al., 2006; Reed et al., 2010; Stewart et al., 2004). Dole et al. (2016) found teachers were more successful when provided with realistic hands-on learning experiences that included guidance from experienced professionals. Teachers in this study further attributed a majority of their success in classroom PA implementation to early hands-on learning experiences in the active lessons. Future professional development design should include hands-on activities that are practiced in a realistic learning environment (e.g., academic classroom setting) to develop teachers' confidence in their ability to implement classroom PA. This professional development practice could positively influence teacher continued use of movement in the classroom.

Meaningful progressions for integration have also been found to support teachers' continued use of classroom PA over time. Patton et al. (2013) found that teachers were successful in a change of practice when provided with strategies of structure for implementation during professional development. Similarly, Erwin et al. (2011) and Goh et al. (2014a, 2017) identified that professional development methods for classroom PA implementation have included teacher preparation for planning and curriculum integration. Yet, teachers in the current study also identified the need for successful methods of progression to support positive experiences in practice. Future professional development interventions should focus on best 
practices for progression (e.g., planning, progression, etc.) to support teacher-sustained use of classroom PA.

Understanding effective management practices for an active classroom was also identified by teachers in the current study as necessary to support continued classroom PA use. Teachers in the current study identified that the inclusion of expectations aided in the management of the perceived chaotic moving classroom environment and influenced positive student reactions. Descriptions of classroom PA professional development thus far have been unclear as to if rules, routines, and procedures for implementation were included in teacher learning experiences. It is evident from the results of this study that effective management practices for classroom PA must be included in professional development to encourage teacher sustained delivery.

\section{Limitations}

While the current study provides insight into influences on teacher continued use of classroom PA and suggestions for practice, limitations should be considered. Due to the focused selection of participants from different geographic locations within one state, the results of this study may not be generalizable across the United States. However, due to the presence of a state support policy for PA opportunities in the school environment (WV Policy 2510), the findings of this study may be transferable to other states with similar mandates. Additionally, the purposeful selection of participants who attended a specific professional development workshop may have excluded other teachers who have been successful in the continued use of classroom PA who attended another professional development opportunity. Another limitation of participant selection was the inclusion of only participants who identified at least two or more years of classroom PA use. This could have resulted in the exclusion of a teacher with significant insight 
on successful practice who had continued classroom PA use over a shorter period of time. Lastly, given the PI's involvement in classroom PA professional development planning and delivery, research bias may be present in this study. The PI aimed to minimize this limitation by determining research bias prior to the conduction of the investigation data analysis.

\section{Conclusion}

Minimal research to date has addressed the connection between the barriers and facilitators teachers experience in classroom PA implementation and their influence on continued use. The current study, using Opfer et al.'s (2011) model of teacher change, has helped to develop an understanding of teachers' experiences in learning and practice, and their influence on continued success in classroom PA implementation. Experiences in learning related to prior positive teacher belief and/or attitude of classroom PA, social and environmental influences, and professional development were found to most impact teachers' experiences in practice. Experiences in practice that most impacted teachers' continued use were successful integration practices, positive student reactions, and positive teacher belief and/or attitude of classroom PA implementation. The influences identified by teachers relative to the continued delivery of classroom PA and suggestions for successful practice provide focus for future professional development efforts.

While this study identified suggestions to support teacher-sustained delivery of classroom $\mathrm{PA}$, further research is needed to explore the utility of these recommendations. First, future research should focus on how to encourage a positive belief and/or attitude of classroom PA for teachers prior to attendance of professional development learning experiences, as well as during implementation practices. Second, researchers should further investigate best practices of teacher integration that support sustained delivery of classroom PA. While the current study begins to 
shed light on successful planning, management, and delivery of classroom PA, further investigation is needed to better understand necessary topics for professional development learning opportunities to support teacher continued use. Third, the influence of early learning experiences to support sustained teacher implementation raises the question of how pre-service teachers are prepared to use movement in the classroom. Higher education institutions should consider the inclusion of active learning courses in teacher education curricular design to support future teachers in fostering a successful academic learning environment. Further investigation is needed to identify the degree to which higher education institutions have included classroom PA learning in pre-service teacher preparation programs thus far, as well as the influence on inservice teacher implementation of classroom PA. In addition, research thus far has lacked in the investigation of student perceptions of classroom PA. The use of classroom PA not only means a change of culture in the academic environment for the teacher, but also for the student. Future research should also consider methods for investigating student perceptions regarding their participation in movement in the classroom environment. 


\section{References}

Armour, K. M., \& Yelling, M. (2007). Effective professional development for physical education teachers: The role of informal, collaborative learning. Journal of Teaching in Physical Education, 26(2), 177-200.

Beaulieu, L., Butterfield, S. A., Mason, C. A., \& Loovis, E. M. (2012). Physical activity and U.S. public elementary schools: Implications for our profession. The ICHPER-SD Journal of Research in Health, Physical Education, Recreation, Sport \& Dance, 7(1), 12.

Bershwinger, T., \& Brusseau, T. A. (2013). The impact of classroom activity breaks on the school-day physical activity of rural children. International Journal of Exercise Science, 6(2), 6.

Birman, B. F., Desimone, L., Porter, A. C., \& Garet, M. S. (2000). Designing professional development that works. Educational Leadership, 57(8), 28-33.

Brusseau, T. A., Hannon, J., \& Burns, R. (2016). The effect of a comprehensive school physical activity program on physical activity and health-related fitness in children from lowincome families. Journal of Physical Activity \& Health, 13(8), 888-894. doi:10.1123/jpah.2016-0028

Burn, K., Hagger, H., Mutton, T., \& Everton, T. (2003). The complex development of studentteachers' thinking. Teachers and Teaching, 9(4), 309-331.

Carlson, J., Engelberg, J., Cain, K., Conway, T., Mignano, A., Bonilla, E., Geremia, C., \& Sallis, J. (2015). Implementing classroom physical activity breaks: Associations with student physical activity and classroom behavior. Preventive Medicine, 81, 67-72. doi:10.1016/j.ypmed.2015.08.006 
Centeio, E., McCaughtry, N., Gutuskey, L., Garn, A. C., Somers, C., Shen, B., ... \& Kulik, N. L. (2014b). Chapter 8 Physical Activity Change through Comprehensive School Physical Activity Programs in Urban Elementary Schools. Journal of Teaching in Physical Education, 33(4), 573-591. doi:10.1123/jtpe.2014-0067

Centers for Disease Control and Prevention (CDC). (2015). Childhood Obesity Facts. Retrieved from https://www.cdc.gov/healthyschools/obesity/facts.htm.

Cothran, D. J., Kulinna, P. H., \& Garn, A. C. (2010). Classroom teachers and physical activity integration. Teaching and Teacher Education, 26(7), 1381-1388. doi:10.1016/j.tate.2010.04.003

Delk, J., Springer, A. E., Kelder, S. H., \& Grayless, M. (2014). Promoting teacher adoption of physical activity breaks in the classroom: Findings of the Central Texas CATCH Middle School Project. Journal of School Health, 84(11), 722-730.

Desimone, L.M. (2009). Improving impact studies of teachers' professional development: Toward better conceptualizations and measures. Educational Researcher, 38(3), 181199. doi:10.3102/0013189X08331140

Dole, S., Bloom, L., \& Kowalske, K. (2016). Transforming pedagogy: Changing perspectives from teacher-centered to learner-centered. Interdisciplinary Journal of Problem-Based Learning, 10(1), 1-14.

Egan, C., Webster, C., Weaver, R., Brian, A., Stodden, D., Russ, L., . . \& V Vazou, S. (2018). Partnerships for active children in elementary schools (paces): First year process evaluation. Evaluation and Program Planning, 67, 61-69. doi:10.1016/j.evalprogplan.2017.12.002 
Erwin, H. E., Beighle, A., Morgan, C. F., \& Noland, M. (2011). Effect of a Low-Cost, TeacherDirected Classroom Intervention on Elementary Students' Physical Activity. Journal of School Health, 81(8), 455-461. doi: 10.1111/j.1746-1561.2011.00614.x.

Erwin, H., Fedewa, A., \& Ahn, S. (2017). Student academic performance outcomes of a classroom physical activity intervention: A pilot study. International Electronic Journal of Elementary Education, 4(3), 473-487.

Eyler, A., Chriqui, J., Maddock, J., Cradock, A., Evenson, K. R., Gustat, J., ... \& Zieff, S. G. (2014). Opportunity meets planning: An assessment of the physical activity emphasis in state obesity-related plans. Journal of Physical Activity and Health, 11(1), 45-50. doi:10.1123/jpah.2012-0037

Gay, L. R., Mills, G. E., \& Airasian, P. W. (2011). Educational research: Competencies for analysis and applications (10 ed.). Upper Saddle River, NJ: Pearson Higher Education

Goh, T. L., Hannon, J. C., Brusseau, T. A., Webster, C., Podlog, L., \& Newton, M. (2014a). Effects of a classroom based physical activity program on children's physical activity levels. Journal of Teaching in Physical Education, 33(4), 558-572. doi:10.1123/jtpe.2014-0068

Goh, T. L., Hannon, J. C., Webster, C. A., Podlog, L., \& Pillow, W. (2014b). Classroom Physical Activity Breaks: Teachers' Perspectives of an Intervention Study. Research Quarterly for Exercise and Sport, 85(S1), A1.

Goh, T. L., Hannon, J. C., Webster, C. A., \& Podlog, L. (2017). Classroom teachers' experiences implementing a movement integration program: Barriers, facilitators, and continuance. Teaching and Teacher Education, 66, 88-95. doi:10.1016/j.tate.2017.04.003 
Grieco, L. A., Jowers, E. M., \& Bartholomew, J. B. (2009). Physically active academic lessons and time on task- the moderating effect of body mass index. Medicine and Science in Sports and Exercise, 41(10), 1921-1926. doi:10.1249/mss.0b013e3181a61495

Guskey, T. R. (2002). Professional development and teacher change. Teachers and Teaching, 8(3), 381-391.

Hollar, D., Messiah, S. E., Lopez-Mitnik, G., Hollar, T. L., Almon, M., \& Agatston, A. S. (2010). Effect of a two-year obesity prevention intervention on percentile changes in body mass index and academic performance in low-income elementary school children. American Journal of Public Health, 100(4), 646-653. doi:10.2105/ajph.2009.165746

Jones, E. M., Taliaferro, A. R., Elliott, E. M., Bulger, S., Kristjansson, A. L., Neal, W., \& Allar, I. (2014). Feasibility study of comprehensive school physical activity programs in Appalachian communities: The McDowell CHOICES project. Journal of Teaching in Physical Education, 33(4), 467-91. doi:10.1123/jtpe.2014-0065

Kulinna, P. H., Brusseau, T. A., Cothran, D., \& Tudor-Locke, C. (2012). Changing school physical activity: An examination of individual school designed programs. Journal of Teaching in Physical Education, 31(2), 113-130. doi:10.1123/jtpe.31.2.113

Magnusson, K. T., Sigurgeirsson, I., Sveinsson, T., \& Johannsson, E. (2011). Assessment of a two-year school-based physical activity intervention among 7-9-year-old children. International Journal of Behavioral Nutrition and Physical Activity, 8(1), 138.

Mahar, M. T., Murphy, S. K., Rowe, D. A., Golden, J., Shields, A. T., \& Raedeke, T. D. (2006). Effects of a classroom-based program on physical activity and on-task behavior. Medicine and Science in Sports and Exercise, 38(12), 2086-2094. doi:10.1249/01.mss.0000235359.16685.a3 
McMullen, J., Kulinna, P., \& Cothran, D. (2014). Physical activity opportunities during the school day: classroom teachers' perceptions of using activity breaks in the classroom. Journal of Teaching in Physical Education, 33(4), 511-27. doi:10.1123/jtpe.2014-0062

Merriam, S. B., \& Tisdell, E. J. (2015). Qualitative research: A guide to design and implementation $\left(4^{\text {th }}\right.$ ed.). San Francisco, California: John Wiley \& Sons.

Miles, M. B., Huberman, A. M., \& Saldaña, J. (2014). Qualitative data analysis: A methods sourcebook $\left(4^{\text {th }}\right.$ ed.). Thousand Oaks, California: SAGE Publications Inc.

Moore, J. B., Carson, R. L., Webster, C. A., Singletary, C. R., Castelli, D. M., Pate, R. R., ... \& Beighle, A. (2018). The Application of an implementation science Framework to comprehensive school Physical Activity Programs: Be a champion!. Frontiers in Public Health, 5, 354. doi: 10.3389/fpubh.2017.00354

Mullender-Wijnsma, M. J., Hartman, E., de Greeff, J. W., Bosker, R. J., Doolaard, S., \& Visscher, C. (2015). Improving academic performance of school-age children by physical activity in the classroom: 1-year program evaluation. Journal of School Health, 85(6), $365-371$

National Association for Sport and Physical Education (NASPE). (2008). Comprehensive school physical activity programs [Position statement]. Reston, VA: National Association for Sport and Physical Education. doi:10.1080/08924562.2008.10590798

National Center for Health Statistics. (2011). Health, United States, 2010: With special feature on death and dying. Washington, DC: U.S. Government Printing Office.

Opfer, V. D., \& Pedder, D. (2011). The lost promise of teacher professional development in England. European Journal of Teacher Education, 34(1), 3-24. 
Opfer, V. D., Pedder, D. G., \& Lavicza, Z. (2011). The role of teachers' orientation to learning in professional development and change: A national study of teachers in England. Teaching and Teacher Education, 27(2), 443-453.

Patton, M. Q. (2002). Qualitative evaluation and research methods (3rd ed.). Newbury Thousand Oaks, CA: SAGE Publications Inc.

Patton, K., Parker, M., \& Pratt, E. (2013). Meaningful learning in professional development: Teaching without telling. Journal of Teaching in Physical Education, 32(4), 441-459.

Raymond, L. A. I. (2013). Just for the health of it: Facilitators and barriers to increasing physical activity in Delaware elementary schools (Doctoral Dissertation). University of Delaware, Newark, Delaware.

Reed, J. A., Einstein, G., Hahn, E., Hooker, S. P., Gross, V. P., \& Kravitz, J. (2010). Examining the impact of integrating physical activity on fluid intelligence and academic performance in an elementary school setting: A preliminary investigation. Journal of Physical Activity and Health, 7(3), 343-351. doi:10.1123/jpah.7.3.343

Society of Health and Physical Educators (SHAPE) (2013). Comprehensive school physical activity programs: Helping all students $\log 60$ minutes of physical activity each day [position statement]. Reston, VA: Society of Health and Physical Educators.

Stewart, J. A., Dennison, D. A., Kohl, H. W., \& Doyle, J. A. (2004). Exercise level and energy expenditure in the TAKE 10 ! ${ }^{\circledR}$ in-class physical activity program. Journal of School Health, 74(10), 397-400. doi: 10.1111/j.1746-1561.2004.tb06605.x

Strampel, C. M., Martin, L., Johnson, M. J., Iancu, H., Babineau, C., \& Carpenter, J. G. (2014). Teacher perceived barriers and potential solutions to implementing daily physical activity in elementary schools. Physical \& Health Education Journal, 80(1), 14-22. 
Taylor, S. J., Bogdan, R., \& DeVault, M. (2015). Introduction to qualitative research methods: A guidebook and resource. San Francisco, California: John Wiley \& Sons.

Troiano, R. P., Berrigan, D., Dodd, K. W., Masse, L. C., Tilert, T., \& McDowell, M. (2008). Physical activity in the United States measured by accelerometer. Medicine and Science in Sports and Exercise, 40(1), 181-188. doi:10.1249/mss.0b013e31815a51b3

US Department of Health and Human Services (USDHHS), Office of Disease Prevention and Health Promotion. (2008). Physical activity guidelines for Americans. Washington, DC: US Department of Health and Human Services.

U.S. Department of Health and Human Services (USDHHS) (2010). Healthy People 2020. Retrieved September 5, 2016, from www.healthypeople.gov.

U.S. Department of Health and Human Services (USDHHS). (2012). Physical activity guidelines for Americans midcourse report: Strategies to increase physical activity among youth. Washington, DC: US Department of Health and Human Services.

West Virginia Department of Education (WVDE). (2014) State Board Policies: Policy 2510. Retrieved from https://wvde.state.wv.us/policies/.

World Health Organization. (2018). Global Strategy on Diet, Physical Activity and Health. Retrieved from https://www.who.int/dietphysicalactivity/pa/en/.

Yin, R. K. (2015). Qualitative research from start to finish (2 ${ }^{\text {nd }}$ ed.). New York, NY: Guilford Publications. 


\section{Tables}

Table 1

Round One Participant Demographics

\begin{tabular}{lc}
\hline Grade & $\begin{array}{c}\# \text { of } \\
\text { Participants }\end{array}$ \\
\hline PK to 2 & 16 \\
3 to 5 & 5 \\
6 to 8 & 2 \\
Other & 2 \\
\hline & \\
\hline Teaching & $\#$ of \\
Experience & Participants \\
\hline 0 to 4 years & 5 \\
5 to 9 years & 8 \\
10 to 14 years & 9 \\
15 to 19 years & 4 \\
20 to 24 years & 0 \\
25 or more years & 0 \\
\hline
\end{tabular}


Table 2

Round Two Participant Demographics

\begin{tabular}{ccccc}
\hline Teacher & $\begin{array}{c}\text { WV } \\
\text { County }\end{array}$ & Grade & $\begin{array}{c}\text { Teaching } \\
\text { Experience }\end{array}$ & Classroom PA Use \\
\hline Teacher A & Raleigh & 1 & 5 to 9 years & 3 years \\
Teacher B & Lewis & 4 & 10 to 14 years & 3 years \\
Teacher C & Wood & K & 5 to 9 years & more than 5 years \\
Teacher D & Barber & 1 & 5 to 9 years & more than 5 years \\
Teacher E & Fayette & PK & 0 to 4 years & 3 years \\
Teacher F & Hardy & K to 6 & 10 to 14 years & more than 5 years \\
\hline
\end{tabular}


Table 3

Impacts of Orientation to Learning and Learning Change

\begin{tabular}{|c|c|c|c|c|c|c|c|}
\hline Question & $\begin{array}{l}\text { Strongly } \\
\text { Disagree }\end{array}$ & $\underline{\text { Disagree }}$ & $\underline{\text { Neutral }}$ & Agree & $\begin{array}{l}\text { Strongly } \\
\text { Agree }\end{array}$ & $\underline{M}$ & $\underline{S D}$ \\
\hline $\begin{array}{l}\text { Q12. My beliefs about physical activity prior to } \\
\text { professional development has influenced my use } \\
\text { of movement in the classroom }\end{array}$ & 0 & 1 & 0 & 14 & 11 & 4.35 & 0.68 \\
\hline $\begin{array}{l}\text { Q13. My specific school environment (e.g. } \\
\text { resources, administration, school context, etc.) } \\
\text { has influenced my use of classroom physical }\end{array}$ & 1 & 1 & 6 & 13 & 5 & 3.77 & 0.93 \\
\hline $\begin{array}{l}\text { Q14. Professional development opportunities } \\
\text { have influenced my use of movement in the } \\
\text { classroom. }\end{array}$ & 0 & 0 & 1 & 6 & 19 & 4.69 & 0.54 \\
\hline $\begin{array}{l}\text { Q15. Students' reactions to participation have } \\
\text { influenced my use of classroom physical activity. }\end{array}$ & 0 & 0 & 0 & 10 & 16 & 4.62 & 0.49 \\
\hline $\begin{array}{l}\text { Q16. My delivery of classroom physical activity } \\
\text { has changed as a result of what I have } \\
\text { experienced in practice. }\end{array}$ & 0 & 0 & 2 & 14 & 10 & 4.31 & 0.61 \\
\hline $\begin{array}{l}\text { Q17. My beliefs about classroom physical } \\
\text { activity have changed as a result of what I have } \\
\text { experienced when using movement in the } \\
\text { academic environment. }\end{array}$ & 0 & 2 & 4 & 11 & 9 & 4.04 & 0.90 \\
\hline
\end{tabular}


Table 4

Inductively Developed Thematic Categories and Sample Quotes

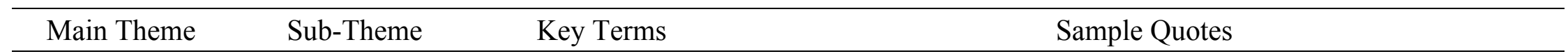

Social and

Environmental

Influences

S1
School Context

Student Need

Student need OR helps students

Classroom size, space OR school resources
"They come to school, and their basic needs need to be met before they can learn. In the use of classroom PA... that makes them want to come in and they want to learn because they think it's fun". (Teacher A)

"It (classroom PA) definitely helps them (students) to learn what it's like being mindful and is important to success in the classroom". (Teacher C)

"The classroom size defiantly was a concern for me because when you think of movement and physical activity you think you have to have a whole lot of space." (Teacher F)

"Well I do think it's affected by how much (resources available)... we're lucky because our PTA gives us pretty much what we need.... Now the first couple of schools I taught at that wasn't really the case, so I don't know back then if I would have been able. I would have had to spend my own money to buy different resources so that definitely affects it. (Teacher C)

Administration, principal OR peers, teachers, co-workers
"We have a very supportive principal at our school. She's all about it and she greatly encourages movement throughout the school day". (Teacher E) 
Professional

Development

P1

Hands-on

Activities \&

Resources

$\mathrm{P} 2$

Content-
Hands-on, experience in activity OR

resources, active lessons rich/standards based PA

Content related, academic OR math, reading,
"A couple co-workers had actually went to the class with me, and that helped to support me as well". (Teacher D)

"You are 100 percent in the action and when you're in it, at the end of the day you can recall all that information because you were being active while you did it. That's a huge motivator. I as an adult experienced the activity myself and learned something... So these kids whose minds are still being grown are absolutely going through the same thing and would have the same reactions". (Teacher E)

"I thought it (professional development) was really great just because they gave you the online resources....it helped me to gain more ideas and more resources so that I could implement it more". (Teacher C) language arts
"I feel like some of the activities that I've learned how to incorporate it into like reading and math, spelling and all those things. They really helped me to kind of shape how I teach it". (Teacher A)

"It helped that they gave us ideas on how to do it with academics, like if you're playing you know this review game, and this is how you can move into it... So that was beneficial and just got me thinking more on how to mindfully put physical activity in the lessons rather than just having them take breaks and move around". (Teacher C) 
Integration

Practices

I1

Planning

$\mathrm{I} 2$

Rules, Routines \& Expectations

Progression for Integration

I4

\section{Resources,} materials OR curriculum, lessons

Rules OR routines OR expectations

Steps, planning tasks OR start OR develop

Student choice OR reward
"For me it was just preparation of making sure I had the activities ready to be able to do." (Teacher E)

"So, getting it (classroom PA) in a schedule in the right place and making it meaningful to the students was important for me". (Teacher C)

"I make sure if it is an activity that has multiple steps for rules and routines, that I always put every step on the board so that the students have something to look at and remind them". (Teacher F)

"So, I was always holding my expectations really high and I remind them of it especially if I see somebody kind of getting off task". (Teacher A)

"Start off small and work your way up to more...maybe start with one subject, then move to two and then move on from there". (Teacher A)

"The planning of the tasks to expand can be really really intimidating if you're starting there from the get go it's overwhelming. Starting small with something your kids already know and are familiar with". (Teacher E)

"The student does pick what we do and I have really structured it as a reward for them, which keeps them focused because they want to do it". (Teacher B)

"I use classroom physical activity as an incentive also, to help them get their work done." (Teacher A) 
Student

Reactions

S1

Student
Enjoyment

\section{Enjoy, fun OR} students like

\section{Student}

Engagement
On Task OR listening OR engaged growing

$\begin{array}{ll}\text { Student Learning } & \begin{array}{l}\text { Learning OR } \\ \text { growing }\end{array}\end{array}$

"The kids really are what has had the most impact on me. I mean the kids enjoy it as they're learning and I'm like all for it. If we can bounce around the classroom and still learn then let's do it".(Teacher D)

"Using movement in the classroom becomes something that they understand because it's playful and it's a game and it's fun... and so it's not a dreaded task anymore...it's something that they can achieve". (Teacher E)

"They (students) kind of stay on task for me better because I'm letting them have that little bit of time to get up and get moving." (Teacher A)

"We also see the kids who used to struggle with those transitions being more successful because when you set the expectation for a kid to stand up straight and quiet in a line, and you change that expectation too, we want you to follow in a line marching down the hallway, that becomes something that they understand ...". (Teacher E)

"I think that the lower learning level students have shown me that they are growing because they're getting it more, they're getting the concept better because they're being active, and their brain is stimulated constantly to where they're able to understand more". (Teacher A)

"We see a better recognition for letter $\mathrm{M}$ if we get to move our bodies and arms into a letter $M$ shape, or sit in the letter $M$ shape, or wiggle like the letter M. So kids are able to recall that information a lot faster because it's fun and it's not just rote memorization". (Teacher E) 
Teacher Beliefs

\& Attitudes

$\mathrm{T} 1$
Positive

Belief/Attitude of Classroom PA

The Active

Classroom

Continued

Engagement
Positive OR

belief, attitude

Moving classroom OR Chaos

Want OR continue
"You have to want to implement it and help your students to actually make it work". (Teacher A)

"When you have those moments where you're reminded of the good that can come from classroom physical activity...this is why we're doing it...then you get back on track". (Teacher E)

"You don't want 20 kids jumping around the classroom bouncing off the wall. I was thinking I need to keep this under control." (Teacher D)

"It is ok for students to get a little louder than they normally would. You have to be able to accept the noise level". (Teacher F)

"I want to do it knowing that it's going to help. It makes me feel better and it makes them feel better". (Teacher A)

"I find that I personally am more physically active when I have my students do more physically active things, which just helps my energy level overall as well. I look forward to the lessons more so that helps overall especially this time of year". (Teacher B) 
Table 5

Recommendations for Professional Development Design

\begin{tabular}{|c|c|}
\hline Recommendation & Summary \\
\hline $\begin{array}{l}\text { Informing Professional } \\
\text { Development Design }\end{array}$ & $\begin{array}{l}\text { Collect teacher perceptions and perceived support prior to professional } \\
\text { development attendance to inform framework. }\end{array}$ \\
\hline & $\begin{array}{l}\text { - Face-to-face learning lasting five+ hours, and continued online support } \\
\text { - Less time spent in lecture, and more time spent in hands-on experiences } \\
\text { - Experiences in PA breaks and content-rich/standards based PA }\end{array}$ \\
\hline Providing Resources & $\begin{array}{l}\text { - } \text { Clear outline of purpose } \\
\text { - Type of classroom PA } \\
\text { - Steps for implementation } \\
\text { - Additional lesson materials needed for instruction }\end{array}$ \\
\hline Hands-On Experience & $\begin{array}{l}\text { - Sample lessons from experts } \\
\text { - Teacher experience in implementation with peers } \\
\text { - Teacher experience in implementation with students with feedback from } \\
\text { expert }\end{array}$ \\
\hline $\begin{array}{l}\text { Meaningful Progression for } \\
\text { Implementation }\end{array}$ & $\begin{array}{l}\text { - Planning and preparation } \\
\text { - Start small in implementation using classroom PA breaks } \\
\text { - Increase implementation when teacher and student comfort is developed } \\
\text { - Use content-rich/standards based PA once management is established }\end{array}$ \\
\hline Effective Management & $\begin{array}{l}\text { - Rules, routines, and expectations } \\
\text { - Teaching expectations prior to implementation } \\
\text { - Upholding expectations during classroom PA }\end{array}$ \\
\hline
\end{tabular}




\section{Appendices}

\section{Appendix A - Questionnaire}

Thank you for your willingness to participate in this study on the use of physical activity in the academic classroom. Your completion and submission of this questionnaire implies that you agree to participate in this study. This questionnaire should take ten to fifteen minutes to complete and consists of three sections including; (1) participant information, (2) classroom physical activity implementation, and (3) impacts on classroom PA implementation.

At the bottom of each page, please use the "next" button to move to the next page. If you choose to leave the questionnaire before completion or submission, your responses will not be saved. All questions should be completed to be considered for further participation in the next phase of this study.

Please review the following definitions prior to completion of the recruitment questionnaire.

- Movement in the Classroom/Classroom Physical Activity- Physical activity opportunities that occur in the classroom environment, offered in two formats including physical activity breaks and content-rich physical activity.

- Physical Activity Breaks- Short active periods in the classroom setting that provide students the opportunity to participate in physical activity and take a break from academic content learning.

- Content-rich Physical Activity- Active lessons in the academic classroom that teach core concepts through the use of movement and provide increased opportunity for students to participate in physical activity.

\section{Section 1: Participant Information}

1. Grade Level(s) Taught: *PreK-2*3-5, *6-8

2. Number of Years Teaching: *0-4*5-9*10-14*15-19*20-24*25 or more

3. WV County Currently Employed:

4. Email for further contact:

Section 2: Classroom Physical Activity Implementation

5. For how many years have you been implementing movement in the classroom?

a 0 years, b. 1 year, c. 2 years, d. 3 years, e. 4 years, f. 5 years, g. more than 5 years

\section{On average, how many days per week do you implement classroom physical activity?}

○ a. 0-1 days a week, b. 2-3 days a week, c. 4-5 days a week 
7. On average, how many times per day do you implement classroom physical activity?

- a. 0-1 times a day, b. 2-3 times a day, c. 4-5 times a day, d. more than five times a day

8. What type of classroom physical activity do you use? (mark all that apply)

$\circ$ a. Physical activity breaks, b. Content-rich physical activity breaks, c. other

9. How often do you use physical activity breaks in the classroom?

○ a. 0-1 days a week, b. 2-3 days a week, c. 4-5 days a week

10. How often do you use content-rich physical activity in the classroom?

○ a. 0-1 days a week, b. 2-3 days a week, c. 4-5 days a week

11. During the use of classroom physical activity, how many of your students are actively participating?

- a. none of the students, b. less than half the students, c. half the students, $d$. more than half the students, e. all of the students

Section Three: Impacts on Classroom PA Implementation

Please answer the questions below on a scale of "strongly disagree" to "strongly agree" about things that have influenced your use of classroom physical activity.

12. My beliefs of physical activity prior to professional development has influenced my use of movement in the classroom?

$\circ \quad$ a. strongly disagree, b. disagree, c. neutral, d. agree, e. strongly agree

13. My specific school environment (e.g. resources, administration, school context, etc.) has influenced my use of classroom physical activity?

$\circ$ a. strongly disagree, b. disagree, c. neutral, d. agree, e. strongly agree

14. Professional development opportunities have influenced my use of movement in the classroom?

$\circ$ a. strongly disagree, b. disagree, c. neutral, d. agree, e. strongly agree

15. Students' reactions to participation have influenced my use of classroom physical activity?

$\circ$ a. strongly disagree, b. disagree, c. neutral, d. agree, e. strongly agree

16. My delivery of classroom physical activity has changed as a result of what I have experienced in practice?

$\circ$ a. strongly disagree, b. disagree, c. neutral, d. agree, e. strongly agree

17. My beliefs about classroom physical activity have changed as a result of what I have experienced when using movement in the academic environment?

- a. strongly disagree, b. disagree, c. neutral, d. agree, e. strongly agree 
Your answers have been submitted. Your willingness to participate in this study is greatly appreciated. You will be notified via email if selected to participate in future data collection. Thank you for your time and participation.

Sincerely,

Annie Machamer, M.S.

Andreea Taliaferro, Ph.D. 


\title{
Appendix B - Semi-Structured Interview Guide
}

\author{
Semi-Structured Interview Guide \\ Physical Activity in the Academic Classroom: From the Teachers Perspective
}

\begin{abstract}
A Semi-Structured Interview
Thank you so much for taking the time to participate in this interview as a part of your participation in the research study focused on teacher use of movement in the classroom. My name is Annie Machamer, and I am a Doctoral student in the College of Physical Activity and Sports Sciences at West Virginia University. This interview is being conducted to examine the experience that PK-8 educators have when implementing physical activity into the academic classroom. By participating in this research, you will help capture and understand experiences that occur and how they can be improved. The study has been reviewed and acknowledged by the Institutional Review Board at West Virginia University. Your participation in this research is entirely voluntary. You may skip any question that you do not wish to answer, and you may discontinue at any time. Your responses will be confidential. This interview will be audiotaped. If at any time you do not wish for your comments to be recorded, the recorder can be disabled. Interview information of all participants will be used for overall evaluation, research, and research publications, and will not identify any of the participants by name. There are no known risks to participation in this study. Do you have any questions before we begin?
\end{abstract}

\section{Participant Information:}

Researcher Prompt: I would like to verify information with you before we begin the interview questions.

Please provide your county and grade level in which you currently teach?

Researcher Prompt: Thank you. The questions that I am going to ask you are divided into three main topics including: (1) your prior beliefs of classroom physical activity and professional development experienced, (2) your experiences in the use of movement in the classroom, and (3) what has helped you the most in your continued delivery.

\section{Section 1: Orientation to Learning}

Researcher Prompt: First, I would like to talk to you about your experience in learning about classroom physical activity. 
1. What were your beliefs about the use of classroom physical activity prior to professional development, and how may these have influenced your continued use?

Prompt: Before attending professional development, what were your thoughts about the use of physical activity in the classroom?

Prompt: How has your personal outlook on the use of classroom physical activity influenced continued use?

2. In what ways did your school environment influence your belief in the ability to integrate movement in the classroom?

Prompt: How has your schools' environmental surroundings and resources influenced your belief in the ability to use classroom physical activity?

Prompt: How have individuals in your school setting impacted your belief in the ability to use movement in the classroom?

3. In the professional development you have experienced, what did you do or learn that has most contributed to your continued use of classroom physical activity?

Prompt: What experiences in professional development have positively contributed to your use of classroom physical activity?

Prompt: Did your experiences in professional development lead to any changes in your belief of the ability to use movement in the classroom?

4. Considering your prior beliefs, school environment, and professional development experienced, what most influenced your delivery of movement in the classroom?

Prompt: Did your prior beliefs, school environment, or professional development have the most impact on you desire to use physical activity in the classroom? 
Prompt: Has more than one of these had a significant impact on your use of classroom physical activity? How?

\section{Section 2: Learning Change}

Researcher Prompt: Now that I understand your background and experience in learning about classroom physical activity, I would like to talk to you about your personal experience in the use of physical activity in the classroom.

5. When you first started to integrate physical activity in the classroom, what were your initial thoughts?

Prompt: After you first started to use classroom physical activity, did you have any negative feelings regarding continuing use?

Prompt: What were your most positive feelings after you first started to use physical activity in the classroom?

6. How do you fit classroom physical activity into your daily schedule?

Prompt: Do you use more physical activity breaks or content-rich physical activity in implementation?

Prompt: Why have you chosen to integrate classroom physical activity in this way?

7. What did you have to change or do differently in your daily teaching practice to integrate classroom physical activity?

Prompt: How did you change your daily teaching to integrate classroom physical activity?

Prompt: What changes in your practices helped you the most to use physical activity in the classroom? 
Researcher Prompt: Now that I understand how you implement classroom physical activity, I would like to talk to you about how you see this affecting your students.

8. Have you observed any changes in students as a result of the use of classroom physical activity?

Prompt: Have you seen any changes in student's classroom performance as a result of classroom PA implementation?

Prompt: What about time on task, discipline problems, or student motivation to participate?

9. How have these student changes contributed to your continued use of classroom physical activity?

Prompt: What student actions have positively contributed to you continued use of classroom physical activity?

Prompt: What type of student actions were barriers to your use of classroom physical activity?

Researcher Prompt: Considering all that you have experienced, I would like to talk about your developed beliefs, as a result of your experiences, in the continued use of classroom physical activity?

10. Have your beliefs towards movement in the classroom changed throughout your experience in implementation?

Prompt: Can you provide some examples of how your beliefs have changed and why?

Prompt: What has most influenced changes in your beliefs of using movement in the classroom? Students and/or practice? 


\section{Section 3: Suggestions for Successful Practice}

11. What common practices have most helped you to continue to implement classroom physical activity on a daily basis?

Prompt: What teaching practices have helped you the most in continuing to deliver classroom physical activity daily?

Prompt: What have you done that has best supported your continued use of movement in the classroom?

12. What common practices have most helped you to continue to implement physical activity breaks and/or content-rich physical activity?

Prompt: What teaching practices have helped you the most in continuing to deliver classroom physical activity breaks and academic physical activity?

Prompt: What have you done that has best supported your continued use of content related physical activity and physical activity breaks in the classroom?

13. If you could give yourself words of wisdom when beginning the use of movement in the classroom, what would you say?

Prompt: What would be the most important things you would tell a teacher who is starting to use physical activity in the classroom?

Prompt: What advice would you give to a teacher who is just beginning to integrate movement in the classroom?

14. Is there anything else you would like to share with us to help us better understand what has influenced your continued use of classroom PA?

Thank you once again for your time. I appreciate you sharing your experiences with me on the use of physical activity in your classroom. The recording will now be turned off, and any content following this statement will not be recorded. 


\section{Appendix C - Inductively Developed Codebook}

\begin{tabular}{|c|c|c|}
\hline Main Theme & Sub-Theme & Description \\
\hline $\begin{array}{l}\text { Social and } \\
\text { Environmental } \\
\text { Influences }\end{array}$ & & $\begin{array}{l}\text { School setting and environment influences on the use of physical activity in } \\
\text { classroom }\end{array}$ \\
\hline S1 & Student Need & Teacher views of the students need for movement in the classroom. \\
\hline $\mathrm{S} 2$ & School Context & $\begin{array}{l}\text { Teacher views of the school context influences and impact on the use of } \\
\text { physical activity in the classroom }\end{array}$ \\
\hline S3 & $\begin{array}{l}\text { Support from } \\
\text { Others }\end{array}$ & $\begin{array}{l}\text { Teacher views of support from others (i.e., administration, peers, parents) in } \\
\text { the use of physical activity in the classroom }\end{array}$ \\
\hline$\frac{\text { Professional }}{\text { Development }}$ & & Teacher learning of using classroom physical activity \\
\hline $\mathrm{P} 1$ & $\begin{array}{l}\text { Hands-on Activities } \\
\text { \& Resources }\end{array}$ & $\begin{array}{l}\text { Teacher views of hands-on activities and resources presented in professional } \\
\text { development and the impact on understanding for the implementation of } \\
\text { physical activity in the classroom }\end{array}$ \\
\hline $\mathrm{P} 2$ & $\begin{array}{l}\text { Content- } \\
\text { rich/standards based } \\
\text { PA }\end{array}$ & $\begin{array}{l}\text { Teacher views of professional development related to content-rich/standards } \\
\text { based active lessons and the impact on understanding for implementation of } \\
\text { physical activity in the classroom }\end{array}$ \\
\hline
\end{tabular}

Integration

Practices

I1

$\mathrm{I} 2$
Planning

Rules, Routines \& Expectations
Changes made by the teacher in practice to implement classroom physical activity

Planning strategies that teachers identify as needed for successful integration of classroom physical activity

Teacher practice of routines, rules, and expectations in the integration of classroom physical activity 
I3

I4

Student

Reactions

S1

$\mathrm{S} 2$

S3

Teacher Beliefs

\& Attitudes

$\mathrm{T} 1$

$\mathrm{T} 2$

T3
Progression for

Integration

Incentive Use

\section{Student}

Engagement

Student Learning

Positive

Belief/Attitude of

Classroom PA

The Active

Classroom

Continued

Engagement
Teacher suggestions for integration progression when beginning the use of classroom physical activity

Teacher use of classroom physical activity as incentive to students' participation

Students reactions as a result of teacher use of classroom physical activity

Students demonstrate enjoyment in the classroom related to participation in classroom physical activity

Students demonstrate increased levels of engagement in the classroom related to participation in classroom physical activity

Students demonstrate academic learning development related to participation in classroom physical activity

Teacher identified beliefs/attitudes related to the use of classroom physical activity

Teacher identified positive belief/attitude of classroom physical activity and continued use

Teacher identified perceptions of the moving classroom environment

Teacher developed belief/attitude to want to continue the use of movement in the classroom 


\section{Appendix D - Extended Literature Review}

Physical inactivity has been identified by the World Health Organization (2018) as the fourth leading risk factor for death in the world. Physical activity (PA) levels of youth in the United States have been a focus of concern, considering that a large percentage of individuals are not meeting national recommendations of a daily minimum of 60 minutes of moderate-tovigorous PA (MVPA), including vigorous physical activity (VPA), on at least three days per week (CDC, 2015; National Center for Health Statistics, 2011; U.S. Department of Health \& Human Services [USDHHS], 2008, 2010). The National Health and Nutrition Examination Survey found that only $42 \%$ of children aged 6 to 11 years, and $8 \%$ of youth aged 12 to 15 years, have met guidelines of at least 60 minutes of MVPA per day (Troiano et al., 2008). Considering these percentages, national leading organizations in the area of PA and health have developed plans for increasing student daily PA participation. The USDHHS (2012) has determined that the school environment is the best place to begin addressing student physical inactivity levels because of the high percentage of youth that are enrolled in schools (95\%), as well as this is where a majority of the students day is spent (6-7 hours).

Regional and state-level PA plans and policies have also been developed to further support the increase of PA opportuntities for students (Eyler et al., 2014; WVDE, 2014; USDHHS, 2008). Within the United States, forty-three states adopted plans to increase PA between the years of 2002-2010 (Eyler et al., 2014). In the state of West Virginia, Policy 2510 was initiated by the West Virginia Board of Education (WVBE) in the 2014-2015 school year. This policy required elementary and middle schools to provide at least 30 minutes of daily PA through recess and other opportunities, which must extend beyond course requirements in health 
and PE (WVDE, 2014). While state adopted plans may be in place, the implementation of daily PA is still in the hands of each school's administrators, teachers, and other stakeholders.

The national organization SHAPE America (2013) has encouraged a whole school approach to increase daily PA opportunities titled Comprehensive School Physical Activity Program (CSPAP). The CSPAP approach provides opportunities for students to learn about healthy and active lifestyles within a safe and positive environment, along with encouraging family and community engagement. Multiple components are included in the CSPAP approach such as physical education (PE), PA during school, PA before and after school, family and community engagement, and staff involvement (SHAPE, 2013).

Schools have been most successful in CSPAP implementation when focused on singular component that best fit the school needs and environment of support (Beaulieu et al. 2012; Kulinna et al., 2012). Classroom PA has been identified as the most common method of delivery to increase students' PA opportunities, and has been found to be least impacted by environmental surroundings (Centeio et al. 2014b; Beaulieu et al. 2012; Brusseau et al., 2016; Kulinna et al., 2012). Classroom PA research has found that not only does teacher use increase student PA participation, increases have also been found in students' time on task (TOT) (Carlson et al., 2015; Grieco et al., 2009; Mahar et al., 2006) and academic performance (Erwin et al., 2017; Hollar et al. 2010; Mullender-Wijnsma et al., 2015; Reed et al., 2010). Despite the inclusion of professional development to support teachers in the use of movement in the classroom, barriers in implementation have included time and space constraints, the time needed to focus on academics, and the difficulty of PA integration into an existing curriculum. These findings suggest that infleunces of teacher use of movement in the classroom are also impacted by factors outside of professional development. 
Opfer, Pedder, and Lavicza (2011) have suggested a model of teacher change that includes the impact of teacher orientation to learning and experience in learning change. While research in classroom PA has identified multiple influences within each of these components, there is a lack of research connecting the impact on continued change. Using Opfer et al.'s (2011) model to investigate and connect what teachers have experienced in the use of classroom PA, and the resulting impact on teacher continued change, will help to develop the success of future interventions. Literature to be reviewed to support the development of future research will include (a) CSPAP implementation (b) movement in the classroom, (c) teacher experience in practice, (d) professional development support needed, and (e) Opfer et al.'s (2011) model of teacher learning change.

\section{Comprehensive School Physical Activity Programs}

SHAPE America developed a CSPAP framework in an effort to increase students' daily PA participation through the development of five components (PE, PA during school, PA before and after school, family and community involvement, and staff involvement) (CDC, 2015; Elliot et al., 2013; SHAPE America, 2013). SHAPE (2013) defined CSPAP as:

A systematic approach by which schools use all opportunities for school-based physical activity to develop physically educated students who participate in the nationally recommended 60-plus minutes of physical activity each day and who develop the knowledge, skills, and competence to be physically active for a lifetime (p. 3).

The foundation of a successful CSPAP is quality PE (QPE) (NASPE, 2008; SHAPE, 2013). The National Association for Sport and Physical Education (NASPE) defined QPE as standards-based instruction that includes MVPA for a minimum of fifty percent of the lesson (NASPE, 2003). According to SHAPE America, QPE instruction is delivered by certified 
physical educators and provides developmentally appropriate learning opportunities and quality skill development experiences for all students (SHAPE, 2013). The CDC has recommended that PE classes should meet for at least 150 minutes per week at the elementary school level, and 225 minutes per week at the middle and secondary school level (CDC, 2013; CDC 2015).

Before and after school PA can provide students with opportunities to further develop skills learned in PE and support meeting the recommended 60 minutes of daily PA. Before and after school programs should offer safe social environments that encourage lifelong PA participation (SHAPE America, 2013; 2016). PA opportunities should focus on providing the greatest amount of involvement for all students and include experiences such as intramural activities, interscholastic sports, active transportation, activity clubs, youth sports and traditional daycare/after-school programs (Beighle \& Moore, 2012; NASPE, 2008; SHAPE, 2013). In order for before and after school programs to be provided, Support is often needed from staff and community organizations for before and after school programs to be provided (SHAPE, 2013).

The family and community engagement component of a CSPAP focuses on building connections, encouraging participation, and maintaining support with families and the community to promote opportunities for students to meet daily recommended levels of PA (SHAPE, 2013; Castelli, Centeio, Beighle, Carson, \& Nicksic, 2014; CDC, 2012). It is suggested that the time that children spend at home with their families and in the community shapes their daily routines, behavioral patterns, and lifestyle habits (NASPE, 2008; SHAPE, 2013). Therefore, it is important to reach out to students' families and the community in which they reside to promote, influence, and provide quality PA opportunities.

The staff involvement component of CSPAP is focused on providing opportunities for staff to increase daily PA participation themselves, as well as encourage staff to provide PA 
opportunities for other teachers and students. School employee wellness programs increase staff involvement by offering opportunities including PA fitness programs and education on daily health including nutrition, stress, and mental health (Elliot et al., 2013; SHAPE, 2013). Staff involvement can also include teachers leading and supporting fitness and health opportunities for colleagues and serving as PA role models for students by providing daily movement in the classroom (Elliot et al., 2013).

PA during the school day establishes opportunities outside of PE as part of the daily curriculum (Erwin, Beighle, Carson, \& Castelli, 2013; SHAPE America, 2013). PA opportunities during the school day are offered in both structured and unstructured formats including classroom PA and recess. These daily opportunities encourage high levels of student engagement in PA and provide all children with the ability to reach their full potential as learners (Castelli \& Ward, 2012; SHAPE, 2013). Recess is a scheduled opportunity within the school day for students and teachers to participate in interactive PA movements, allowing for social interaction and play (Erwin et al., 2013). NASPE states that recess offered within elementary schools should (a) provide a minimum of 20 minutes of daily PA, (b) allow for unstructured PA opportunities for students to be creative and make decisions on play, and (c) be supervised by teachers; but should not replace PE (Erwin et al., 2013; NASPE, 2006). This unstructured PA opportunity allows students to relieve stress related to the pressure of classroom academic achievement, and reset their attention to the classroom (Castelli et al., 2014). Researchers have found that recess can contribute up to $44 \%$ of students' daily PA participation (Erwin, Beighle, Morgan, and Noland, 2011).

Classroom PA is a structured opportunity for students to be active and can be provided in two forms including PA breaks and content-rich PA. Classroom PA is typically led by generalist 
teachers and is often implemented within the regular education classroom (Erwin et al., 2013). A quality classroom PA lesson should have students moving for at least 5-10 minutes, after a maximum of 60 minutes of sedentary learning. These PA opportunities can either be added to a teacher's existing lesson or can be developed within the curriculum (Donnelly \& Lambourne, 2011). PA breaks are short active periods to provide students the opportunity to participate in MVPA and take a break from academic content learning. Content-rich PA lessons teach core concepts through the use of movement and provide children with the additional periods of recommended MVPA. These lessons are designed to increase PA without sacrificing academic instruction time (Grieco et al., 2009).

Implementation of CSPAP. Many researchers have investigated the impact of CSPAP on students and have identified important considerations in development. For example, in a collection of school report data by it was found that elementary schools $(n=1055)$ efforts to increase students' daily PA levels used multiple components of CSPAP (Beaulieu et al., 2012). The top overall component used was PE (64.3\%), followed by PA during school (58\%), and before and after school PA (50.7\%). Differences in the socioeconomic and cultural environments were found among PE and before and after school PA. In contrast, no differences were found among socioeconomic and cultural environments in the development of $P A$ during school (Beaulieu et al., 2012). In comparison of findings within CSPAP component development, it can be suggested that environmental surroundings of schools have impacted teacher success in development. PE and before and after school opportunities were dependent upon the availability and accessibility of surrounding resources, and often a limitation for some teachers' development in the lack of support present. Yet the development of PA opportunities during the school day was found not to be affected by school economic surroundings. It can be suggested that $P A$ 
during school may be the most accessible component for development in all school settings, regardless of socioeconomic and environmental influences.

Jones et al. (2014) used a multicomponent needs assessment in PK-12 schools to investigate the feasibility and contextual factors influencing CSPAP development. The assessment included interviews with principals $(n=11)$ and PE teachers $(n=10)$, PA facility audits, observations of PE equipment and curriculum resources available, and professional development needs based on school context. Reoccurring factors that influenced CSPAP development among the schools included (a) the need for PA leaders, (b) PA professional development training for teachers, (c) additional PA instructional materials, (d) time limitations within the school day, and (e) supportive funding and community connections for further development. Interviews with teachers also identified the ease of implementation in the $P A$ during school component through the delivery of classroom PA breaks (Jones et al., 2014). It can be suggested that teachers identify the schools' environment, additional support, and preparation for implementation as impactful factors to CSPAP development. Teachers expressed ease of the delivery of classroom PA has also determined that movement in the academic setting may be an accessbile method, despite any additional needs to support implementation.

Centeio et al. (2014a) used a collective case study design to identify major themes for success in the implementation of a CSPAP. Qualitative measurements were collected and compared among PE teachers $(N=10)$ including interviews, observations, field notes, open-ended survey questions and an online forum with each teacher. One major theme identified for CSPAP success was the availability of resources in the school setting. Additional major themes included preparation and support in implementation, and the influence of teacher belief on practice.

Moore et al. (2018) created and evaluated a how-to guide for successful implementation of 
CSPAP called Be a Champion (BAC). Application of this guide was tested in three elementary schools, with findings indicating that many barriers and facilitators existed in each implementation phase. Evaluation of school setting and influential stakeholders revealed that school resources and space impacted success in implementation, and continued academic focus overpowered daily PA opportunities. Moore et al. (2018) found that classroom teachers implemented more academic PA lessons than brain breaks and found that teachers believed that movement breaks were often a misuse of valuable instructional time. It was also found that before and after school programs and family and community engagement were the hardest to implement due to lack of support, resources, and time to provide these opportunities.

Researchers have also found that educators are more successful in the delivery of some CSPAP components than others, alongside greater impacts found on students. For example, in an investigation of the development of CSPAP in four schools, Kulinna et al. (2012) found differences in components implemented and their impact on student daily PA levels. Over a year-long period of CSPAP development, school day PA and 24-hour step count were measured in third through eighth grade students $(N=616)$ using pedometers worn for five days pre and post-intervention. School-reported PA data and monthly teacher recorded PA break logs were collected to determine what CSPAP components were implemented. Results of paired sample ttests showed that three out of the four schools were successful in increasing students' daily PA participation (school day PA increase of 19\%-44\%, 24-hour step count increase of 7\%-18\%). These three schools took similar actions in the development of CSPAP which included (a) increased PE time throughout the week provided by a certified PE teacher or PA leader, (b) multiple classroom PA breaks per day, (c) structured recess opportunities, (d) before and after school programs accessible to all students, and (e) increased student and family access to PA 
facilities within the community. Additionally, it was found that teachers recorded the highest levels of PA implementation in the form of movement in the academic classroom. This finding has suggested that classroom PA may have had the most impact on student PA participation levels.

Centeio et al. (2014b) found students' daily PA levels significantly increased during CSPAP implementation. Over an 8-month period, fourth-grade students $(n=301)$ from 20 urban elementary schools experienced increases in PE, PA opportunities during the school day (e.g., classroom PA and recess) and after-school programs encouraging the involvement of teachers and parents as leaders and participants. Student accelerometer data collected for three consecutive days both pre and post-intervention led researchers to find a significant increase of 4.5-minutes daily spent in MVPA $(p<.001)$, with students ranging from 7.37 to 11.67 total minutes of MVPA per day. Student MVPA minutes increased the greatest in classroom PA (58.1\%), followed by PE (54.5\%), and recess (31.5\%) (Centeio et al., 2014b). These findings have suggested that CSPAP during the school day in the form of $P E$, classroom $P A$, and recess are significant components in increasing students' PA participation and can be an effective method in helping children reach the daily recommendation. Greatest increase in students' MVPA minutes were seen in the participation of classroom PA and should be considered to be included in teachers' beginning development of increased PA opportunities in the school setting.

Brusseau et al. (2016) found that CSPAP implementation on elementary students from low-income families significantly increased PA levels and daily step count. Students in kindergarten through sixth grade $(n=1390)$ experienced CSPAP components including $P E$ and PA during school (e.g., classroom PA and recess breaks). Throughout a 12-week intervention, teachers received monthly training to support the use of $P A$ during the school day. Researchers 
found in the collection student PA data (e.g., pedometer and accelerometer) that students significantly increased daily step count $\left(M_{d i f f}=603.1, p<.001, d \approx 0.39\right)$ and minutes spent in MVPA ( $M_{\text {diff }}=4.9$ minutes, $p<.001, d \approx 0.39$ ) at the end of the CSPAP intervention (Brusseau et al., 2016). Fu et al. (2014) found through student perception that increased levels of enjoyment occurred when movement in the classroom was experienced. Students in third through sixth grade $(n=758)$ were provided student-centered classroom PA lessons and allowed for student choice in participation. Following the intervention, students completed the Physical Activity Enjoyment Scales (PACES), composed of eleven questions using a five-point Likert scale (1=I dislike it, $5=\mathrm{I}$ enjoy it). Researchers found greater enjoyment scores of students after classroom PA implementation $\left(M_{\text {diff }}=7 \%, p<.001\right)$, and post hoc analysis data exposed that greater enjoyment levels occurred in older students than third grade students (Fu et al., 2014). Teacher use of classroom PA had a positive impact on students' PA participation and activity levels, and the inclusion of student choice led to increased levels of enjoyment. It can also be suggested that older students may benefit from student-centered PA, whereas younger students respond better to more structured PA opportunities.

Investigations into factors of infleunce on teachers' CSPAP implementation have identified the issue of resources and surroundings as a significant impact in development. Research has found that CSPAP components including $P E$, before and after school PA, and family community engagement are difficult to develop in all school environments, related to the limitation of support and resourcs needed. Yet $P A$ during school has been found to be effected very little by these limitations, and it can be suggested that this may be the best component for teachers to begin with in the development of a CSPAP (Beaulieu et al., 2012; Moore et al., 2018). Findings of PA during school have found that this component is most often delivered in 
the form of movement in the classroom, which has also significantly increased students' PA levels (Brusseau et al., 2016; Centeio et al., 2014b; Kulinna et al., 2012). Understanding that classroom PA may be the most common and accessible compenent with the greatest impact on student PA participation, further research will be reviewed to better understand teacher practice of movement in the classroom, the impact on students, and methods to support in implementation.

\section{Movement in the Classroom}

Classroom physical activity resources. Multiple classroom PA resources have been developed to support teacher implementation of movement in the academic environment. Some of these include resources such as Energizers (Mahar et al., 2004), TAKE 10! (Kibbe et al., 2011), and Active Academics ${ }^{\circledR}$ (eLearning for Kids Inc., 2005-2013). Research on these resources will be discussed below, along with the impact on students' and teachers' experience in practice.

The classroom PA resource, called Energizers, has provided simple classroom-based opportunities for students in grades kindergarten through fifth grade and consist of short and quick PA implementation lasting around 10 minutes. Energizers are typically led by the classroom teacher, within the normal teaching environment, and are focused on integrating PA breaks and academic content through movement (Mahar et al., 2004). Health and education experts who attended an obesity-focused conference developed the resource called TAKE 10 ! to support teacher implementation of PA in the academic classroom. TAKE 10 ! is a web-based classroom PA resource that has provided a series of PA opportunities lasting for ten minutes. This resource was designed to increase structured PA minutes within the elementary classroom, 
with many PA lessons aligned to academic content to avoid sacrificing academic learning time. (Kibbe et al., 2011).

Active Academics ${ }^{\circledR}$ is another active classroom resource that has been created to provide teachers practical PA ideas that can be used in the academic environment. This continually growing online resource has provided activities focused on getting students moving through both PA movement breaks and content-rich active lessons. Lessons are aligned with both common core and national standards and are organized by grade and content. Active Academics ${ }^{\circledR}$ activities last anywhere between 5-20 minutes. Additional lessons are provided for recess and big play space PA opportunities. Teachers can submit individual lesson ideas to be reviewed and possibly posted for other teachers to access on the Active Academics ${ }^{\circledR}$ website (eLearning for Kids Inc., 2005-2013). In the comparison of these classroom PA resources, similarities in support of teacher use can be found. For example, each of these resources have provided teachers with a guide to implementation of classroom PA in the form of both PA breaks and academic PA. PA lessons are also short in time delivery to aid in the ease of implementation in the daily classroom environment (eLearning for Kids Inc., 2005-2013; Kibbe et al., 2011; Mahar et al., 2004). In an effort to understand the effectiveness of these resources, researchers have investigated the impact on students in the academic classroom and teacher experience in practice (Kibbe et al., 2011; Mahar et al., 2004). While Active Academics ${ }^{\circledR}$ is similar to other classroom PA resources, a limitation of this resource is that little research has been published on its use to date.

The impact of classroom physical activity. Many researchers have investigated the impact of classroom PA on students. Common themes arise among each of these studies including increases in students' PA participation, time on task in the classroom, and academic 
performance. For example, Stewart et al. (2004) found that students across multiple grade levels experienced MVPA when the participated in the classroom PA resource. Prior to implementation, teachers were provided with a two-hour training session. Elementary students $(n=71)$ within three classrooms in grades one, three, and five were evaluated over a five-day period, with five students wearing accelerometers while the remaining students wore pedometers. Students across each grade levels experienced similar levels of PA, all within the MVPA range $(p>0.05)$. Students across each grade level experienced similar daily PA step count, with third grade students at the highest levels third $(659-1,376)$, followed by students in fifth (1,002-1,041) and first grade (644-931) (Stewart et al., 2004). It is found that classroom PA opportunities in the form of TAKE 10 ! have supported students in participation of MVPA, and similarities of student PA participation suggest that these lessons could be transferred across multiple grade levels. Teacher recorded logs of TAKE 10! implementation found that frequency of use occurred on average eight to nine times throughout a week, suggesting that teachers delivered one or more classroom PA lessons daily. While findings of this study are significant in support of the use of classroom PA, a limitation occurred in the lack of baseline collection of both teachers' recorded PA and students' PA levels. This information could have determined if TAKE 10! had a significant impact on increased student PA participation and teacher reported use.

Erwin et al. (2011) found that teacher-directed classroom PA had a significant effect on students' daily PA levels. Elementary classroom teachers $(n=9)$ were provided with multiple forms of classroom PA resources (e.g., activity cards and web-based resources), were trained in the use of these developed resources and best practices for use and were encouraged to implement one PA break per day. Elementary students $(n=106)$ wore pedometers for four 
consecutive days during baseline, follow-up, and post follow-up data collection. Students in active classrooms had 33\% more daily steps at follow-up and post follow-up, with no significant differences seen between boys and girls (Erwin et al., 2011). These findings have supported that classroom PA breaks positively impacted students' daily PA participation. No significant difference found between genders has determined that guided classroom PA can reach all students and provided equal opportunities to increase students' daily PA participation. While student PA level were found to have increased as a result of teacher delivery of classroom PA, it was found that only about half of the teachers $(n=5)$ met the daily requirement of one PA break, often recording more than one PA break per day (Erwin et al., 2011). While this study did not identify why almost half the teachers were unable to implementation daily classroom PA, a developed understanding of teacher issues in practice could help future efforts of support in the use of movement in the classroom.

Magnusson et al. (2011) found that continued support in teacher use of classroom PA past a one-year intervention is needed for increases in student levels of PA to be sustained. Second grade students $(n=262)$ from six elementary schools were randomly assigned to a control group with regular daily PE (3 schools), or an intervention group with daily PE and additional PA opportunities in the classroom ( 3 schools). Accelerometer data of students who experienced classroom PA revealed significantly higher activity levels of PA in the first year ( $\mathrm{p}>.0001)$ than students who only experienced daily PE. At the end of the second year, no significant difference was found between the groups in PA volume $(p=.10)$ or intensity $(p=.71)$. Teacher recorded log data found an alignment to student PA participation, discovering an increase in implementation in the first year, with a drop off in the second year (Magnusson et al., 2011). The large increase and sudden drop off in teacher recorded classroom PA and the impact on student PA levels 
suggest the importance of continued support, specifically in the second year of an intervention (Magnusson et al., 2011). While these findings determine the need for continued support for teachers to sustain the use of movement in the classroom, further investigation behind teachers' decrease in delivery could develop a better understanding of specific factor of influence to continued motivation of implementation.

Bershwinger and Brusseau (2013) found that teacher and student involvement in the development of classroom PA led to increased student daily PA participation and time spent in MVPA. These developed lessons were delivered by the teachers on a daily basis, with PA delivered in bouts of five to fifteen minutes. Fourth-grade students $(n=18)$ who participated in the developed classroom PA lessons significantly increased steps per day $(5651 \pm 627, p<.01)$ and minutes spent in MVPA/per day $(22.3 \pm 3.5, p<.01)$. These findings not only support the use of movement in the classroom to increase student PA levels but have also identified the value behind student and teacher involvement in choice and development of classroom PA to be experienced (Bershwinger \& Brusseau, 2013).

In an 8-week investigation of the TAKE 10! resource, Goh et al. (2014a) also found a significant impact of classroom PA on elementary students' participation in MVPA and VPA. Before implementation, classroom teachers $(n=9)$ attended an hour-long professional development that included a hands-on training session with sample PA lessons in academic content. Follow-up professional development support was provided where teachers consulted with researchers and addressed questions or concerns in the use of PA in the academic classroom. Teachers were provided with the option of choice in PA that fit best into their curriculum and were asked to use one to three activities per day (Goh et al., 2014a). Third, fourth, and fifth-grade students $(N=210)$ participated in these classroom PA opportunities, with 
some students wearing accelerometers $(n=64)$ and others wearing pedometers. Student time spent in PA from baseline $(18.6 \pm 4.4$ minutes $)$ to the end of the intervention $(18.7 \pm 4.1$ minutes $)$ had no significant increases. Students' minutes spent in MVPA and VPA levels significantly increased from baseline (MVPA $33.4 \pm 8.8$, VPA $14.8 \pm 5.5$ ) to the end of the intervention (MVPA $35.4 \pm 7.6$, VPA $16.7 \pm 5.0$ ) (Goh et al., 2014a). Student increased levels of MVPA and VPA, yet not in PA time, can determine that while students in this study had previously participated in classroom PA, teacher use of TAKE 10! led to higher levels of student PA participation. While findings have supported the use of the develop classroom PA resources, collection of previous teacher experience and use of classroom PA may have identified the reason behind the absence of increases in students' time spent in PA opportunities.

In addition to findings of classroom PA and the impact on student PA, research has also identified an impact on student TOT and academic performance. For example, a study of the classroom PA resource Energizers found increased student PA levels and time on task (TOT) (Mahar et al., 2006). TOT is the ability of a child to make an effort in learning and pay attention to material presented (Bartholomew \& Jowers, 2011; Donnelly \& Lambourne, 2011). Before the use of Energizers in the academic classroom, teachers received training in best practices of the use of movement in the classroom setting. During a 12 week intervention period, teachers were required to include at least one activity per day. Students in kindergarten through fourth grade $(n=135)$ received Energizers, with pedometers worn for one week per grade level throughout the intervention to measure student PA participation during the school day. Students who experience Energizers had significantly more steps than students who did not participate in classroom PA (782 more steps, $p<0.05)$. TOT of students in third $(n=37)$ and fourth-grade $(n=25)$ was observed directly before and after teachers' delivery of Energizers. Significant increases of student focus 
were found when classroom PA was experienced $(8 \%, p<0.017)$ (Mahar et al., 2006). The observation of student increased TOT as a result of Energizers support that classroom PA can increase student focus in the academic setting, and therefore could impact academic performance.

Grieco et al. (2009) also found that classroom PA had a positive impact on elementary students $(N=97)$ TOT. In this study, teachers were trained prior to implementation of classroom PA receiving additional resources for support and were asked to use at least one PA opportunity in the classroom per day. Direct observations of student behavior were collected for fifteen minutes both pre- and post- lesson delivery, in both the classroom that experienced movement and the control classroom. TOT of students that experience classroom PA had no change from pre to post observation; however, a decrease in TOT was observed for students who did not participate in movement in the classroom (Grieco et al., 2009). It can be suggested from these findings that students' participation in classroom PA had a positive impact on TOT following an active lesson.

Carlson et al. (2015) also found positive association among classroom PA breaks, student PA levels, and students' TOT. During a year-long classroom PA intervention, elementary students $(N=1322)$ accelerometer data and teacher $(N=397)$ reported data of classroom PA and observed student behavior were collected. A positive association was found between student time spent in MVPA and minutes of classroom PA use reported by teachers $(\beta s=.07-.14 ; p=$ .012-.016). A negative association was found between students' MVPA participation and offtask behavior $(\beta=-.17 ; p=.042)$. The positive association of student time spent in MVPA and teacher implementation suggest that student participation in MVPA opportunities is dependent upon the frequency in which teachers' use movement in the classroom. The negative association 
of student MVPA participation and off-task behavior suggest that classroom PA can have a positive impact on students' focus in the academic classroom. Carlson et al. (2015) also found a negative association between teacher implementation and student lack of effort $(\beta=-.17 ; p=$ .042). This finding has suggested that student lack of effort or desire to participate in classroom PA may have discouraged teacher implementation.

Other researchers have also identified the positive impact that PA has on students' academic performance. For example, Hillman et al. (2009) found that small bouts of PA had significant effects in some areas of students' academic performance. Students $(n=20$, age $9.5 \pm$ 0.5 years) experienced either resting sessions or twenty minutes of treadmill walking, immediately followed by cognitive function assessments and standardized academic achievement tests. Comparison across students in the resting and walking sessions found that participation in PA before testing significantly increased reading comprehension $(p=0.016)$ and student response accuracy $(p<0.05)$. No significant increases were found on student math and spelling performance $(p>0.39)$, or task performance $(p=0.24)$ (Hillman et al., 2009). These findings support increased student performance in reading occurred when PA was experienced prior to academic performance. While these findings have identified significant impact of PA on student academic performance, PA opportunities were not provided within the classroom setting. It would be interesting to see if findings were similar when the PA intervention was delivered in a classroom environment.

Ménard and Ellemberg's (2010) study found that different types of PA had differing effects on students' cognitive functions. Students $(N=54)$ in three sixth-grade classes were randomly assigned to a neuromotor (e.g., balance, coordination, gait, agility) training $(n=20)$, aerobic exercise training $(n=19)$, or a control group $(n=15)$. During a ten-week intervention, 
students experienced thirty minutes of daily PA, specific to each training group, and completed pre and post-cognitive test of verbal fluency and verb generation. Students who participated in neuromotor PA experienced significant increases in verbal fluency $(p<0.05)$ and verb generation $(p=0.068)$. Students who participated in PA in the form of aerobic exercise only experienced significant increases in verbal fluency ( $p=0.057$ ) (Ménard \& Ellemberg, 2010). These findings have supported that the use of both neuromotor and aerobic training can be used to increase student cognitive performance, with student particiation neuromotor PA indentified as the most significant method of delivery in the impact on all areas of students' cognitive performance. While the delivery of PA opportunties were not within a classroom setting, these results support the use of both neuromotor and aerobic classroom PA opportunities to increase students academic performance. It would also be interesting to further observe the impact of both types of PA delivered together on student cognitive performance.

Phillips et al. (2015) found that brief bouts of VPA had significant effects on standardized math test performance in eighth grade students $(N=72)$. Some students $(n=36)$ participated in twenty-minute VPA sessions focused on aerobic circuit training, while other students were sedentary. Standardized math tests were completed at lapses of 30 and 45 minutes post-intervention in both groups of students. Students' mean math scores increased when tests were completed 30 minutes after VPA $(M=5.75, S D=2.38)$ and 45-minute time lapse $(M=4.3$, $S D=1.88$ ), yet only significant increases were found when tests were complete 30 minutes after VPA $(p<.001)$. Sedentary students' math scores were lower than students that experienced VPA, with no significant increases found in both times lapse test deliveries (30 min, $M=4.21$ and 45 min, $M=4.04$ ) (Phillips et al., 2015). Results of this study lead to the understanding that students who are active prior to academic testing achieve at a higher level than sedentary students, and 
more specifically if given the academic test 30 minutes post participation. While PA opportunities were not delivered in the academic classroom, these findings support the implementation of movement in the classroom and the positive impact on student academic performance.

Many other researchers have identified similar impacts of PA on student performance but have used the implementation of PA in the form of movement in the academic classroom. For example, Reed et al. (2010) found that classroom PA had significant impacts on student math and reading performance, as well as areas of core content testing. Teachers $(N=6)$ received professional development that included hands-on training before and throughout integration, with half ( $n=3$ ) required to include thirty minutes of PA a day, for three days a week, during a three-month period. Classroom PA included multiple fundamental motor skills (e.g., running, hopping, walking) within core academic content such as language arts, math, and socials studies. Third-grade students $(n=155)$ in who participate in classroom PA scored significantly higher in math and reading fluid intelligence $(M=38.61, p=.045)$ than students in control classrooms $(M=36.66)$. While increases were found in math and language arts academic achievement tests, students only scored significantly higher on social studies $(82 \%>60.9 \%, \mathrm{p}=.004)$ (Reed et al., 2010). Results of this study support that the use of content-rich classroom PA can impact students' understanding of math and reading academic concepts. While these findings are significant in the encouragement of teacher use of classroom PA, the absence of teacher frequency and type of classroom PA related content used lead to a lack of understanding of why students experience increases social studies and not math and language arts. This further investigation may explain the relationship of significant increases found as a result of teacher use of content-rich classroom PA opportunities. 
Hollar et al. (2010) found that TAKE 10! classroom PA resources significantly increased student's academic achievement in math. Teachers were provided with the TAKE 10! resource and were asked to implement at least one PA lesson per day. Elementary students $(N=1173)$ across multiple classrooms either participated in classroom PA opportunities $(n=974)$ or were assigned to a control classroom $(n=199)$. No significant differences were found in math and reading scores between groups at baseline $(p=.46$ and $p=.68)$. At the conclusion of one year of TAKE 10! integration, students who participate in classroom PA scored significantly higher in math $(p<.001)$, and non-significantly higher reading $(p=.08)$ (Hollar et al., 2010). Student scores support that participation of movement in the classroom can increase students' math and reading scores but is most significant in the impact on math performance. While these findings are significant support in teacher use of classroom PA, the further investigation of types of TAKE 10 ! lessons delivered could help to understand why only increases in students' math score were found.

Mullender-Wijnsma et al. (2015) found that students who experienced classroom PA spent significant time in MVPA, were on task the majority of the lesson, and often scored significantly higher in academic achievement tests. Students in the second and third grade $(N=288)$ were either in a classroom with PA or a control classroom, where active classrooms experienced teacher-led PA in math and language arts on a daily basis over a one-year period. During an active lesson, $64 \%$ of students' time in the lesson was spent in MVPA (about 16 minutes of a 25-minute lesson), and second grade students experienced significantly more time in MVPA than third grade students $(t=2.18, p<.05)$. Classroom observations of students' TOT revealed that students spent above $70 \%$ of the time demonstrated in on-task behaviors. Students were on-task related to the lesson content for $72 \%$ of the time and were on task related to PA 
movements $73 \%$ of the time. Third grade students who experience classroom PA scored significantly higher in both math $(F[1,99]=11.72, p<.05)$ and reading $(F[1,98]=6.97, p<.05)$. Second grade students who experience classroom PA scored significantly lower in math $(F[1,109]=12.40, p<.05)$, and no differences found with the control group in reading scores $(F[1,109]=0.72, p=.40)$ (Mullender-Wijnsma et al., 2015). It can be identified from the results of this study that content related PA in the classroom is effective in keeping students at MVPA levels for more than $50 \%$ of the lesson and can keep students at high levels of on-task behavior in the academic environment. While younger students may spend more time in MVPA during active content lessons, it is not beneficial to the impact on academic achievement. Content related PA lessons can be recommended to be beneficial for increasing academic content for third grade students and possibly older students.

Erwin et al. (2017) found that third grade students' $(n=15)$ academic performance was significantly influenced by movement in the classroom. Before implementation, teachers completed two graduate-level courses focused on PA and youth and attended a one-day training. This professional development training focused on the importance of PA, best methods for implementation in the academic classroom, and provided teachers with additional resources to support integration into their existing curriculum. Academic performance of students was measured during a 20-week period of teacher-led classroom PA related to math and reading content, with active lessons lasting around twenty minutes per day. Researchers used a mixeddesign ANOVAs to evaluate data collected from student PA, grades, math and reading fluency, and academic achievement test scores. Students who participated in classroom PA scored significantly higher in math scores $(M=24.56, S D=2.21)$ than students in the control classroom $(M=13.69, S D=2.45)$ at the end of the intervention $(M$ diff $=10.87, p=.003)$. Students who 
experienced classroom PA also scored significantly higher in reading fluency throughout the entire intervention $(M$ diff $=79.46, p<.01$ for time $1 ; M$ diff $=87.41, p<.01$ for time $2 ; M$ diff $=$ 92.46, $p<.01$ for time 3). These findings continued to support that short content-rich classroom PA has not distracted students from academic focus, but rather increased academic performance.

Research has found that students' daily participation in PA, specifically in the academic classroom, can have a significant impact on student PA levels, TOT, and academic performance. The use of classroom PA developed resources has increased students' daily PA participation across multiple grade levels in the elementary school setting (Goh et al., 2014a; Stewart et al., 2004), as well as increased students' TOT in the academic classroom (Carlson et al., 2015; Grieco et al., 2009; Mahar et al., 2006). Research has also identified the significant impact of student PA participation on academic performance (Hillman et al., 2009; Ménard \& Ellemberg, 2010; Philips et al., 2015). Some studies in classroom specific PA opportunities have found varied results in the impact on student academic performance (Hollar et al. 2010; Reed et al., 2010; Erwin et al., 2017; Mullender-Wijnsma et al., 2015). Hollar et al.'s (2010) study found a significant impact of classroom PA on multiple age ranges in elementary academic achievement, while other researchers only found academic increases of significance in older elementary students (Mullender-Wijnsma et al., 2015; Erwin et al. 2017; Reed et al., 2010). These varied findings of significance in student academic achievement raise the question of whether these differences are connected to the type of classroom PA content delivered and/or teacher practices of implementation.

Future research should consider the investigation of teacher frequency and type of classroom PA used and the impact on students to better understand how teacher choice in the use of content-rich PA is connected to students' academic performance. The connection between 
teacher daily use of movement in the classroom and changes observed in students could help to better identify aspects that support and hinder implementation. Research has found that teacher support in the use of movement in the classroom has been important to include in the encourage delivery of classroom PA (Erwin et al., 2011; Magnusson et al.,2011). While support has been included in classroom PA interventions, Erwin et al.'s (2011) study found that only about half of the teachers in the intervention were successful during the initial implementation of classroom PA. Magnusson et al. (2011) also found that without continued support in integration, teachers discontinued use. Carlson et al. (2015) further identified that student willingness and interest in participation negatively affected teacher implementation, and most likely caused decreases in teacher desire to continue the practice.

\section{Teacher Experience in Practice}

Research has found that while classroom PA has had a significant impact on students, teachers have often experienced varied levels of success in delivery. While many classroom PA interventions have included the support of professional development, not all teachers have been successful in implementation. Teachers have also found that the use of movement in the classroom is also impacted by other areas of influence outside of professional development support. Considering these findings, further literature will be reviewed on what teachers have experienced in the use of movement in the classroom to better understand support needed to be successful in implementation.

Investigations focused on teacher experience in the use of classroom PA have found many similar barriers and facilitators experienced in the process of delivery and continued use. For example, Cothran et al. (2010) collected K-12 teachers' $(N=23)$ journals and conducted pre and post interviews during a year-long implementation of classroom PA to better understand 
teachers' experience in practice. Before implementation of movement in the classroom, teachers received multiple methods of support in implementation which included: professional development training with modeled lessons and hands-on experience, developed active lesson resources, and a PE mentor to model successful integration as a co-teacher. Results of teacher interviews and journals revealed common facilitators which included teachers' personal interest in PA, pre-conceived positive attitudes towards PA in the academic classroom, the ability of PA to help meet the whole child, and a developed understanding of PA and its influence on academic achievement. Teachers further expressed that pre-developed classroom PA resources provided an outline for implementation, however, a barrier included was that resources were sometimes difficult to integrate within an existing curriculum. Other barriers found included time restrictions and the difficulty of planning for PA within the classroom due to focused academic success (Cothran et al., 2010). Results of this study support the importance of professional development learning and resources to aid teacher use of classroom PA, as well as the need to influence teacher pre-conceived attitudes and beliefs if support of continued change is desired.

Raymond (2013) also identified similar barriers and facilitators in teachers' use of movement in the classroom through the collection of semi-structured interviews with elementary classroom teachers $(n=12)$, PE teachers $(n=6)$, and administrators $(n=6)$, along with survey data from all teachers $(n=163)$ across the six schools. Teacher identified facilitators included; the support of continued professional development training, developed PA lessons in academic content, ease of integration, and support from all school stakeholders. Another facilitator identified was teacher pre-conceived attitude and belief of PA in the academic classroom. Teachers expressed that a positive attitude/belief of classroom PA aided in implementation, while a negative attitude/belief hindered the willingness to make a change in their current 
classroom environment. Other teacher identified barriers included time restraints, lack of accountability from school environment, and lack of support among other teachers in implementation.

Strampel et al. (2014) investigated elementary school teachers' $(n=137)$ experiences in the implementation of 20 minutes of daily PA in the academic classroom. Data collected included a Likert scale survey where teachers ranked pre-determined barriers and solutions, along with two open-ended questions. Many common barriers and facilitators were found among teachers and are discussed below with survey data reported as mean value and open-ended question responses reported as percentage of teachers in agreement. Multiple common facilitators were found and included; lessons with minimal equipment (16\% of teachers) and set up $(M=4.36, S D=0.68)$, or even no equipment $(M=4.35, S D=0.65)$, developed lessons focused on PA within a classroom space $(M=4.26, S D=0.78)$, better infrastructure for PA within the classroom and school $(M=4.09, S D=0.81)$ and a learned knowledge of the importance of PA and the impact on students $(M=3.01, S D=1.07)$. Barriers perceived by teachers in implementation of classroom PA included; time demands within the school day $(M=$ $3.64, S D=1.14)$ and being able to fit all content planned ( $50 \%$ of teachers), lack of administrative support $(M=3.84, S D=0.97)$, the focus on academic achievement and testing $(M$ $=4.05, S D=0.83)$, ease of implementation $(M=2.69, S D=0.94)$ due to lack of supporting resource such as lesson ideas and equipment needed ( $24 \%$ of teachers), limited classroom space $(M=2.37, S D=1.07)$ causing an un-safe environment ( $22 \%$ of teachers), and lack of staff training (10\% teachers) providing an unclear mission for PA implementation within the academic curriculum. 
Goh et al. (2014b) collected semi-structured interview data from elementary classroom teachers $(N=9)$ following an eight-week implementation of TAKE 10 ! in third, fourth, and fifth grade academic classrooms. Five months following the TAKE 10! intervention, teachers completed a follow-up interview and questionnaire to examine sustainability and additional perceptions of daily classroom PA implementation experience. Teacher identified facilitators of implementation included; developed knowledge in the need for PA and the impact on students, the impact of physical and psychological relief for both students and teachers, positive student response, and lesson preparation of daily classroom PA implementation. Teacher identified barriers of implementation included; time and space constraints, negative behaviors of sedentary students, the difficulty of encouraging students to move and think in academic content, and the need for more time to develop content within individual curriculums.

McMullen et al. (2014) collected K-12 classroom teachers' $(n=12)$ perceptions of classroom PA following a year-long intervention through teacher journals and interviews. Before implementation of movement in the classroom, teachers received additional resources such as pedometers and developed classroom PA lessons, along with multiple professional development $(N=10)$ opportunities throughout the year for continued support. Teacher facilitators experiences included; the use of resources that were shorter and academically aligned, using PA breaks as rewards to students, developing a safe classroom with management rules and procedures for active lessons, and a surrounding environment of support including other teachers and resources. Teacher identified barriers in implementation included issues of space and time available, getting students back on task after the activity, and the increased amount of time the lessons took to actually implement in comparison to the predicted time. McMullen et al. (2014) identified that a possible limitation was the collection of data from teachers in one community area, where a 
collection among a diverse number of communities would lead to generalizability. This suggests that future research should consider a diverse population for a more generalized understanding of experience.

Goh et al. (2017) used observations of teachers' $(n=15)$ classroom PA delivery, semistructured interviews, and questionnaires to understand teachers' use of TAKE 10!. Facilitators of classroom PA implementation included; supported training in integration practices, teacher willingness and value of PA, the use of developed TAKE 10 ! resources, and adaptability to the current curriculum. Barriers included; the limitation of time within the school day, small classroom space, student resistance to activity, and teacher inability to teach and use PA. It was also found that teachers who continued the TAKE 10! program in the classroom found success when classroom PA opportunities were scheduled into weekly routines, collaboration among teachers in implementation practice occurred, and students continued to request participation in the activities. Teachers' confidence also increased over time, and hence facilitated continued practice. Goh et al. (2017) determined that the limitation of evaluating teachers within one school district could have influenced results considering the culture of the district including policies, priorities, and norms. It has been suggested that future research related to continued practice should collect teacher participants from varying geographical locations to avoid the bias of one particular area.

Facilitators. Research focused in teacher experience in the use of classroom PA has found that many similar facilitators in implementation have occurred among teachers. These facilitators should be considered in future classroom PA interventions to support continued teacher success in the use of classroom PA. One of the most common facilitator that teachers have found supported the use of movement in the classroom was the inclusion of continued 
professional development support throughout the process of developing PA practices in the academic classroom (Cothran et al., 2010; Goh et al., 2017; Raymond, 2013). Teachers expressed an increased willingness to continue implementation of PA when professional development occurred throughout practice, along with an expert mentor available if needed (Goh et al., 2017). Teachers also found that opportunties of increased knowledge in the impacts of classroom PA on students often led to an increased understanding of why the change to be made was important (Cothran et al., 2010; Raymond, 2013). Teachers found that when professional development opportunties provided pre-developed classroom PA resources, implementation of classroom PA was much easier to begin (Goh et al., 2014b; Raymond, 2013; Strampel et al., 2014). Teachers specified that lessons that were short in length (Goh et al., 2014b; McMullen et al., 2014), involved minimal equipment (Strampel et al., 2014), and were academically aligned to the current curriculum (Cothran et al., 2010; McMullen et al., 2014; Strampel et al., 2014) were the most efficient in support of classroom PA delivery. Another common key facilitator found was the need for support from all stakeholders to enable a supportive infrastructure for daily use of classroom PA (Goh et al., 2017). In addition, teachers found the be more successful in continued practice when PA opportunties were scheduled within the weekly curriculum (Goh et al., 2017).

Barriers. While teachers have found many facilitators in the use of classroom PA, barriers of integration have continued to occur have and often led to discontinued use. One of the most common barriers found among teachers was the issue of time constraints within the school day (Cothran et al., 2010; Goh et al., 2014b; Goh et al., 2017; McMullen et al., 2014; Raymond, 2013; Strampel et al., 2014). While this may be the most common barrier identified, it may be related to another reoccurring barrier of a lack of support from all stakeholders (i.e. state, school, 
administrations, teachers, students) in the implementation of daily movement in the classroom (Cothran et al., 2010; Goh et al., 2017; Raymond, 2013; Strampel et al., 2014). The absence of stakeholder support has also identified other barriers such as the continued focus on academic success, which in turn have infleunced teachers' pre-conveived attitude/belief that classroom PA is not feasable in the individuals' school environment (Cothran et al., 2010; Strampel et al., 2014). The absence of a supportive school community led to teacher difficulty in the implementation of classroom PA, leading to a lack of integration (Goh et al., 2017). Despite efforts of professional development teachers have also identified that a lack of support from experts in the continuted learning through practice is a barrier to continued classroom PA use (Goh et al., 2017; Raymond, 2013; Strampel et al., 2014). While teachers have found that additional resources have facilitated classroom PA delivery, it has also been found that lack of guidance in best methods of alignment to an existing curriculum is a barrier in teacher success of integration (Goh et al., 2017).

Many barriers and facilitators that have contributed to teachers' success in use of classroom PA can be categorized into major themes of support including: (a) professional development learning and practice, (b) experience in a change of practice, and (c) student change observed. These identified themes and related findings can be significant to the development of future intervention efforts and determining what support teachers need to be successful in implementation. It is interesting to have discovered that many teachers have perceived current professional development support as a barrier in implementation, because many of these studies have included methods of support in teacher practice (Cothran et al., 2010; Goh et al., 2014b; McMullen et al., 2014). This suggests that the current structure and delivery of professional 
development may not be meeting all the needs of teachers, and further comparison is needed on effective methods of professional development to support future interventions.

\section{Classroom Physical Activity Professional Development Efforts}

Research has found that professional development thus far have not successfully addressed continued teacher barriers in the use of movement in the classroom, and further review of classroom PA professional development in comparison to determined effective methods of professional development will help to develop future interventions, and in turn encourage continued teacher change. It is suggested in research outside of classroom PA that an increased teacher knowledge and skill in a new idea or practice has led to a change in attitude and practice, which then impacts a change in student learning (Armour \&Yelling, 2007; Guskey, 1986, 2002). If the continued use of movement in the classroom is desired, significant methods of successful professional development, alongside current classroom PA interventions, need to be reviewed to support education in practice and encourage teacher continued use. Classroom PA interventions thus far have focused on three areas for consideration in developed professional development opportunities; (a) content, (b) methods of delivery, and (c) duration of support. These areas of focus will be reviewed below and then compared to determine effective methods of professional development to draw a conclusion on what is needed for teachers to be successful.

Content. When supportive content is provided during professional development opportunities, teachers experienced increased levels of knowledge in the content area and are more supported in a successful change to be made in practice (Desimone, 2009). In the comparison of current professional development content in classroom PA interventions, multiple common themes are found in an effort to support teachers in delivery. The first theme of provided was the inclusion of hands-on experience in the practice of classroom PA 
implementation for teachers. This hands-on experience helped teachers to develop skills for PA integration that included classroom management and appropriate curriculum alignment.

Classroom PA interventions that included hands-on experience for teachers found increased student daily PA levels and academic performance (Erwin et al., 2011; Goh et al., 2014a; Grieco et al., 2009; Mahar et al., 2006; Reed et al., 2010; Stewart et al., 2004). Research of effective professional development methods has also suggested that in addition to hands-on experience, teachers have found to be more successful in the use of classroom PA when provided with individualized feedback from a mentor (Grierson \& Woloshyn, 2013). Considering this finding in comparison to current classroom PA professional development, a limitation is found in that few professional development opportunties have included individualized feedback and a mentor throughout the learning process. The absence of this additional support may explain why teachers have continued to experience barriers related to professional development opportunties provided.

The second most common inclusion of professional development content delivered was additional classroom PA resource provided to support teacher delivery. These additional resources were provided to aid teachers in practice, with the intent of increased ease of classroom PA use. Research has found that when additional resource are provided, student PA participatio (Erwin et al., 2011; Goh et al., 2014a; Stewart et al., 2004) and academic performance increased (Grieco et al., 2009; Mahar et al., 2006; Reed et al., 2010). Research has found that teachers have experienced ease in implementation when additional resources have included specific activity instructions, accompanying equipment, management routines and procedures, and alignment of lessons to academic content and grade level. While additional resources have aided teachers' delivery of classroom PA, a continued barriers identified has been the difficulty to integrate these 
PA opportunities within an existing curriculum (Cothran et al., 2010; McMullen et al., 2014).

McCaughtry et al. (2006) found that while these pre-developed resources aided instruction and were inspirational to daily use, teachers experienced multiple concerns in the use of resources and, therefore led to a lack of confidence in delivery. Bershwinger and Brusseau (2013) found that when teachers were included in resource development, a developed sense of buy-in of use and confidence in implemenation occurred. While developed resources can provide significant structure in the delivery of classroom PA, teachers need to be more involved in the development and choices for delivery to be successful in continued use. Patton et al. (2013) investigation of effective methods for professional development found that teachers $(n=88)$ were successful in a change of practice when provided with teacher-centered strategies that included structure for implementation rather than dictation, experience in the creation and testing of new ideas, and opportunity for feedback in practice (Patton et al., 2013). Future professional development interventions should consider the inclusion of teachers' input in resource development and implementation to sustain teacher use of movement in the classroom.

The third most common theme of content amongst multiple studies was the development of teacher knowledge in the impact of classroom PA. Interventions that have included a focus on the development of teacher understanding of the importance of classroom PA and impacts have found results of increased student PA levels and academic performance (Carlson et al., 2015; Erwin et al., 2011, 2017; Mahar et al., 2006). Increased understanding of the positive impacts of classroom PA on student performance led to teachers' willingness to make a change in daily instructional practice (Erwin et al., 2011). Research has found that when teacher knowledge is not developed, and willingness of implementation is absent, this has resulted in a lack of motivation and discontinued use of classroom PA (Magnusson et al., 2011). Research in 
effective professional development methods have found that focus on alignment to national, state, county, and school-wide policies and standards have also supported teacher buy-in, and in turn supported implementation (Desimone, 2009, 2011). It can be suggested that professional development content may be more successful in impacting teacher continued use if knowledge is developed alongside the importance of meeting policies and standards in education.

Delivery. In addition to content included, research has found that delivery of professional development opportunities has also impacted teacher success in changes made in practice (Desimone, 2009; Egan et al., 2018). Classroom PA interventions have most often included faceto-face delivery of professional development, with some additional online support to allow for consultation with experts (Cothran et al., 2010; Erwin et al., 2011; McMullen et al., 2014). The combination of face-to-face and online professional development opportunities are suggested to provide a supportive environment for teachers to be successful in making a change in daily instructional practice. For example, Delk et al. (2014) found that middle school teachers $(N=831)$ in a three-year intervention revealed the highest use of classroom PA with the support of both face-to-face mentorship and continued online social media support (38.7\% of classroom time, $p<.001)$. Egan et al. (2018) also found that teachers $(N=12)$ who experienced face-to-face training and one-on-one continued consultation with a university expert experienced the most success in the delivery and increased daily use over time $(M=2.2 ; \mathrm{SD}=0.9, p=0.04)$. In contrast, teachers who experienced a one-time face-to-face training experienced decreased implementation over time $(M=-2.5 ; S D=2.8)$. While classroom PA interventions have included suggested the suggested combination of face-to-face and online support, research has continued to find teacher barriers related to lack of support in professional development throughout classroom PA implementation (Cothran et al., 2010; McMullen et al., 2014). 
Desimone $(2009,2011)$ has determined that success in implementation is often a derivative of collective professional development participation among a community of teachers from similar grades, content areas, schools, counties, etc. This type of delivery has encouraged a supported community of practice where all teachers have worked together towards a similar goal. Support from other teachers in the process of learning has increased lasting teacher change in implementation (Birman et al., 2000; Guskey, 2002). It can be suggested that both a community of support and continued interaction with experts in implementation are needed to support teachers' continued use of classroom PA.

Duration. The duration of professional development includes the number of hours and the length of time over which it occurs, and should provide significant opportunity for teacher to be support in change (Desimone, 2009). Many classroom PA interventions have included preimplementation trainings that have spanned in time from forty-five-minute session (Mahar et al., 2006), to a one-hour session (Goh et al., 2014a), to a session at two hours (Stewart et al., 2004). However, single pre-workshop experiences, which tend to be most common in teacher professional development, have provided little support behind continued teacher change (Pianta, 2011). Many classroom PA interventions have included multiple professional development opportunities that have spanned in time and frequency. For example, Erwin et al. (2011) (two sessions at thirty minutes) and Reed et al. (2010) (two sessions at ninety minutes) interventions provided two professional development opportunities shorter in length, and Grieco et al.'s (2009) intervention included longer pre-intervention professional development (one day), with a shorter follow-up review (half day). While time and frequency have differed among classroom PA interventions, each study identified the positive impact of pre and mid classroom PA professional development opportunities, and found that student PA participation and academic performance 
increased (Erwin et al., 2011; Grieco et al., 2009; Reed et al., 2010). McMullen et al. (2014) found that including multiple professional development workshops $(N=10)$ throughout teacher use of classroom PA still led to identified barriers of implementation in the school setting such as time constraints and difficulty of integration within a curriculum. Martin et al. (2008) found that elementary PE teachers $(N=30)$ who attended a day-long, eight-hour workshop, and some teachers $(n=15)$ received two additional day-long workshops and two site visits, groups experienced similar significant increased efficacy levels in relation to components of implementation $(p<0.01)$. While many researchers argue that continued professional development support is more significant in the impact of teacher use, these findings have supported that frequency can be just as important as time. Comparison of professional development duration among classroom PA interventions has suggested that significant content and delivery methods of support may override the importance of duration

Conclusion. Current methods of classroom PA professional development have included multiple areas of influence that effective professional development research has found to significantly impact of teacher change, yet a lack of effective professional development methods is also present. This finding may explain why teachers have continued to identify barriers related to professional development in the use of movement in the classroom. Future classroom PA interventions should consider alignment with professional development methods found to be effective to address educations continued barriers in delivery. While the comparison of effective professional development methods has helped to develop future classroom PA interventions, future researh should also consider investigation of specific professional development components experienced by teachers and the direct impact on continued use (Lander et al., 2017). Understanding specific connections on continued use from the teachers' perspective could 
help to further develop professional development opportunities and support teachers' ability to sustain the use of classroom PA. Teachers have also identified barriers in classroom PA implementation outside of professional development (e.g., supportive environment, change in practice, student reaction and change). Further investigation from the teachers' perspective on the connection of professional development and other significant components as a whole may help to identify how these experiences are connected and further support needed to develop continued teacher change.

\section{Theoretical Framework}

A theoretical framework designed to investigate the process of teacher change will help to understand what teachers have experienced in the development and continued use of movement in the academic classroom. Many models of teacher change have been designed to investigate the connection of what teachers have experienced in the process of change in practice (Richardson and Placier, 2001; Opfer et al., 2011). Multiple models of teacher change have suggested a linear method for investigation and have identified that experiences in change occur in a step by step process (Desimone, 2009; Guskey 1986). Desimone (2009) developed a linear model that determined teacher change occurs following professional development with a change in teacher belief, followed by a change in practice, which then leads to a change in student performance. Guskey $(1986,2002)$ also developed a linear model of a different order, suggesting that following professional development, teachers make a change in practice which then causes a change in students, and this change leads to developed teacher attitudes and beliefs. In contrast to these linear models, other researchers have suggested that elements of teacher change are often reciprocal of each other and continuously occur (Opfer et al., 2011). This would suggest that a linear model of design may not be most effective in understanding influential components of 
teacher change. Opfer et al. (2011) suggested that teacher change is a complex process and is influenced by both an teachers' orientation to learning and learning change. Please refer to Figure 2 for a visual representation of the relationship between teacher orientation to learning and teacher learning change (Opfer et al., 2011).

Figure 2. Teacher Orientation to Learning and the Influence on Teacher Learning Change.

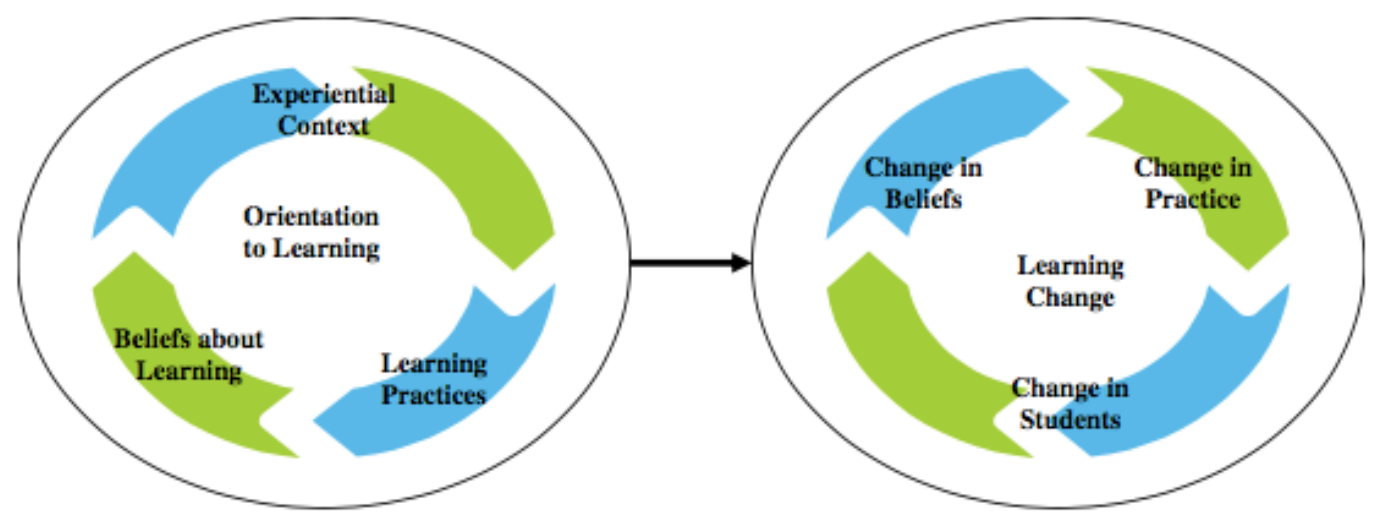

(Opfer et al., 2011, p. 447).

While models may differ, a similar first component of influence is the learning that occurs before and during professional development. Each teacher has their own individual orientation to learning which is impacted by (a) beliefs about learning, (b) the experiential context, and (c) learning practices. Teachers' beliefs about learning refer to preconceived notions of the change to occur. Beliefs about learning are also related to teachers' perceptions of the feasibility of the change to occur within the specific experiential context. Research has found that teacher beliefs are formed based upon experiences of the past and present (Burn, Hagger, Mutton, and Everton, 2003). Learning practices are what teachers have experienced in professional development opportunities. It is suggested that prior to attending professional development, teachers have already formed their own beliefs in practice in relation to their personalized context (e.g., school and content of focus). These pre-developed beliefs, practices, and considerations of context, influence what a teacher wants to learn, and in turn participation 
and engagement in professional development efforts. Researchers have suggested that many professional development efforts have failed due to the lack of consideration of teacher motivation and the process of change (Guskey, 2002; Opfer et al., 2011). Understanding orientation to learning could help to develop significant learning experiences in professional development. Future research should consider teachers' motivation behind learning, prior beliefs of classroom PA, and the context from which teachers will make the change to develop quality professional development learning practices of support in implementation.

Opfer et al.'s (2011) model of teacher change has identified that teachers' orientation to learning is followed by teacher experiences in the process of the change to be made. Areas of experience that impact teacher change include teacher change of practice, change observed in students, and change in beliefs (Opfer et al., 2011). A teachers' orientation to learning is what initially influences a change in learning. A change of practice is when teachers make an adjustment to instruction based upon what was learned in professional development. Changes observed in students refers to how teachers see students reacting to the change made in practice, such as participation, behavior, enjoyment, and other impacts on learning. A change in beliefs occurs when teachers develop new perceptions based upon what has been experienced in the change of practice and change observed in students. Researchers have suggested that new experience are occurring for teachers on a daily basis, and that the process of learning change can be constantly occurring (Opfer et al. (2011).

Model of teacher change findings. Classroom PA research on teacher experience in practice have identified multiple influences within each of these components. For example, research has found that teachers experienced difficulty in finding time and space to implement movement in the classroom, along with issues in the integration of opportunities within an 
existing curriculum (Cothran et al., 2010; Goh et al., 2017; Goh et al., 2014b; McMullen et al., 2014; Raymond, 2013; Strampel et al., 2014). Goh et al.'s (2017) investigation found schedule PA opportunities helped to remind and support teachers in constant implementation. It was also found that student enjoyment in the participation of classroom PA was a facilitator in teacher continued use. While findings of classroom PA investigations to date have provided understanding of what teachers have experienced in a change of practice and student reaction related to the process of making a change, little research has investigated the connections of these experiences on teacher developed attitudes and beliefs to continue use.

Research aligned to Opfer et al.'s (2011) model of teacher change have found that areas of influence in teachers' orientation to learning and learning change have been impacted at different levels of support. Opfer et al. (2011) collected teacher reported surveys $(n=1126)$ to determine the impact of each component on teacher change. Highest levels of influence on belief to make a change $(M=3.38)$ and support in practice $(M=3.32)$ occurred when professional development provided the opportunity to practice the change and reflect on experiences in implementation. Moderate levels of influence were identified on teachers' belief to make a change $(M=2.55)$ and support in practice $(M=2.41)$ when provided with developed knowledge in the professional development content area. Teachers also reported that the use of collaborative learning groups in professional development had the lowest levels of influence on belief to make a change $(M=3.08)$ and support of practice $(M=2.88)$. Teachers also perceived what was learned in professional development opportunities had the most impact on a developed teaching practice $(M=2.85)$ and in turn an influence on student change $(M=2.42)$. Teachers also identified that what was learned in professional development opportunities had the lowest impact on developed attitude and beliefs to continue change. Opfer and Pedder (2011) further found that teachers 
believed the highest level of influence in making a change was impacted by a committed school environment $(M=3.30)$ and supporting surrounding community $(M=3.27)$.

Dole et al. (2016) found in the collection of teacher interviews $(n=36)$ related to experience and the impact on change, teachers identified that experience in a realistic environment and learning from practice supported by experts was most highly rated in helping to develop teacher acceptance of change. Limitations in making a change were most highly reported as related to the issue of support from the school administration. Success in teacher change in practice was most highly related to teachers' ability to accept changes in daily instructional practices. It was also found that changes in practice were most impacted by the issue of time and continued focus on academics in the school setting. Teachers reported that changes in practice were most supported in the inclusion of student development in the activity to be delivered. This inclusion of students in development led to a sense of ownership and increased willingness to participate, which in turn impacted the ability for the teacher to easily make the change in practice.

In review of Opfer et al.'s (2011) model of teacher change and connected findings, it can be suggested that while teachers' experience in orientation to learning has impacted practice, teachers' developed beliefs of continued use are most influenced by what is experienced in practice. A gap exists in the current classroom PA literature in the connection to teacher continued change related to these experiences. Considering findings in teachers' orientation to learning and the process of learning change, future classroom PA investigations should focus on the connections among what teachers have experienced in the learning and practice of classroom PA, and how this has impacted teacher developed attitude and belief to continue change. Opfer et al. (2011) also identified a limitation in research design asking teachers to generally reflect in 
survey data on what was experienced and the impact on change. A developed understanding of teachers' specific experiences and the impact on teacher continued use of classroom PA can help to further focus interventions, and pin point specific support experiences needed to sustain teachers' use of movement in the classroom.

\section{Conclusion}

CSPAP has been used by many schools to provide opportunties for students to increase daily PA opportunites. Teachers' experience in the development of CSPAP components have found classroom PA was one of the most recorded methods to provide increased PA opportunties, and was more accessible that other opportunties infleunced by additional support needed for implementation. While classroom PA opportuntities have signficantly impacted students' PA participation, TOT, and academic performance, teachers have continued to identify barriers in implementation. Review of classroom PA interventions have found that professional development has varied, and has lacked in the support of teacher continued use. While research focused in effective methods of professional development can help to guide future interventions, teachers have also identified barriers in implementation that have occurred outside of professional development related to teachers' learning environment and experieces in practice. These findings support that teachers' use of classroom PA is dependent upon multiple areas of infleunce, and a connection of these experiences is needed to understand how all have impacted teacher change in practice.

A model of teacher change proposed by Opfer et al. (2011) has suggested that multiple areas of infleunce are present within an teachers' orientation to learning and experience in learning change, and are often reciprocal of each other yet have varying levels of impact on teacher change. Comparison of classroom PA investigations and this guiding theoretical model 
of teacher change find that current research has lacked in the ability to make connections between what teachers have experienced and the impact on change. Opfer et al.'s (2011) suggestion of a more specific focus of connection should be consider to identify specific teacher experiences that have had the most impact on continued classroom PA use. This proposed study will investigate and compare experiences of teachers who have been successful in the continued use of classroom PA. The specific impact of connections among each area of infleuence in regards to teachers' orientation to learning and learning change will be investigated to determine what has led to the positive belief to integrate movement in the classroom. Findings of the proposed research study can contribute to the development of significant support in classroom PA integration and a lasting change in teacher practice. 


\section{Appendix E - Extended List of References}

American Psychological Association (APA). (2010). Publication manual of the American Psychological Association. Sixth Edition. Washington: American Psychological Association.

Armour, K. M., \& Yelling, M. (2007). Effective professional development for physical education teachers: The role of informal, collaborative learning. Journal of Teaching in Physical Education, 26(2), 177-200.

Ball, D. L., Camburn, E., Correnti, R., Phelps, G., \& Wallace, R. (1999). New tools for research on instruction and instructional policy: A web-based teacher log. Seattle, WA: Center for the Study of Teaching and Policy.

Bartholomew, J. B., \& Jowers, E. M. (2011). Physically active academic lessons in elementary children. Preventive Medicine, 52, S51-S54. doi:10.1016/j.ypmed.2011.01.017

Beaulieu, L., Butterfield, S. A., Mason, C. A., \& Loovis, E. M. (2012). Physical activity and US public elementary schools: Implications for our profession. The ICHPER-SD Journal of Research in Health, Physical Education, Recreation, Sport \& Dance, 7(1), 12.

Beighle, A., \& Moore, M. (2012). Physical activity before and after school. Journal of Physical Education, Recreation \& Dance, 83(6), 25-28. doi:10.1080/07303084.2012.10598792

Bershwinger, T., \& Brusseau, T. A. (2013). The impact of classroom activity breaks on the school-day physical activity of rural children. International Journal of Exercise Science, 6(2), 6 .

Birman, B. F., Desimone, L., Porter, A. C., \& Garet, M. S. (2000). Designing professional development that works. Educational leadership, 57(8), 28-33. 
Brinkmann, S. \& Kvale, S. (2015). Interviews: Learning the craft of qualitative research. California, US: SAGE.

Brusseau, T. A., Hannon, J., \& Burns, R. (2016). The effect of a comprehensive school physical activity program on physical activity and health-related fitness in children from lowincome families. Journal of Physical Activity \& Health, 13, 888-894. doi:10.1123/jpah.2016-0028

Burn, K., Hagger, H., Mutton, T., \& Everton, T. (2003). The complex development of studentteachers' thinking. Teachers and Teaching, 9(4), 309-331.

Carlson, J., Engelberg, J., Cain, K., Conway, T., Mignano, A., Bonilla, E., Geremia, C., \& Sallis, J. (2015). Implementing classroom physical activity breaks: Associations with student physical activity and classroom behavior. Preventive Medicine, 81, 67-72. doi:10.1016/j.ypmed.2015.08.006

Castelli, D. M., Centeio, E. E., Beighle, A. E., Carson, R. L., \& Nicksic, H. M. (2014). Physical literacy and comprehensive school physical activity programs. Preventive Medicine, 66, 95-100. doi:10.1016/j.ypmed.2014.06.007

Castelli, D. M., \& Ward, K. (2012). Physical activity during the school day. Journal of Physical Education, Recreation \& Dance, 83(6), 20-29. doi:10.1080/07303084.2012.10598791

Centeio, E., Erwin, H., \& Castelli, D. (2014a). Comprehensive school physical activity programs: Characteristics of trained teachers. Journal of Teaching in Physical Education, 33(4), 492-510.

Centeio, E., McCaughtry, N., Gutuskey, L., Garn, A. C., Somers, C., Shen, B., ... \& Kulik, N. L. (2014b). Chapter 8 Physical Activity Change through Comprehensive School Physical 
Activity Programs in Urban Elementary Schools. Journal of Teaching in Physical Education, 33(4), 573-591. doi:10.1123/jtpe.2014-0067

Centers for Disease Control and Prevention (CDC). (2013). Comprehensive school physical activity programs: A guide for schools. Atlanta, GA: US Department of Health and Human Services, 500, 5-49.

Centers for Disease Control and Prevention (CDC). (2015). Childhood Obesity Facts. Retrieved from https://www.cdc.gov/healthyschools/obesity/facts.htm.

Centers for Disease Control and Prevention (CDC), National Center for Health Statistics. (2005). NHANES 2003-2004 Public Data General Release File Documentation. Retrieved from https://wwwn.cdc.gov/Nchs/Nhanes/2003-2004/PAQ_C.htm

Cothran, D. J., Kulinna, P. H., \& Garn, A. C. (2010). Classroom teachers and physical activity integration. Teaching and Teacher Education, 26(7), 1381-1388. doi:10.1016/j.tate.2010.04.003

Delk, J., Springer, A. E., Kelder, S. H., \& Grayless, M. (2014). Promoting teacher adoption of physical activity breaks in the classroom: Findings of the Central Texas CATCH Middle School Project. Journal of School Health, 84(11), 722-730.

Desimone, L.M. (2009). Improving impact studies of teachers' professional development: Toward better conceptualizations and measures. Educational Researcher, 3(38), 181199. doi:10.3102/0013189X08331140

Desimone, L.M. (2011). A primer on effective professional development. Kappan, 92(6), 68-71. doi:10.1177/003172171109200616 
Dole, S., Bloom, L., \& Kowalske, K. (2016). Transforming pedagogy: Changing perspectives from teacher-centered to learner-centered. Interdisciplinary Journal of Problem-Based Learning, 10(1), 1.

Donnelly, J. E., \& Lambourne, K. (2011). Classroom-based physical activity, cognition, and academic achievement. Preventive Medicine, 52, S36-S42.

doi:10.1016/j.ypmed.2011.01.021

Egan, C., Webster, C., Weaver, R., Brian, A., Stodden, D., Russ, L., . . \& \& Vazou, S. (2018).

Partnerships for active children in elementary schools (paces): First year process evaluation. Evaluation and Program Planning, 67, 61-69. doi:10.1016/j.evalprogplan.2017.12.002

eLearning for Kids Inc. (2005-2013). Active Academics. Retrieved from http://activeacademics.org/?pid=20\&homepage.

Elliot, E., Erwin, H., Hall, T., \& Heidorn, B. (2013). Comprehensive school physical activity programs: helping all students achieve 60 minutes of physical activity each day. Journal of Physical Education, Recreation \& Dance, 84(9), 9-15. doi:10.1080/07303084.2013.838105

Erwin, H., Beighle, A., Carson, R. L., \& Castelli, D. M. (2013). Comprehensive school-based physical activity promotion: A review. Quest, 65(4), 412-428. doi:10.1080/00336297.2013.791872

Erwin, H. E., Beighle, A., Morgan, C. F., \& Noland, M. (2011). Effect of a Low-Cost, TeacherDirected Classroom Intervention on Elementary Students' Physical Activity. Journal of School Health, 81(8), 455-461. doi: 10.1111/j.1746-1561.2011.00614.x. 
Erwin, H., Fedewa, A., \& Ahn, S. (2017). Student academic performance outcomes of a classroom physical activity intervention: A pilot study. International Electronic Journal of Elementary Education, 4(3), 473-487.

Eyler, A., Chriqui, J., Maddock, J., Cradock, A., Evenson, K. R., Gustat, J., ... \& Zieff, S. G. (2014). Opportunity meets planning: An assessment of the physical activity emphasis in state obesity-related plans. Journal of Physical Activity and Health, 11(1), 45-50. doi:10.1123/jpah.2012-0037

Fu, Y., Burns, R., Brusseau, T., \& Hannon, J. (2016). Comprehensive school physical activity programming and activity enjoyment. American Journal of Health Behavior, 40(4), 496502. doi:10.5993/AJHB.40.4.11

Galletta, A. (2013). Mastering the semi-structured interview and beyond: From research design to analysis and publication. NYU Press. doi: 10.18574/nyu/9780814732939.001.0001

Gay, L. R., Mills, G. E., \& Airasian, P. W. (2011). Educational research: Competencies for analysis and applications. Pearson Higher Ed

Goh, T. L., Hannon, J. C., Brusseau, T. A., Webster, C., Podlog, L., \& Newton, M. (2014a). Effects of a classroom based physical activity program on children's physical activity levels. Journal of Teaching in Physical Education, 33(4), 558-572. doi:10.1123/jtpe.2014-0068

Goh, T. L., Hannon, J. C., Webster, C. A., Podlog, L., \& Pillow, W. (2014b). Classroom Physical Activity Breaks: Teachers' Perspectives of an Intervention Study. Research Quarterly for Exercise and Sport, 85(S1), A1. 
Goh, T. L., Hannon, J. C., Webster, C. A., \& Podlog, L. (2017). Classroom teachers' experiences implementing a movement integration program: Barriers, facilitators, and continuance. Teaching and Teacher Education, 66, 88-95. doi:10.1016/j.tate.2017.04.003

Grieco, L. A., Jowers, E. M., \& Bartholomew, J. B. (2009). Physically active academic lessons and time on task- the moderating effect of body mass index. Medicine and Science in Sports and Exercise, 41(10), 1921-1926. doi:10.1249/mss.0b013e3181a61495

Grierson, A. L., \& Woloshyn, V. E. (2013). Walking the talk: Supporting teachers' growth with differentiated professional learning. Professional Development in Education, 39(3), 401419.

Guskey, T. R. (1986). Staff development and the process of teacher change. Educational Researcher, 15(5), 5-12. doi:10.2307/1174780

Guskey, T. R. (2002). Professional development and teacher change. Teachers and Teaching, 8(3), 381-391.

Hillman, C. H., Pontifex, M. B., Raine, L. B., Castelli, D. M., Hall, E. E., \& Kramer, A. F. (2009). The effect of acute treadmill walking on cognitive control and academic achievement in preadolescent children. Neuroscience, 159(3), 1044-1054.

Hollar, D., Messiah, S. E., Lopez-Mitnik, G., Hollar, T. L., Almon, M., \& Agatston, A. S. (2010). Effect of a two-year obesity prevention intervention on percentile changes in body mass index and academic performance in low-income elementary school children. American Journal of Public Health, 100(4), 646-653. doi:10.2105/ajph.2009.165746

Jones, E. M., Taliaferro, A. R., Elliott, E. M., Bulger, S., Kristjansson, A. L., Neal, W., \& Allar, I. (2014). Feasibility study of comprehensive school physical activity programs in 
Appalachian communities: The McDowell CHOICES project. Journal of Teaching in Physical Education, 33 (4), 467-91. doi:10.1123/jtpe.2014-0065

Kibbe, D. L., Hackett, J., Hurley, M., McFarland, A., Schubert, K. G., Schultz, A., \& Harris, S. (2011). Ten Years of TAKE 10!®: Integrating physical activity with academic concepts in elementary school classrooms. Preventive medicine, 52, S43-S50.

Kulinna, P. H., Brusseau, T. A., Cothran, D., \& Tudor-Locke, C. (2012). Changing school physical activity: An examination of individual school designed programs. Journal of Teaching in Physical Education, 31(2), 113-130. doi:10.1123/jtpe.31.2.113

Lander, N., Eather, N., Morgan, P. J., Salmon, J., \& Barnett, L. M. (2017). Characteristics of teacher training in school-based physical education interventions to improve fundamental movement skills and/or physical activity: A systematic review. Sports medicine, 47(1), $135-161$.

Lauckner, H., Paterson, M., \& Krupa, T. (2012). Using Constructivist Case Study Methodology to Understand Community Development Processes: Proposed Methodological Questions to Guide the Research Process. Qualitative Report, 17, 25.

Magnusson, K. T., Sigurgeirsson, I., Sveinsson, T., \& Johannsson, E. (2011). Assessment of a two-year school-based physical activity intervention among 7-9-year-old children. International Journal of Behavioral Nutrition and Physical Activity, 8(1), 138.

Mahar, M.T., Kenny, R.K., Shields, A.T., Scales, D.P., \& Collins, G. (2004). Energizers: Classroom-based Physical Activities. North Carolina Department of Public Instruction, Raleigh, NC. Available at http://www.ecu.edu/cs-hhp/exss/apl.cfm. Accessed January 21, 2016. 
Mahar, M. T., Murphy, S. K., Rowe, D. A., Golden, J., Shields, A. T., \& Raedeke, T. D. (2006). Effects of a classroom-based program on physical activity and on-task behavior. Medicine and Science in Sports and Exercise, 38(12), 2086-2094. doi:10.1249/01.mss.0000235359.16685.a3

Martin, J. J., Mccaughtry, N., Hodges-Kulinna, P., \& Cothran, D. (2008). The influences of professional development on teachers' self-efficacy toward educational change. Physical Education and Sport Pedagogy, 13(2), 171-190.

McAlister, A., Lee, D., Ehlert, K., Kajfez, R., Faber, C., \& Kennedy, M. (2017). Qualitative coding: An approach to assess inter-rater reliability. In ASEE Annual Conference \& Exposition.

McCaughtry, N., Martin, J., Hodges Kulinna, P., \& Cothran, D. (2006). What makes teacher professional development work? The influence of instructional resources on change in physical education. Journal of In-Service Education, 32(2), 221-235.

McMullen, J., Kulinna, P., \& Cothran, D. (2014). Physical activity opportunities during the school day: classroom teachers' perceptions of using activity breaks in the classroom. Journal of Teaching in Physical Education, 33(4), 511-27. doi:10.1123/jtpe.2014-0062

Ménard, M. C., \& Ellemberg, D. (2010). Effects of Neuromotor and Aerobic Training on Executive Functions in Children: 1880. Medicine \& Science in Sports \& Exercise, 42(5), 431-432.

Merriam, S. B., \& Tisdell, E. J. (2015). Qualitative research: A guide to design and implementation. John Wiley \& Sons.

Miles, M. B., Huberman, A. M., \& Saldaña, J. (2014). Qualitative data analysis: A methods sourcebook. Thousand Oaks, Califorinia. 
Moore, J. B., Carson, R. L., Webster, C. A., Singletary, C. R., Castelli, D. M., Pate, R. R., ... \& Beighle, A. (2018). The Application of an implementation science Framework to comprehensive school Physical Activity Programs: Be a champion!. Frontiers in Public Health, 5, 354.

Mullender-Wijnsma, M. J., Hartman, E., de Greeff, J. W., Bosker, R. J., Doolaard, S., \& Visscher, C. (2015). Improving academic performance of school-age children by physical activity in the classroom: 1-year program evaluation. Journal of School Health, 85(6), 365-371.

National Association for Sport and Physical Education (NASPE). (2003). What constitutes a quality physical education program? [Position statement] Reston, VA: Author.

National Association for Sport and Physical Education. (2006). Recess for elementary school students [Position statement]. Reston, VA: Author

National Association for Sport and Physical Education (NASPE). (2008). Comprehensive school physical activity programs [Position statement]. Reston, VA: National Association for Sport and Physical Education. doi:10.1080/08924562.2008.10590798

National Center for Health Statistics. (2011). Health, United States, 2010: With special feature on death and dying. Washington, DC: U.S. Government Printing Office.

Opfer, V. D., \& Pedder, D. (2011). The lost promise of teacher professional development in England. European Journal of Teacher Education, 34(1), 3-24.

Opfer, V. D., Pedder, D. G., \& Lavicza, Z. (2011). The role of teachers' orientation to learning in professional development and change: A national study of teachers in England. Teaching and Teacher Education, 27(2), 443-453. 
Patton, M. Q. (2002). Qualitative evaluation and research methods (3rd ed.). Newbury Thousand Oaks, CA: Sage.

Patton, K., Parker, M., \& Pratt, E. (2013). Meaningful learning in professional development: Teaching without telling. Journal of Teaching in Physical Education, 32(4), 441-459.

Phillips, D., Hannon, J. C., \& Castelli, D. M. (2015). Effects of vigorous intensity physical activity on mathematics test performance. Journal of Teaching in Physical Education, 34(3), 346-362. doi:10.1123/jtpe.2014-0030

Pianta, R. C. (2011). Teaching Children Well: New Evidence-Based Approaches to Teacher Professional Development and Training. Center for American Progress.

Raymond, L. A. I. (2013). Just for the health of it: Facilitators and barriers to increasing physical activity in Delaware elementary schools. University of Delaware.

Reed, J. A., Einstein, G., Hahn, E., Hooker, S. P., Gross, V. P., \& Kravitz, J. (2010). Examining the impact of integrating physical activity on fluid intelligence and academic performance in an elementary school setting: A preliminary investigation. Journal of Physical Activity and Health, 7(3), 343-351. doi:10.1123/jpah.7.3.343

Richardson, V., \& Placier, P. (2001). Teacher change. Handbook of research on teaching, 4, 905-947.

Saldaña, J. (2015). The coding manual for qualitative researchers. Sage.

Society of Health and Physical Educators (SHAPE) (2013). Comprehensive school physical activity programs: Helping all students $\log 60$ minutes of physical activity each day [position statement]. Reston, VA: Author. 
Society of Health and Physical Educators (SHAPE) (2016). Comprehensive school physical activity programs. Retrieved September 5, 2016, from http://www.shapeamerica.org/cspap/

Stewart, J. A., Dennison, D. A., Kohl, H. W., \& Doyle, J. A. (2004). Exercise level and energy expenditure in the TAKE 10!® in-class physical activity program. Journal of School Health, 74(10), 397-400. doi: 10.1111/j.1746-1561.2004.tb06605.x

Strampel, C. M., Martin, L., Johnson, M. J., Iancu, H., Babineau, C., \& Carpenter, J. G. (2014). Teacher perceived barriers and potential solutions to implementing daily physical activity in elementary schools. Physical \& Health Education Journal, 80(1), 14-22.

Taylor, S. J., Bogdan, R., \& DeVault, M. (2015). Introduction to qualitative research methods: A guidebook and resource. John Wiley \& Sons.

Troiano, R. P., Berrigan, D., Dodd, K. W., Masse, L. C., Tilert, T., \& McDowell, M. (2008). Physical activity in the United States measured by accelerometer. Medicine and Science in Sports and Exercise, 40(1), 181-188. doi:10.1249/mss.0b013e31815a51b3

US Department of Health and Human Services (USDHHS), Office of Disease Prevention and Health Promotion. (2008). Physical activity guidelines for Americans. Washington, DC: US Department of Health and Human Services.

U.S. Department of Health and Human Services (USDHHS) (2010). Healthy People 2020. Retrieved September 5, 2016, from www.healthypeople.gov.

U.S. Department of Health and Human Services (USDHHS). (2012). Physical activity guidelines for Americans midcourse report: Strategies to increase physical activity among youth. Washington, DC: US Department of Health and Human Services. 
West Virginia Department of Education (WVDE). (2014) State Board Policies: Policy 2510. Retrieved from https://wvde.state.wv.us/policies/.

World Health Organization. (2018). Global Strategy on Diet, Physical Activity and Health. Retrieved from https://www.who.int/dietphysicalactivity/pa/en/.

Yin, R. K. (2015). Qualitative research from start to finish. Guilford Publications. 


\section{Appendix F - IRB Exemption Notice}

\section{W. WesthriginiaUniversity. \\ Office of Research Integrity and Compliance \\ 886 Chestnut Ridge Road Morgantown, WV 26506}

\section{Acknowledgement of Exemption}

$01 / 31 / 2019$

To: Andrea Taliaferro

From: WVU Office of Research Integrity \& Compliance

Protocol Type: Exempt

Submission Type: Initial

Funding: N/A

WVU Protocol \#: 1901432171

Protocol Title: Movement in the Classroom: Factors of Teacher Change
Approval Date: 01/31/2019

Expiration Date: 01/30/2022

The West Virginia University Institutional Review Board has reviewed your submission of Exempt protocol 1901432171. Additional details regarding the review are below:

- This research study was granted an exemption because the Research involves educational tests, survey procedures, interview procedures or observation of public behavior and (i) information obtained is recorded in such a manner that human subjects cannot be identified, directly or through identifiers linked to the subjects; and (ii) any disclosure of the human subjects responses outside the research could not reasonably place the subjects at risk of criminal or civil liability or be damaging to the subjects financial standing, employability, or reputation [45 CFR 46.101(2)]. All exemptions are only good for three years. If this research extends more than three years beyond the approved date, then the researcher will have to request another exemption. The following documents have been acknowledged for use in this study and are available in the WVU+kc system:

The following documents were reviewed and approved for use as part of this submission. Only the documents listed below may be used in the research. Please access and print the files in the Notes \& Attachments section of your approved protocol.

- Appendix G_Reminder of SemiStructured Interview.pdf

- Appendix F_Confirmation of SemiStructured Interview.pdf

- Appendix A_Recruitment Script.pdf

- Appendix B_Cover Letter.pdf

- Appendix D_SemiStructured Interview.pdf

- Appendix C_Questionnaire.pdf

- Appendix E_Letter of Invitation.pdf 
WVU IRB acknowledgement of protocol 1901432171 will expire on 01/30/2022.

If the study is to continue beyond the expiration date, a renewal application must be submitted no later than two (2) weeks prior to expiration date. It is your responsibility to submit your protocol for renewal.

Once you begin your human subjects research, the following regulations apply:

1. Unanticipated or serious adverse events and/or side effects encountered in this research study must be reported to the IRB within five (5) days, using the Notify IRB action in the electronic protocol.

2. Any modifications to the study protocol should be submitted only if there will be an increase in risk to subjects accompanying the proposed change(s).

3. You may not use a modified information sheet until it has been reviewed and acknowledged by the WVU IRB prior to implementation.

The Office of Research Integrity and Compliance will be glad to provide assistance to you throughout the research process. Please feel free to contact us by phone, at 304.293 .7073 or by email at IRB@mail.wvu.edu.

Sincerely,

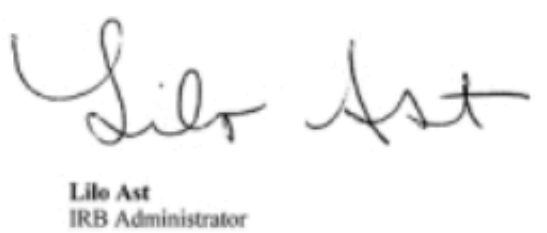

Protocol \#: 1901432171

FWA: 00005078

IORG: 0000194
Phone: 304-293-7073

Fax: 304-293-3098

Email: IRB@mail.wvu.edu 


\section{Appendix G - Recruitment Email Script}

\section{Dear WV Educator,}

This email is an invitation for you to take part in a research project to understand teachers' experiences in the implementation of classroom physical activity, and things that have influenced your continued use of classroom physical activity. You have been invited to participate in this study because of your previous attendance at a classroom physical activity professional development. As a follow-up to this experience, I would like to learn more about how you have continued practices of classroom physical activity integration, and what has helped you to be successful. This study is being conducted by doctoral student Annie Machamer under the supervision of Assistant Professor Dr. Andrea Taliaferro in the College of Physical Activity and Sports Sciences at West Virginia University.

Participation in this research study will include completion of an online questionnaire about your experiences using classroom physical activity that will take 10-15 minutes of your time. Depending upon the answers you provide in the questionnaire, you may be selected to further participate in a 30-60 minute semi- structured interview that will be conducted over the phone at your convenience. If you are selected and complete the semi-structured interview, you are eligible to receive a $\$ 25$ gift card of your choice, along with random drawings for additional $\$ 50$ prizes to support classroom physical activity implementation.

If you are interested in participating in this study, please click on the link below. This link will direct you to a cover letter including key information for this study, followed by the questionnaire.

Please complete by Sunday (DATE TBD) at 5:00 pm. INSERT Link to Cover Letter \& Questionnaire

If selected to participate in the semi-structured interview portion of the study, you will be further contacted by doctoral student Annie Machamer by email.

I hope that you will participate in this research project. Your feedback will be critical as we continue to refine related programming efforts in the future.

Thank you in advance for your participation in this study and your support in the development of an active classroom.

Sincerely, Annie Machamer, M.S. Andrea Taliaferro, Ph.D. 


\section{Appendix H - Cover Letter \\ Key Information for: Movement in the Classroom: Contingent Factors Underlying Teacher Change}

We are asking you to choose whether or not to volunteer in the research described below. This page provides key information that may help you to make this decision.

\section{Why is this research being done and what is involved?}

This study aims to understand teachers' experiences in the implementation of classroom physical activity, and things that have influenced your continued use of classroom physical activity. If you agree to participate in this study, you will first be asked to complete an online questionnaire about your experiences using classroom physical activity that will take 10-15 minutes of your time. Depending upon the answers you provide in the survey, you may also be selected to participate in a 30-60 minute semi-structured interview that will be conducted over the phone at your convenience.

\section{Do I have to participate and what are the risks?}

Your involvement in this project will be kept as confidential as legally possible. All data will be reported in the aggregate. You must be 18 years of age or older to participate. Participation in this research study is completely voluntary. You may skip any questions that you do not wish to answer, and you are free to withdraw from the research at any time prior to the data being deidentified. There are no direct benefits to you for participating in this study; however, the knowledge gained from this study could benefit others. If you are selected to participate in the semi-structured interview, you will be eligible to receive a $\$ 25$ gift card of your choice, along with random drawings for additional $\$ 50$ prizes to support classroom physical activity implementation, upon completion of the interview.

\section{Who can I talk to if I have questions or concerns?}

If you have any questions or concerns about this research, you can contact Dr. Andrea Taliaferro at Andrea.Taliaferro@mail.wvu.edu from the Dept. of Coaching and Teaching Studies at West Virginia University or doctoral student Annie Machamer at aemachamer@mix.wvu.edu. West Virginia University's Institutional Review Board acknowledgment of this project is on file.

If you agree to participate in this study, please select "I agree" below and continue to the next page where the questionnaire will begin.

- I agree 


\section{Appendix I - Letter of Invitation}

Dear WV Educator,

Congratulations! Based upon your responses to the questionnaire you have been selected to take part in a semi-structured interview to provide a better understanding of what you have experienced in the use of PA in the academic classroom. This study is being conducted by doctoral student Annie Machamer and Assistant Professor Dr. Andrea Taliaferro in the College of Physical Activity and Sports Sciences at West Virginia University.

As a reminder, this semi-structured interview will be conducted via phone and will last between 30-60-minutes. In the completion of the semi-structured interview, you are eligible to receive a $\$ 25$ gift card of your choice, along with random drawings for additional \$50 prizes to support classroom physical activity implementation. If you are interested in further study participation, please follow the link below to select a time and date that is convenient within your schedule to complete a semi-structured interview. In selection, please use your email to identify yourself. Please be reminded that the semi-structured interview will be phone, and cell service will be necessary for completion.

Once participants have responded, you will be further contacted by doctoral student Annie Machamer via email confirming a selected date for completion of the semi-structured interview. If you find that an alternate time slot is needed to conduct this semi-structured interview, please feel free to contact Annie Machamer via email or by direct phone number at 336-908-5465. If you have any additional questions about participation, please feel free to contact Annie Machamer via email at aemachamer@mix.wvu.edu or Dr. Andrea Taliaferro via email at Andrea.Taliaferro@mail.wvu.edu.

Please submit your selection preferences by Sunday (DATE) at 5:00 pm. INSERT Doodle Poll Link

Again, thank you for considering participation and your support in the development of an active classroom.

Sincerely,

Annie Machamer, M.S. Andrea Taliaferro, Ph.D. 


\section{Appendix J - Confirmation of Semi-Structured Interview}

Dear Educator,

Thank you again for your participation in this study. Below you will find your final scheduled semi-structured interview time and date based upon your submitted preference.

As a reminder, semi-structured interviews are intended to be completed between 30 to 60 minutes, with each time slot allowing for one hour per participant. Please be reminded that the semi-structured interview will be conducted via the phone, and cell service will be necessary for completion.

Date of scheduled semi-structured interview:

Time of scheduled semi-structured interview:

You will receive a reminder during the week of your scheduled date and time for the semistructured interview. Please respond to this email with a preferred number of contact (phone number).

If you may have any questions regarding further participation in this study, please feel free to contact Annie Machamer via email at aemachamer@mix.wvu.edu or Dr. Andrea Taliaferro via email at Andrea.Taliaferro@mail.wvu.edu. If you find that an alternate time slot is needed to conduct this semi-structured interview, please feel free to contact Annie Machamer via email or by direct phone number at 336-908-5465. Thank you again for your participation in this study.

Sincerely,

Annie Machamer, M.S.

Andrea Taliaferro, Ph.D. 


\section{Appendix K - Reminder of Scheduled Semi-Structured Interview}

\section{Dear Educator,}

This email is to serve as a reminder of your scheduled semi-structured interview for your participation in the research study on teacher use of movement in the classroom.

Thank you again for your participation in this study. Below you will find your final scheduled semi-structured interview time and date based upon your submitted preference. As a reminder, semi-structured interviews are intended to be completed between 30 to 60 minutes, with each time slot allowing for one hour per participant. Please be reminded that the semi-structured interview will be conducted via phone, and cell service is necessary for completion.

Date of scheduled semi-structured interview:

Time of scheduled semi-structured interview:

Preferred number of contact:

On the date and time of your scheduled interview, the interviewer will contact you from the following phone number. (336) 908-5465

If you may have any questions regarding further participation in this study, please feel free to contact Annie Machamer via email at aemachamer@mix.wvu.edu or Dr. Andrea Taliaferro via email at Andrea.Taliaferro@mail.wvu.edu. If you find that an alternate time slot is needed to conduct this semi-structured interview, please feel free to contact Annie Machamer via email or by direct phone number at 336-908-5465. Thank you again for your participation in this study.

Sincerely,

Annie Machamer, M.S.

Andrea Taliaferro, Ph.D 


\section{Appendix L - Codebook Version 1}

Codebook developed from analysis of semi-structured interviews.

\begin{tabular}{|c|c|c|c|}
\hline Section & Theme & Sub-Theme & Description \\
\hline \multirow[t]{9}{*}{ Orientation to } & Prior Beliefs/Attitudes & & $\begin{array}{l}\text { Teacher prior beliefs/attitudes of classroom physical activity } \\
\text { before professional development is experienced }\end{array}$ \\
\hline & $\mathrm{P} 1$ & $\begin{array}{l}\text { The Importance of } \\
\text { Physical Activity }\end{array}$ & $\begin{array}{l}\text { Teacher positive prior belief/attitude of the importance behind } \\
\text { physical activity in the classroom }\end{array}$ \\
\hline & $\mathrm{P} 2$ & Classroom Chaos & $\begin{array}{l}\text { Teacher negative belief/attitude of a chaotic environment during } \\
\text { the use of physical activity in the classroom }\end{array}$ \\
\hline & $\begin{array}{l}\text { School Environmental } \\
\underline{\text { Influences }}\end{array}$ & & $\begin{array}{l}\text { School setting and environment influences on the use of physical } \\
\text { activity in the classroom }\end{array}$ \\
\hline & S1 & Student Need & $\begin{array}{l}\text { Teacher views of the students need for movement in the } \\
\text { classroom. }\end{array}$ \\
\hline & S2 & Support from Others & $\begin{array}{l}\text { Teacher views of support from others (i.e., administration, peers, } \\
\text { parents) in the use of physical activity in the classroom }\end{array}$ \\
\hline & S3 & School Context & $\begin{array}{l}\text { Teacher views of the school context influences and impact on the } \\
\text { use of physical activity in the classroom }\end{array}$ \\
\hline & $\frac{\text { Professional }}{\text { Development }}$ & & Teacher learning of using classroom physical activity \\
\hline & PD1 & $\begin{array}{l}\text { Sample Activities \& } \\
\text { Resources }\end{array}$ & $\begin{array}{l}\text { Teacher views of activities and resources presented in professiona } \\
\text { development and the impact on understanding for the } \\
\text { implementation of physical activity in the classroom }\end{array}$ \\
\hline
\end{tabular}


PD2

Learning

Change

\section{Change in Students}

Professional

Development on

Content-rich/Standards

based Physical Activity

Integration Practices

Use as an Incentive

Commonly Used

Classroom Physical

Activity

Student Enjoyment

Student Learning

Student Engagement
Teacher views of professional development related to contentrich/standards based active lessons and the impact on understanding for implementation of physical activity in the classroom

Changes made by the teacher to their daily teaching practice to implement classroom physical activity

Teacher practice of routines, rules, and expectations in the integration of classroom physical activity

Teacher use of classroom physical activity as incentive to students participation

Teacher sample lessons and resources used in the implementation of classroom physical activity.

A change in students as a result of teacher use of classroom physical activity

Students demonstrate enjoyment in the classroom related to participation in classroom physical activity

Students demonstrate academic learning development related to participation in classroom physical activity

Students demonstrate increased levels of engagement in the classroom related to participation in classroom physical activity 


\section{Change in}

Beliefs/Attitudes

CB1

CB2

Influences on
Continued
Use

Hands-on Activities

Positive

Belief/Attitude

Common Planning

Practice for

Success

\section{Student Reactions}

Continued Engagement

Belief of Contentrich/Standards based Physical Activity

PL1

PL2
A change in teacher beliefs/attitude as a result of using classroom physical activity

Teacher developed belief/attitude to want to continue the use of movement in the classroom

Teacher developed belief/attitude of the use of contentrich/standards based active lessons in the classroom

The influence of student reactions on teacher continued use of classroom physical activity

The influence of teacher experience in hands-on professional development on the continued use of classroom physical activity

The influence of teacher positive belief/attitude on continued use of classroom physical activity

Planning strategies that teachers identify as needed for successful integration of classroom physical activity

Teacher suggestions of having materials prepared for classroom physical activity lessons

Teacher suggestions for integration progression when beginning the use of classroom physical activity 
Management

M1

M2

Mindset

MS1

MS2

Peer Collaboration
Classroom management strategies that teachers identify as needed for successful integration of classroom physical activity.

Teacher suggestions that routines, rule, and expectations are presented to students at all times

Teacher suggestions to maintain consistent with routines, rules, and expectations to support classroom physical activity implementation

Teacher determined mindset necessary to support continued use of classroom physical activity

The active classroom Teacher suggestions of the acceptance of differences present in a moving classroom environment

Teacher suggestion of sticking with classroom physical activity throughout trials and tribulations of implementation

Teacher suggestions of collaboration with colleagues to support use of classroom physical activity 